\title{
North Atlantic simulations in Coordinated Ocean-ice Reference Experiments phase II (CORE-II). Part I: Mean states
}

Gokhan Danabasoglu $^{a, *}$, Steve G. Yeager ${ }^{a}$, David Bailey ${ }^{a}$, Erik Behrens ${ }^{b}$, Mats Bentsen ${ }^{c}$, Daohua Bi $^{d}$,

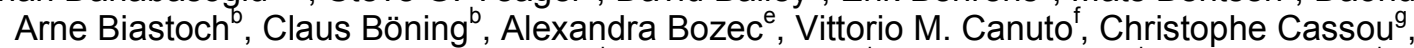
Eric Chassignet $^{\mathrm{e}}$, Andrew C. Coward ${ }^{\mathrm{h}}$, Sergey Danilovi, Nikolay Diansky, Helge Drange ${ }^{\mathrm{k}}$, Riccardo Farneti', Elodie Fernandez ${ }^{g}$, Pier Giuseppe Fogli ${ }^{\mathrm{m}}$, Gael Forget ${ }^{\mathrm{n}}$, Yosuke Fujii', Stephen M. Griffies ${ }^{p}$, Anatoly Gusev ${ }^{j}$, Patrick Heimbach ${ }^{n}$, Armando Howard ${ }^{f, q}$, Thomas Jung', Maxwell Kelley ${ }^{f}$, William G. Large ${ }^{a}$, Anthony Leboissetier ${ }^{f}$, Jianhua Lu ${ }^{e}$, Gurvan Madec ${ }^{r}$, Simon J. Marsland ${ }^{d}$, Simona Masina ${ }^{m}$,, Antonio Navarra ${ }^{m, s}$, A.J. George Nurser ${ }^{h}$, Anna Pirani ${ }^{t}$, David Salas y Mélia ${ }^{u}$, Bonita L. Samuels ${ }^{p}$, Markus Scheinert ${ }^{b}$, Dmitry Sidorenko', Anne-Marie Treguier ${ }^{v}$, Hiroyuki Tsujino ${ }^{\circ}$, Petteri Uotila ${ }^{d}$, Sophie Valcke ${ }^{g}$, Aurore Voldoire ${ }^{u}$, Qiang Wangi

\footnotetext{
${ }^{a}$ National Center for Atmospheric Research (NCAR), Boulder, CO, USA

${ }^{\mathrm{b}}$ Helmholtz Center for Ocean Research, GEOMAR, Kiel, Germany

c Uni Climate, Uni Research Ltd., Bergen, Norway

d Centre for Australian Weather and Climate Research, a partnership between CSIRO and the Bureau of Meteorology, Commonwealth Scientific and Industrial Research Organisation (CSIRO), Melbourne, Australia e Center for Ocean-Atmospheric Prediction Studies (COAPS), Florida State University, Tallahassee, FL, USA

f NASA Goddard Institute for Space Studies (GISS), New York, NY, USA

${ }^{g}$ Centre Europ'een de Recherche et de Formation Avanc'ee en Calcul Scientifique (CERFACS), Toulouse, France

${ }^{\mathrm{h}}$ National Oceanography Centre Southampton (NOCS), Southampton, UK

'Alfred Wegener Institute for Polar and Marine Research (AWI), Bremerhaven, Germany

${ }^{j}$ Institute of Numerical Mathematics, Russian Academy of Sciences, Moscow, Russia

${ }^{\mathrm{k}}$ University of Bergen, Bergen, Norway

' International Centre for Theoretical Physics (ICTP), Trieste, Italy

${ }^{m}$ Centro Euro-Mediterraneo sui Cambiamenti Climatici (CMCC), Bologna, Italy

${ }^{\mathrm{n}}$ Massachusetts Institute of Technology, Cambridge, MA, USA

${ }^{\circ}$ Meteorological Research Institute (MRI), Japan Meteorological Agency, Tsukuba, Japan

${ }^{\mathrm{p}}$ NOAA Geophysical Fluid Dynamics Laboratory (GFDL), Princeton, NJ, USA

${ }^{q}$ Medgar Evers College of the City University of New York, Brooklyn, NY, USA

r IPSL/LOCEAN, CNRS-IRD-UPMC, Paris, France

s Istituto Nazionale di Geofisica e Vulcanologia (INGV), Bologna, Italy

${ }^{\mathrm{t}}$ International CLIVAR Project Office, National Oceanography Centre, Southampton, UK

"Centre National de Recherches M'et'eorologiques (CNRM), Toulouse, France

${ }^{\vee}$ Laboratoire de Physique des Oc'eans, UMR 6523, CNRS-Ifremer-IRD-UBO, IUEM, Plouzane, France

*: Corresponding author : Gokhan Danabasoglu, Tel.: +1 3034971604 ; fax: +1 3034971700 ; email address : gokhan@ucar.edu
}

\section{Abstract:}

Simulation characteristics from eighteen global ocean-sea-ice coupled models are presented with a focus on the mean Atlantic meridional overturning circulation (AMOC) and other related fields in the North Atlantic. These experiments use inter-annually varying atmospheric forcing data sets for the 60- 
year period from 1948 to 2007 and are performed as contributions to the second phase of the Coordinated Ocean-ice Reference Experiments (CORE-II). The protocol for conducting such CORE-II experiments is summarized. Despite using the same atmospheric forcing, the solutions show significant differences. As most models also differ from available observations, biases in the Labrador Sea region in upper-ocean potential temperature and salinity distributions, mixed layer depths, and sea-ice cover are identified as contributors to differences in AMOC. These differences in the solutions do not suggest an obvious grouping of the models based on their ocean model lineage, their vertical coordinate representations, or surface salinity restoring strengths. Thus, the solution differences among the models are attributed primarily to use of different subgrid scale parameterizations and parameter choices as well as to differences in vertical and horizontal grid resolutions in the ocean models. Use of a wide variety of sea-ice models with diverse snow and sea-ice albedo treatments also contributes to these differences. Based on the diagnostics considered, the majority of the models appear suitable for use in studies involving the North Atlantic, but some models require dedicated development effort.

\section{Highlights}

- Phase II of the Coordinated Ocean-ice Reference Experiments (CORE-II) is introduced. Solutions from CORE-II simulations from eighteen participating models are presented. Mean states in the North Atlantic with a focus on AMOC are examined. The North Atlantic solutions differ substantially among the models. Many factors, including parameterization choices, contribute to these differences.

Keywords: Global ocean-sea-ice modelling ; Ocean model comparisons ; Atmospheric forcing ; Experimental design ; Atlantic meridional overturning circulation ; North Atlantic simulations

\section{Introduction}

The Coordinated Ocean-ice Reference Experiments (COREs) were first introduced in Griffies et al., 2009. The CORE framework defines protocols for performing global ocean-sea-ice coupled simulations forced with common atmospheric data sets. Therefore, the most essential element of the CORE framework is the forcing data sets developed by Large and Yeager, 2004 and Large and Yeager, 2009. The first phase of this project, namely CORE-I, involved using an idealized, i.e., synthetically constructed, one-year repeating cycle of forcing, referred to as normal year forcing (NYF). The primary goal was to investigate and document the climatological mean ocean and sea-ice states obtained after long (at least 500 years) integrations, with the hypothesis that global ocean-sea-ice models run under the same atmospheric state produce qualitatively similar solutions. A comprehensive analysis of the model simulations participating in CORE-I along with many other aspects of the CORE framework are presented in Griffies et al., 2009, which finds that the above hypothesis is not valid in general, primarily depending on the particular diagnostic chosen.

The second phase of COREs, CORE-II, uses inter-annually varying atmospheric forcing (IAF) over the 60-year period from 1948 to $2007 . .^{-}$In the oceanographic community, the CORE-II simulations are usually referred to as hindcast experiments. These hindcasts provide a framework to evaluate ocean and sea-ice model 
performance and study mechanisms of time-dependent ocean phenomena and their variability from seasonal to decadal time scales for the recent past. Specifically, we believe that the CORE-II hindcast experiments directly contribute to: i) evaluation, understanding, and improvement of the ocean components of earth system models; ii) investigation of mechanisms for seasonal, inter-annual, and decadal variability; iii) attribution of ocean-climate events to forced and natural variability; iv) evaluation of robustness of mechanisms across models; and v) bridging observations and modeling, by complementing ocean reanalysis from data assimilation approaches. They also provide consistent ocean and sea-ice states that can be used for initialization of climate (e.g., decadal) prediction experiments. Some examples of recent work demonstrating use and benefits of inter-annually forced simulations include mechanisms and attributions studies on the mid-1990s weakening and warming of the North Atlantic sub-polar gyre (SPG), e.g., Lohmann et al. (2009) and Yeager et al. (2012), respectively, and studies on the link between the SPG and the Atlantic Meridional Overturning Circulation (AMOC) as discussed in Hatun et al. (2005). We note that, among these studies, Yeager et al. (2012) analysis utilized a CORE-II hindcast simulation as well as decadal prediction experiments which were initialized using ocean and sea-ice initial conditions from the CORE-II simulation.

In contrast to only seven participants in CORE-I, the present CORE-II effort has grown considerably to eighteen participants (see Table 1 and Appendix A for a list of the participating groups along with brief descriptions of models). They represent quite a diverse set of ocean and sea-ice models used in climate simulations. For example, with respect to their vertical coordinates, although the majority of the models use the traditional depth coordinate (e.g., NCAR, GFDL-MOM, NEMObased models), we have the participation of isopycnal coordinate (BERGEN and GFDL-GOLD), hybrid coordinate (FSU), mass coordinate (GISS), and terrain fol- 
lowing coordinate (INMOM) ocean models. Additionally, the solutions from the first unstructured finite element ocean model (FESOM from AWI) are included. We also welcome a data assimilation contribution (MRI-A) forced with the CORE-II IAF data sets. Inclusion of such an effort in the present study is intended to stimulate discussions and collaborations between the free-running and data assimilation ocean modeling communities as they have been working largely in isolation from each other. We believe that joint analysis of their simulations will benefit both communities by identifying robust features and physical mechanisms as well as systematic biases and shortcomings, leading to improvements in both approaches. As such, we do not use the MRI-A solutions as a benchmark to which the free-running simulations are compared, but rather treat it as just another contribution, commenting on its solutions when warranted. With their $\mathcal{O}\left(1^{\circ}\right)$ horizontal resolutions, none of the participating models can resolve eddies, i.e., they are non-eddying ocean models. We note that while some participants (e.g., NCAR, GFDL-MOM, GFDL-GOLD) represent mature efforts, some others (e.g., FSU, INMOM, AWI) are from relatively new endeavors.

The CORE-II simulations are being analyzed in several separate studies, each focusing on a specific aspect of the solutions, e.g., sea surface height (Griffies et al., 2013), the Southern Ocean and ventilation properties, the Arctic Ocean and sea-ice, and the South Atlantic. The current work represents one such study: an analysis of the Atlantic basin solutions with a focus on AMOC and related variables in the North Atlantic. We present our results in two companion papers. Part I (this study) documents the mean states to provide a baseline for the variability analysis presented in Part II (Danabasoglu et al., 2013).

Our focus on AMOC is motivated primarily by the role that it is thought to play in decadal and longer time scale climate variability, as well as in prediction of the earth's future climate on these time scales. This is because its large heat and 
salt transports significantly influence the climate of the North Atlantic and can even impact global climate through atmospheric interactions (e.g., Sutton and Hodson, 2005; Hurrell et al., 2006). Essentially, an important, dynamically active component of the memory of the climate system is thought to reside in AMOC. We believe that the CORE-II hindcast experiments provide a framework to reconstruct AMOC behavior during the recent past, complementing both observations and reanalysis products. This work represents a first step towards more comprehensive studies that use these hindcast simulations to study various AMOC-related questions further.

Our hypothesis remains similar to that of CORE-I: global ocean - sea-ice models integrated using the same inter-annually varying atmospheric forcing data sets produce qualitatively very similar mean and variability in their simulations, but we apply this hypothesis to the North Atlantic. Alternatively, we ask how similar or dissimilar the solutions are from ocean - sea-ice models that are forced with the same inter-annually varying atmospheric data sets and investigate reasons for differences in their solutions. As we focus on the mean states in the North Atlantic in this paper, one particular goal is to assess model fidelity by comparing model solutions to available observations, thus potentially identifying outliers. We also explore time-mean relationships between AMOC and other fields such as meridional heat transports, mixed layer depths, and sea-ice cover. We note that in contrast with the climatological mean states discussed in Griffies et al. (2009) for CORE-I, our analysis is for present-day conditions, providing the background states for the variability analysis of Part II. Moreover, we have results from eighteen models - a more comprehensive set than in Griffies et al. (2009). In addition, the present models (except FSU) incorporate many improvements compared to those used in Griffies et al. (2009). Therefore, differences in overall characteristics of these models between CORE-I and CORE-II simulations reflect the combined effects of changes in model formulations 
and forcing.

The paper is organized as follows. In section 2, we briefly describe the CORE-II IAF data. The degree of equilibrium achieved by the models is assessed in section 3. The time-mean results for the AMOC; meridional heat transport; potential temperature $(\theta)$, salinity $(S)$, and density; mixed layer depth and ventilation; sea-ice; and gyre transports are given in sections 4 through 9. The relationships between the mean AMOC and the Labrador Sea (LS) hydrographic properties, LS sea-ice extent, and Nordic Seas overflows are investigated in section 10. Section 11 includes a summary and conclusions. As this paper is intended to be the primary reference for the CORE-II IAF framework, brief model descriptions, CORE-II IAF experimental protocol, and some details of the hydrological forcing and salinity restoring are presented in Appendices A, B, and C, respectively. Because all models, except GISS, use a distorted horizontal grid, a brief summary of how the zonal averages and transports are calculated by the models is given in Appendix D. We discuss an interesting sensitivity of meridional heat transport to a particular parameterization (i.e., the Neptune parameterization) in the NOCS contribution in Appendix E. Finally, a list of major acronyms is included in Appendix F.

\section{CORE-II IAF Data}

The CORE-II IAF global data sets used in this study are version 2 of the CORE data sets described in Large and Yeager (2009). The input data are based on NCEP reanalysis for the sea level pressure and near surface atmospheric state, i.e., vector wind, temperature, specific humidity and density, and on a variety of satellite based radiation, sea surface temperature (SST), sea-ice concentration, and precipitation products. Some of these data are adjusted / corrected using more reliable in situ and satellite measurements to address some known biases and limitations of the data. 
Here, the data sets cover the 60-year period from 1948 to 2007. All forcing fields vary for the 24-year period from 1984 to 2007. However, radiation and precipitation before 1984 and 1979, respectively, are available only as climatological mean annual cycles. The data frequencies are 6-hourly for sea level pressure, vector wind, temperature, specific humidity, and density; daily for radiation; and monthly for precipitation. The data sets are available on a spherical grid of T62 resolution (about $\left.1.9^{\circ}\right)$ and they do not have leap years.

The river runoff data, containing river discharges at discrete river mouth locations on a $1^{\circ} \times 1^{\circ}$ global grid, are also inter-annually varying at monthly frequency. They are an updated version of the Dai and Trenberth (2002) and Dai et al. (2009) runoff to correct for identified discrepancies and to ensure compatibility between the 12-month climatological data and the inter-annual data. There are missing data for many rivers since October 2004. The gaps were filled with the latest 5-year mean values, i.e., October 1999 - September 2004, for each month. The same fill procedure was used to construct the entire runoff data for 2007. Finally, we added a time-invariant distribution of runoff along the coast of Antarctica as continental runoff. Based on the precipitation minus evaporation balance, Large and Yeager (2009) estimate this runoff as $0.073 \mathrm{~Sv}\left(1 \mathrm{~Sv} \equiv 10^{6} \mathrm{~m}^{3} \mathrm{~s}^{-1}\right)$. This is distributed as a uniform flux along the coastal points around Antarctica. It enters the ocean as a liquid, so there is no prescribed calving of land ice. This new river runoff dataset has a global long-term discharge of about $1.22 \mathrm{~Sv}$, including Antarctica.

The CORE data sets are collaboratively supported by the National Center for Atmospheric Research (NCAR) and the Geophysical Fluid Dynamics Laboratory (GFDL) under the umbrella of the Climate Variability and Predictability (CLIVAR) Working Group on Ocean Model Development (WGOMD). All data sets, codes for the bulk formulae, technical report, and other support codes along with the release 
notes are freely available at http://data1.gfdl.noaa.gov/nomads/forms/core.html. Future releases of these data can be expected as improvements are made to the data products and to our understanding of their biases and as data become available for recent years (now available through 2009).

\section{Assessment of Equilibrium}

Following the CORE-II IAF experimental protocol (Appendix B; Griffies et al., 2012), all the participating groups integrated their models for 300 years, corresponding to five cycles of the forcing data. As the model solutions exhibit drift below the upper ocean, this length of integration is clearly too short for investigations involving deep ocean tracer properties that evolve on long diffusive time scales. For such studies, longer integrations and / or detrending of model data may be needed. In contrast, in our experience (as documented in, e.g., Doney et al., 2007; Lohmann et al., 2009; Yeager et al., 2012), 300-year integration lengths are sufficient for studies involving, for example, AMOC, subtropical and subpolar gyres, convection and deep water formation in the North Atlantic, and upper ocean mean and variability.

To evaluate the degree of equilibrium achieved in the simulations, we use the AMOC annual-mean maximum transport time series at $26.5^{\circ} \mathrm{N}$ as our metric (Fig. 1). This latitude is chosen as a representative latitude as we obtain qualitatively similar results at several other latitudes - AMOC at $26.5^{\circ} \mathrm{N}$ will also be used for comparisons with the RAPID observations (Rapid Climate Change mooring data, Cunningham et al., 2007) later. Here, we seek to determine the repeatability of the AMOC time series from one forcing cycle to the next one for each model - except MRI-A because it was run for only one forcing cycle. This is quantified in Fig. 2 by considering root-mean-square (rms) differences and correlations of the AMOC time series of Fig. 1 for each subsequent forcing cycle pair. Specifically, for each model, 
we compute rms differences and correlations between forcing cycles 2 and 1, 3 and 2, 4 and 3 , and finally 5 and 4 . The rms measures the differences in the means, trends, and variability from one cycle to the next one and if a model duplicates its AMOC time series identically without any trends, then the rms differences are expected to asymptote to zero. Correlations are more specific, focusing only on the repeatability of the AMOC variability during each subsequent forcing cycle pair, using detrended (and mean subtracted) time series. At equilibrium, correlations would approach unity. A major caveat in our rms and correlation analysis here is that we assume internal model variability is much smaller than the forced variability in this class of coarse resolution (viscous), non-eddying ocean models. Otherwise, an equilibrated model would show non-zero rms and correlations of less than one. We note that our analysis excludes the first ten years of each cycle to avoid the large adjustments associated with the unphysical jump in the forcing from 2007 back to 1948 .

Using an arbitrary lower limit of 0.95 for the correlation coefficients and an upper limit of $0.5 \mathrm{~Sv}$ for the rms differences, Fig. 2 shows that half of the participating models (NCAR, MIT, MRI-F, ACCESS, NOCS, CERFACS, CNRM, CMCC, and GFDL-GOLD) obtain a practical AMOC equilibrium state by the fifth forcing cycle. In some of these models, the above equilibrium criteria are satisfied even earlier by the third cycle. BERGEN and GISS also come very close to satisfying both criteria. In contrast, AWI, GFDL-MOM, ICTP, FSU, and INMOM duplicate neither the variability nor the amplitude (or mean) of AMOC transports between two consecutive cycles as also evidenced in Fig. 1. KIEL reproduces the variability between the fourth and fifth cycles, but the rms differences reflect the large upward trend seen in Fig. 1.

We will discuss the differences in AMOC transports among the models in the following sections. Here, we note that the models show a significant spread in their 
initial AMOC magnitudes - despite very similar initialization of the ocean models (see Appendix B) - and there are substantial differences in their spin-ups. Such differences were also reported in Griffies et al. (2009) for the CORE-I simulations.

In the rest of this paper, we focus on the results from the fifth cycle of the simulations. Unless otherwise noted, we define the mean states as the 20-year timemeans for years 1988-2007, corresponding to simulation years 281-300. We also use March-mean data obtained by averaging monthly-mean March data for the same 20 years. For our LS analysis, we perform spatial averages in a region bounded by $60^{\circ}-45^{\circ} \mathrm{W}$ and $50^{\circ}-65^{\circ} \mathrm{N}$ (indicated in Fig. 8). Furthermore, in our presentation, we tried to group together the results from the models with close family ties, i.e., similar ocean base codes or usage of non-level vertical coordinate systems. Thus, the MOM-based models (GFDL-MOM, ACCESS, ICTP), the NEMO-based models (KIEL, NOCS, CERFACS, CNRM, CMCC), and the density (BERGEN, GFDLGOLD), hybrid (FSU), mass (GISS), and sigma (INMOM) coordinate models are grouped together, respectively (see Table 1).

In addition to AMOC spatial distributions, AMOC maximum transports at $26.5^{\circ}$ and $45^{\circ} \mathrm{N}$ are used as two representative latitudes, with the former latitude allowing the opportunity to compare model results to those of the RAPID observations and the latter latitude providing a measure of mid-latitude AMOC. We use the total AMOC transports in our analysis, i.e., the sum of the Eulerian-mean, mesoscale eddy, and submesoscale eddy contributions, if the latter two are available. While all but one (INMOM) of the models include a variant of the Gent and McWilliams (1990) parameterization to represent the advective effects of the mesoscale eddies, only four models (ACCESS, GFDL-GOLD, GFDL-MOM, and NCAR) employ a submesoscale eddy parameterization (Fox-Kemper et al., 2011). Because we are primarily interested in large-scale sub-thermocline (below $500 \mathrm{~m}$ ) characteristics of 
AMOC and the impacts of both the mesoscale and submesoscale eddies are largely confined to the upper few hundred meters in the North Atlantic, missing subgridscale contributions from some models is not expected to affect our findings. For convenience, we refer to total AMOC simply as AMOC in the rest of this paper.

\section{4. $\mathrm{AMOC}$}

We present the time-mean AMOC distributions in both depth and density $\left(\sigma_{2}\right)$ space in Figs. 3 and 4, respectively (see Appendix D for a brief summary of zonal transport calculations). We note that time-mean AMOC in density space is calculated offline in most models, based on monthly-mean $\theta$ and $S$. Starting with the AMOC in depth space, we see that the cell associated with the North Atlantic Deep Water (NADW; clockwise circulation in the figures) shows substantial differences in its maximum transport magnitude as well as in its spatial structure among the models. Likely due to interpolation issues from sigma coordinates to depth space, the NADW cell is rather noisy in INMOM. The maximum NADW transports usually occur between $30^{\circ}-45^{\circ} \mathrm{N}$ and broadly around $1000 \mathrm{~m}$ depth. There are, however, several noteworthy exceptions to these generalizations: i) the maximum transport is located further north at about $55^{\circ} \mathrm{N}$ in ICTP; ii) INMOM has many local maxima and small-scale circulation patterns, and iii) there are at least four local maximum transport locations in MRI-A - a feature likely resulting from internal sources and sinks of heat and salt (density) and also seen in several other ocean reanalysis products (see Munoz et al., 2011). The maximum NADW transport magnitudes are between about 8-28 Sv with FSU, NOCS, MIT, and CMCC at the low end (8-12 Sv) and NCAR and ICTP at the high end (26-28 Sv) of this range. The NADW penetration depth as measured by the depth of the zero contour line also varies significantly among models from about $2500 \mathrm{~m}$ in MIT and AWI to as deep as 3750-4000 $\mathrm{m}$ in 
NCAR, CNRM, GISS, and MRI-A. In FSU, the NADW penetration depth is rather shallow $(<2000 \mathrm{~m})$ between about $45^{\circ}$ and $65^{\circ} \mathrm{N}$. The transports associated with the Antarctic Bottom Water (AABW; counter clockwise circulation at depth in the figures) are $<6 \mathrm{~Sv}$, with most models showing maximum transports of about 2-4 Sv.

A comparison of AMOCs in depth and density space (Figs. 3 vs. 4) shows that the NADW maximum transport locations are shifted northward to about $45^{\circ}-60^{\circ} \mathrm{N}$ with usually similar or slightly stronger maximum transports in density space than in depth space. An exception is ICTP where the maximum transport is down from 28 to $16 \mathrm{~Sv}$. Another notable feature is that FSU in density space shows an even weaker maximum transport (in high density classes) than its maximum in depth space (about 4 vs. 8 Sv, respectively). Model differences displayed in Fig. 3 are also present in Fig. 4, including weaker transports for FSU, NOCS, MIT, and CMCC.

Figure 5 provides a quantitative comparison of the model AMOC profiles with the profile based on the RAPID data (Cunningham et al., 2007) at $26.5^{\circ} \mathrm{N}$. In these plots, we use the 4-year mean for years 2004-2007 for the model data while the RAPID data represent the 4-year mean for April 2004 - March 2008. Additionally, we do not adjust the model profiles to have no net mass (or volume) transport across this latitude whereas in the RAPID analysis such a constraint was enforced. Therefore, the model profiles include relatively small $(\mathcal{O}(1 \mathrm{~Sv}))$ Bering Strait and even smaller surface freshwater flux contributions (if applicable). The profiles show the total integrated transport between the surface and a given depth, with negative and positive slopes indicating northward and southward flow, respectively. The RAPID estimate for the NADW maximum transport at this latitude is $18.6 \mathrm{~Sv}$, occurring at about 1000 m depth. Over this short observational record, the annual-mean AMOC maximum transports in RAPID vary by about $\pm 1 \mathrm{~Sv}$ around its mean value. This observational 
profile, including its maximum transport, is captured remarkably well by NCAR in the upper $2000 \mathrm{~m}$. The majority of the models underestimate the maximum transport with FSU showing the smallest transport with 5.5 Sv. However, several models (GFDL-MOM, KIEL, CNRM, BERGEN, GISS, and INMOM) are within $10 \%$ of the RAPID maximum transport estimate. It is quite evident that the NADW penetration depth is much shallower in most of the models than in RAPID, but NCAR, MRI-A, and CNRM penetration depths come close to that of RAPID. Here, NCAR employs an overflow parameterization to represent Nordic Seas (GreenlandIceland-Norwegian Seas) overflows (Danabasoglu et al., 2010) and MRI-A assimilates observational data. It is also clear that all models have difficulties in the AABW representation, particularly with its depth range. Associated with shallower NADW, AABW occupies a much broader depth range than in RAPID where it is confined to depths deeper than $4400 \mathrm{~m}$. With the exception of NCAR, KIEL, MRI-A, and INMOM, the models have AABW maximum transports of 1-3 Sv, bracketing the RAPID estimate of about $2 \mathrm{~Sv}$. In this integrated measure at this latitude, AABW maximum transport is $<1 \mathrm{~Sv}$ in KIEL and MRI-A; NCAR has near-zero transport; and INMOM does not show any signatures of AABW.

There are some similarities in the AMOC distributions between two of the MOMbased contributions (GFDL-MOM and ACCESS), but they show differences in many details. No obvious grouping of the NEMO family of models is suggested. KIEL, NOCS, CERFACS, CNRM, and CMCC show significant differences in their NADW and AABW depictions among themselves, due to differences in their parameterizations, parameter choices, vertical grid levels, etc. in their ocean models and due to use of different sea-ice models.

Finally, we note that the present FSU contribution uses the same HYCOM (HYbrid Coordinate Ocean Model) code as in the Griffies et al. (2009) CORE-I study 
where its AMOC transport was somewhat larger than reported here. The reasons for weaker AMOC transports with HYCOM under CORE-II forcing remain unclear. However, preliminary results from a new configuration of HYCOM show much improved representation of AMOC with a time-mean maximum NADW transport of $>17$ Sv (Rainer Bleck and Shan Sun, 2013, personal communication). This configuration uses a different sea-ice model; employs a different reference pressure for the potential density; and advects $\theta$ - S, thus preserving both heat and salt in the ocean model. We hope to include the new HYCOM version in future CORE-II studies when its integration is finalized.

\section{Meridional Heat Transport}

The Atlantic Ocean time-mean meridional heat transport (MHT) distributions from all the models are presented in Fig. 6. For comparison purposes, the figure also includes the implied transport estimates from Large and Yeager (2009) calculated using the CORE-II inter-annual fluxes and observed SSTs and sea-ice for the 19842006 period, and the direct estimates with their uncertainty ranges from Bryden and Imawaki (2001) and the estimate from the RAPID data (Johns et al., 2011). Within the latitude range of the maximum MHTs $\left(10^{\circ}-30^{\circ} \mathrm{N}\right)$, the model MHTs are all lower than the mean estimates, but NCAR, AWI, GFDL-MOM, MRI-A, KIEL, CNRM, GISS, and BERGEN remain within the lower bounds of the Bryden and Imawaki (2001) estimates. They are also within or close to the lower envelope of the Large and Yeager (2009) range. None of the models is able to match the RAPID estimate range at $26.5^{\circ} \mathrm{N}$. The lowest MHTs occur in MIT, MRI-F, NOCS, and CMCC, all with maximum transports of about $0.7 \mathrm{PW}$, and in FSU with a maximum transport of about 0.40 PW. (Sensitivity of MHT to the Neptune parameterization in NOCS is discussed in Appendix E.) At $11^{\circ} \mathrm{S}$, while a few models (NCAR, MRI-A, and GISS) 
produce MHTs slightly larger than the mean estimates, the other models remain below the means, but largely within the estimated uncertainty ranges. FSU is the only distribution with southward transports south of the equator in stark contrast with the other models and observationally-based data. The latitudinal variations in MHT for MRI-A reflect its AMOC structure. Such variations seem to be common in the MHT distributions obtained with some other data assimilation products as well (see Munoz et al., 2011). We believe that, as discussed in Msadek et al. (2013), errors in representations of the NADW cell and, particularly, in the vertical structure of $\theta$ (see Fig. 11), are largely responsible for the substantially lower MHTs in all model simulations compared to observational estimates even in simulations with realistic overturning strengths. Although much smaller in its contribution to MHT, errors in the gyre components can explain some of the differences as well (Msadek et al., 2013). We note that non-eddy-resolving horizontal resolutions of the present models can also contribute to low MHTs due to changes in the mean rather than the eddy heat transport (Kirtman et al., 2012).

At equilibrium, there is negligible storage so the positive and negative MHT slopes with respect to latitude in Fig. 6 indicate the corresponding latitude bands of zonally-integrated warming and cooling of the ocean, respectively, by the surface heat fluxes. Assuming such an equilibrium state has been achieved by the participating models, Fig. 6 implies many model differences in details of surface heat fluxes, resulting primarily from differences in simulated SSTs. One example is the much larger heat gain in BERGEN between $10^{\circ}-30^{\circ} \mathrm{N}$ in contrast with most of the other models where much smaller heat gains or even losses are suggested. The oceanic heat gain evident in most models between $45^{\circ}-55^{\circ} \mathrm{N}$ - as indicated by the positive MHT slopes - is associated with the surface heat fluxes acting to damp the cold SST biases present in these models (see Fig. 8) due to the incorrect path of the North 
Atlantic Current (NAC) (e.g., Danabasoglu et al., 2012).

As hinted at above, AMOC is the dominant contributor to the Atlantic Ocean MHT (Böning et al., 2001; Msadek et al., 2013). The relationship between AMOC and MHT is presented in Fig. 7, considering the scatter plot of the maximum AMOC transport against $\mathrm{MHT}$ at $26.5^{\circ} \mathrm{N}$. Here and in subsequent scatter plots showing AMOC strength at $26.5^{\circ} \mathrm{N}$, we also include the RAPID data for reference purposes only, as the model data represents the 20-year time-mean. Thus, these AMOC transports do differ from those of Fig. 5. Figure 7 confirms the general tendency of larger MHTs with stronger AMOC transports with a correlation coefficient of 0.89 . However, comparable MHTs occur for AMOC transports that differ by 2-3 Sv. For example, both GFDL-MOM and AWI show similar MHTs of about 0.95 PW, but their AMOC transports are about 17.8 and $14.6 \mathrm{~Sv}$, respectively. We believe that the larger MHT with smaller AMOC transport in AWI is primarily due to its substantially larger warm biases in the upper ocean (see Fig. 11) compared to those of GFDL-MOM.

\section{Potential Temperature, Salinity, and Density}

The time- and upper-ocean mean $(0-700 \mathrm{~m}) \theta, S$, and in situ density model minus observations (World Ocean Atlas, WOA09; Locarnini et al., 2010; Antonov et al., 2010) difference distributions are given in Figs. 8, 9, and 10, respectively. In many regions, the $\theta$ and $S$ differences are, to some extent, density compensating in most models, as evidenced by the biases of the same signs in Figs. 8 and 9. Prominent examples of such biases are the warm and salty bias off the North American coast and the cold and fresh bias in the mid-latitude North Atlantic present in most models. These biases reach $5^{\circ}-7^{\circ} \mathrm{C}$ and $>0.7 \mathrm{psu}$ and also exist in SST and surface salinity distributions (not shown). They reflect chronic model problems of the too-far-north 
penetration of the Gulf Stream and the too-zonal NAC path compared to observations. Exceptions to the cold and fresh bias associated with the too-zonal NAC path include AWI, ICTP, and INMOM where the NACs are suggested to have more northerly paths than observed. This also appears to be the case for GISS, with large positive $\theta$ and $S$ biases in the SPG. Further north in the LS, while some models show cold and fresh biases, e.g., MIT, NOCS, and FSU, some others have warm and salty biases, e.g., NCAR, ICTP, and GISS. Similar non-uniform differences are also evident in the tropical and subtropical latitudes. Most models have a salty bias near the Gibraltar Strait and off the Northwest African coast, particularly prominent in AWI, GFDL-MOM, and ACCESS. We note that ICTP shows fresh biases of $>0.7 \mathrm{psu}$ in the entire Nordic Seas. We speculate that such fresh biases are likely associated with excessive sea-ice melt during the summer months, as ICTP has an extensive sea-ice cover in the Nordic Seas during the winter months (see Fig. 15).

The density biases, of course, reflect the $\theta$ and $S$ biases, considering the effects of the thermal expansion and saline contraction coefficients that depend on the $\theta$ and $S$ magnitudes (in addition to pressure). For example, at mid-latitudes, the signatures of the cold and fresh biases discussed above are present as positive density biases, indicating dominance of $\theta$. In contrast, in the LS, the density biases appear to reflect the sign of the $S$ biases in most models, as $S$ changes dominate those of $\theta$ due to the smaller magnitude of the thermal expansion coefficient at low temperatures. The $\theta$, $S$, and density bias differences among the models depicted in these figures largely express the differences in the models' subtropical and subpolar gyre circulations, including differences in the Gulf Stream and NAC representations.

The time- and zonal-mean Atlantic Ocean $\theta$ and $S$ model minus observations difference distributions are presented in Figs. 11 and 12, respectively (see Appendix D for a summary of zonal-mean calculations and related caveats). They also show 
mostly same-signed $\theta$ and $S$ differences, but there are many exceptions to this and there are many differences among the models in bias magnitudes, signs, and extents. In general, most models tend to have warm and salty biases in the upper 1000 $\mathrm{m}$ depth and roughly south of $40^{\circ} \mathrm{N}$ and warm biases north of about $50^{\circ} \mathrm{N}$. Several models (e.g., MIT, KIEL, CERFACS, and CNRM) show cold and fresh biases roughly between $1000-2000 \mathrm{~m}$ depth range and $0^{\circ}-60^{\circ} \mathrm{N}$. The large fresh bias of ICTP in the upper ocean at high latitudes is clearly present in Fig. 12. Abyssal ocean biases reflect model drifts, but are usually $<0.5^{\circ} \mathrm{C}$ and $0.1 \mathrm{psu}$ in magnitude. Exceptions include BERGEN and GFDL-GOLD with larger cold and fresh biases and NOCS with particularly larger warm biases. We note that GISS has larger $\theta$ biases of both signs at mid-depth and abyssal ocean, and FSU shows fresh biases at depth south of the equator. Among the models, INMOM has the most extensive and the largest magnitude warm and salty biases.

\section{Mixed Layer Depth and Ventilation}

We highlight the differences in the models' deep water formation (DWF) locations by considering the March-mean mixed layer depth (MLD) distributions shown in Fig. 13 because the deepest MLDs occur in March. From among the many threshold criteria available to determine MLDs (see de Boyer Montégut et al., 2004), for simplicity we adopt a density-based approach where MLD is calculated as the depth at which the potential density (referenced to surface) changes by $0.125 \mathrm{~kg} \mathrm{~m}^{-3}$ from its surface value. We note that, for our present purposes, it is more important to use a common criterion for all models than the specific details of the MLD calculation. In those models that do not directly compute MLD online following this particular method, MLD is calculated offline using the March-mean potential density obtained 
from the March-mean $\theta$ and $S$ distributions. This offline method is also used to get the observational MLD from the WOA09 $\theta$ and $S$.

Broadly consistent with observations, most models show essentially three DWF sites identified by deep MLDs: the Nordic Seas between Iceland and Spitsbergen; south of Greenland and Labrador Sea region; and south of Iceland between Greenland and Scotland. Deep MLDs tend to follow the ice edge at the first two of these sites. There are differences in relative depths of the deep MLD regions among the models as well as between the models and those of the observations. For example, NCAR, AWI, BERGEN, CERFACS, and GISS show MLDs that are deeper in the LS region than in the Nordic Seas, while the opposite is evident in ACCESS, NOCS, and FSU. Some of the remaining models, such as GFDL-MOM, CNRM, and GFDL-GOLD, show comparably deep MLDs in their LS and Nordic Seas. The MLDs in the LS are rather shallow in NOCS. In the Nordic Seas, INMOM and ICTP have the shallowest MLDs. In the latter, this is due to a large fresh bias there (see Fig. 9). We note that the model MLDs in LS and Nordic Seas are deeper than in observations in the majority of the models.

To help with assessing the models' mixing processes, ventilation rates, and DWF characteristics, the CORE-II protocol requests that the simulations include an ideal age tracer (Appendix B). Figure 14 presents the time- and zonal-mean ideal age distributions from eleven of the models that incorporated this tracer. In these distributions, regions of low ventilation have the oldest waters while the younger waters indicate recent contact with the ocean surface. We also note that, in a 300-year integration, ideal age should not exceed 300 years, barring conservation issues or dispersion errors. A prominent feature in the figure is the deep penetration of young waters between about $50^{\circ}-70^{\circ} \mathrm{N}$ associated with the DWF in the North Atlantic. Using the depth of the 40-year contour as a metric, the shallowest penetration depths oc- 
cur in MRI-F, NOCS, CMCC, and INMOM with about 1000-1500 m, while NCAR, GFDL-MOM, MRI-A, GFDL-GOLD, and GISS have the deepest penetration depths of $>3500 \mathrm{~m}$. These features appear to be generally consistent with the MLD distributions. Another common aspect of the models is the presence of older waters - usually as a local maximum - centered at about $1000 \mathrm{~m}$ depth near the equator. In the deep ocean, NCAR, AWI, MRI-F, NOCS, CMCC, MRI-A, BERGEN, and INMOM have ideal ages > 280 years below about $3000-4000 \mathrm{~m}$ depth, with AWI, NOCS, and CMCC showing the most extensive span of old waters. Among the models, GFDL-GOLD has the youngest deep waters with ideal ages $<240$ years, indicating more vigorous mixing and ventilation of the deep oceans than in the other models. Finally, we note that significant portions of the deep ocean in INMOM show ages in excess of 300 years, suggesting either tracer conservation issues or significant dispersion errors associated with the model's advection scheme.

\section{Sea-ice}

A detailed analysis of the North Atlantic and Arctic Ocean sea-ice solutions from these CORE-II simulations is covered in a separate study (Rüdiger Gerdes, personal communication). Here, we provide only a brief summary, focusing on the Marchmean sea-ice. Because the sea-ice area (or concentration) distributions are very similar among the models for March, we show the sea-ice thickness distributions instead in Fig. 15. However, the figure can be utilized to compare the simulated sea-ice extents as approximated by the $10-\mathrm{cm}$ contour line to the observational data from Cavalieri et al. (1996, updated yearly) indicated by the $15 \%$ concentration line. Overall, the majority of the models capture the observed March-mean sea-ice extent rather well. An exception is ICTP in which the Nordic Seas are largely ice covered. Although the models similarly display thicker ice in the western Arctic and increasing 
thickness towards the Canadian Archipelago and northern Greenland, the thicknesses vary considerably among the models. In about half of them (e.g., NCAR, MIT, GFDL-MOM, and GFDL-GOLD), the central Arctic thicknesses are about 1.5-2 m with slightly thicker ice of about 2.5-3.5 m towards the Canadian Archipelago and northern Greenland. In contrast, particularly in AWI, KIEL, NOCS, CERFACS, and INMOM, the thicknesses exceed $2.5 \mathrm{~m}$ in the central Arctic and are $>5 \mathrm{~m}$ near the Canadian Archipelago and northern Greenland. The Arctic Ocean sea-ice thickness distributions in AWI, KIEL, NOCS, and CERFACS - the latter three use the same sea-ice model - are in good agreement with the very limited IceSat satellite observations from Kwok et al. (2009) (not shown).

The sources of these model differences in sea-ice simulations are not clear and a detailed analysis is beyond the scope of the present study. However, we offer differences in treatments of snow on sea-ice and of subgrid-scale ice thicknesses and in shortwave / albedo parameterizations as likely possibilities. Another possibility is the differences in oceanic heat transport into the high latitudes and into the Arctic Ocean. Our analysis, however, does not support a clear relationship between heat transport magnitudes and the Arctic Ocean sea-ice area and volume, i.e., larger heat transport into the Arctic Ocean does not necessarily explain reduced sea-ice (not shown). We note that this finding is in contrast with a recent study by Mahlstein and Knutti (2011) where a negative correlation was found between the ocean heat transports at $60^{\circ} \mathrm{N}$ and Arctic sea-ice extents in coupled models that participated in CMIP3. This discrepancy may be due to the missing feedbacks in the present ocean - sea-ice simulations as detailed in Griffies et al. (2009). 


\section{Gyre Transports}

We present the time-mean North Atlantic subtropical gyre (STG) and SPG maximum transports in Fig. 16 (left panel). These transports represent verticallyintegrated (barotropic) streamfunction magnitudes, thus providing measures of largescale horizontal circulations. For consistency across the models, we search for the STG and SPG maximum transports between $80^{\circ}-60^{\circ} \mathrm{W}$ at $34^{\circ} \mathrm{N}$ and $65^{\circ}-40^{\circ} \mathrm{W}$ at $53^{\circ} \mathrm{N}$, respectively. The SPG latitude is chosen to expedite comparisons with available observations (see below). For both transports, the transport values at the North American coast at these latitudes are subtracted. Therefore, the maximum transports are relative to the North American continent. We note that because the diagnostic barotropic streamfunction fields from some models do not have constant transports around continents, including North America, our diagnosed maximum transports are not necessarily unique.

The STG transports span a range of about 17-40 Sv, with INMOM and KIEL at the lower and upper ends of this range, respectively. The majority of the models have STG maximum transports of 23-30 Sv. Previous studies (e.g., Bryan et al., 1995) demonstrated that the dominant forcing mechanism for the STG is the wind stress curl, i.e., the Sverdrup dynamics. Using the CORE-II wind stress curl with the Sverdrup equation, we calculate about $23 \mathrm{~Sv}$ as the maximum STG transport at about $34^{\circ} \mathrm{N}$. The figure shows that most of the model transports are close to this Sverdrup estimate. Given that the participating models are all subject to similar wind stress curl forcing, we believe that the STG transport differences among the models partly reflect differences in their horizontal viscosity parameterizations. We note that due to the relatively coarse resolution of the models, the inertial boundary currents and recirculations are largely absent in the barotropic streamfunction distri- 
butions. Consequently, the modeled Gulf Stream and NAC transports are much less than the downstream transport observations (e.g., $113 \pm 8$ Sv; Johns et al., 1995).

The SPG maximum transport range is $12-44 \mathrm{~Sv}$, a broader range than in STG. Here, while BERGEN and NCAR have the strongest transports, ICTP shows the weakest transport. Based on observational data from Fischer et al. (2004) and Fischer et al. (2010), Xu et al. (2013) report southward transport of about 37-42 Sv at the Labrador Sea exit at $53^{\circ}$ N. ACCESS, INMOM, KIEL, MRI-A, and NCAR are within the estimated range. The rest of the models, except BERGEN, remain below the estimates.

A mechanism that affects the SPG strength is the joint effect of baroclinicity and relief (JEBAR; Sarkisyan and Ivanov, 1971; Holland, 1973) associated primarily with the interaction of the dense Nordic Seas overflow waters with the sloping bottom topography. Several previous studies (e.g., Böning et al., 1996; Redler and Böning, 1997) implicated the characteristics of the overflow waters, e.g., density, as a factor in determining the SPG strength. We show a scatter plot of the SPG maximum transports against an overflow density in Fig. 16 (right panel). Here, we crudely approximate this overflow density as the time-mean density of the densest outflow (or southward flow) at $60^{\circ} \mathrm{N}$ as represented by approximately $1 \mathrm{~Sv}$ AMOC transport in density $\left(\sigma_{2}\right)$ space, using Fig. 4. The figure suggests no meaningful connections between the overflow water densities and the SPG strengths. Although a detailed exploration of the reasons for differing SPG transport magnitudes between the models is beyond the scope of this study, we offer differences in horizontal viscosity parameterizations, sea-ice cover, and surface buoyancy fluxes as possible contributors. 


\section{Relationships Between AMOC and LS Properties, Overflow Densities}

The dense waters resulting from deep convection in the LS combine with the overflow waters from the Nordic Seas (through the Denmark Strait and Faroe Bank Channel) to supply the lower branch of AMOC, i.e., the NADW. In this section, we briefly explore relationships between the mean AMOC transports and the LS hydrographic properties, the LS sea-ice extent, and the overflow proxy density among the models. We will show below that the presented relationships are consistent with the following general view. The models with deeper MLDs in the LS tend to have larger AMOC transports which in turn suggest higher heat and salt transports into the northern North Atlantic. In such models, the LS region exhibits positive $\theta$ and $S$ biases. While the positive $\theta$ biases contribute to smaller sea-ice extents in the LS region, the positive $S$ biases tend to dominate changes in density, contributing to the positive density biases in the upper-ocean, associated with the deeper MLDs. However, our analysis does not distinguish, for example, if such deeper mixed layers result precisely from advective fluxes (from the south) associated with AMOC itself, surface buoyancy fluxes, or specifically sea-ice related changes. Thus, we do not suggest a particular driving mechanism for the mean AMOC transports.

We first show scatter plots of the spatially-averaged $\theta, S$, and density biases against the $\mathrm{AMOC}$ maximum transports at $26.5^{\circ}$ and $45^{\circ} \mathrm{N}$ in Fig. 17. These biases are calculated in the upper $700 \mathrm{~m}$ for the LS region depicted in the NCAR panel of Fig. 8. This region was chosen because it corresponds to a prominent DWF region evident in most models (see section 7). However, we obtain very similar results when we consider a broader area that includes most of the SPG region (not shown). Figure 17 indicates generally larger (smaller) AMOC transports at both latitudes with positive (negative) $\theta$ and $S$ biases in the LS region. Although these 
$\theta$ and $S$ biases tend to partially compensate each other in their contributions to density, as discussed above, density changes are largely governed by changes in $S$ as clearly evidenced in the figure. Specifically, considering the bottom panels of Fig. 17, we see that MIT, ACCESS, MRI-F, NOCS, CMCC, and FSU have cold and fresh biases with negative density anomalies, while NCAR, ICTP, KIEL, MRIA, BERGEN, and GISS show warm and salty biases, producing positive density anomalies. ${ }^{2}$ Thus, we find that fresh and salty LS biases are associated with weaker and stronger AMOC transports, respectively. We note that while the AMOC and $\theta$ bias correlation coefficients are comparable at both $26.5^{\circ}$ and $45^{\circ} \mathrm{N}$, the AMOC and $S$ bias and AMOC and density bias correlation coefficients are larger at $45^{\circ} \mathrm{N}$ than at $26.5^{\circ} \mathrm{N}$ ( 0.74 vs. 0.60 and 0.53 vs. 0.32 , respectively).

We next explore how the mean AMOC strength is related to the magnitude of the March-mean LS MLD. Figure 18 (top panels) shows the scatter plots of the Marchmean LS MLDs against the mean AMOC maximum transports at $26.5^{\circ}$ and $45^{\circ} \mathrm{N}$, respectively. Here, the MLDs represent spatial averages calculated within the same LS region. At both latitudes, the AMOC transports vary considerably for a given MLD, but there appears to be a tendency for larger AMOC transports with deeper MLDs. Such a relationship is more prominent at $45^{\circ} \mathrm{N}$ than at $26.5^{\circ} \mathrm{N}$ as suggested by the respective correlation coefficients of 0.65 and 0.52 . NOCS, one of the models with the weakest AMOC transports, has the shallowest average MLD in the LS or south of Greenland, consistent with Fig. 13. In contrast, ICTP shows extensive and deep MLDs in the LS and northern North Atlantic, with correspondingly vigorous

\footnotetext{
${ }^{2}$ In CERFACS and CNRM, the $\theta$ and $S$ biases compensate each other and the density biases are near-zero. In contrast, the $\theta$ and $S$ biases reinforce each other in GFDL-GOLD and INMOM. In AWI and GFDL-MOM, density biases are dictated by the $S$ and $\theta$ biases, respectively, as the corresponding $\theta$ and $S$ biases are near-zero.
} 
AMOC at $45^{\circ} \mathrm{N}$ - recall that the AMOC maximum in ICTP occurs at higher latitudes than in the other models. Despite an average MLD of about $500 \mathrm{~m}$ that is larger than in MRI-F, NOCS, and INMOM, FSU has the lowest AMOC transport.

The scatter plots of the LS $\theta, S$, and density biases against the LS MLDs are also included in Fig. 18 (bottom panels). They show that the LS MLDs are strongly dictated by the model salinity biases in the LS with a correlation coefficient of 0.87 . Generally, the models with salty biases tend to have deeper MLDs than the models with fresh biases. The correlation coefficient between the density biases and MLD is 0.83 which is much larger then the correlation coefficient between the density biases and the AMOC transports as the LS density changes have a more direct impact on the LS MLDs. Among the models, NOCS has the shallowest MLD with a fresh bias of about $0.3 \mathrm{psu}$, and ICTP has the saltiest LS with the deepest MLDs. MIT, CMCC, and FSU come close to the observational MLD estimate with small density biases, but such small density errors are due to the compensation of large $\theta$ and $S$ biases in density. It is interesting to note that the models appear to require positive $\theta$ and $S$ biases along with positive density and MLD biases in the LS region to achieve better agreement with the observed AMOC transport at $26.5^{\circ} \mathrm{N}$ (e.g., NCAR).

In addition to the upper-ocean hydrographic properties of the LS region, the Nordic Sea overflows can similarly affect AMOC as stated at the beginning of this section. Indeed, several studies (e.g., Döscher and Redler, 1997; Schweckendiek and Willebrand, 2005; Latif et al., 2006; Behrens et al., 2013) indicate strong connections between the mean AMOC maximum transports and the overflows. Specifically, denser overflow waters result in higher AMOC transports, with the Denmark Strait overflow as the major contributor. These findings, however, are in contrast with Danabasoglu et al. (2010) and Yeager and Danabasoglu (2012) where they study impacts of an overflow parameterization on ocean model solutions and on climate, using 
both ocean-only simulations forced with the CORE NYF data sets and fully-coupled experiments. The parameterization produces denser overflow waters compared to control cases without this parameterization. Consequently, the NADW penetrates much deeper (as discussed in section 4 ), but its transport at $26.5^{\circ} \mathrm{N}$ changes very little and the mean AMOC maximum transport actually diminishes. Also, variability of AMOC on decadal and longer time scales is generally lower - but this reduction is not uniform in latitude and depth. These studies suggest that such reductions in the maximum transports and variability are due to the suppressed deep convection in the LS, because the denser overflow waters maintain a stratified LS.

The present study provides an opportunity to explore any links between the overflow densities and the AMOC transports in the participating models. Figure 19 shows the scatter plots of the time-mean AMOC maximum transports at $26.5^{\circ}$ and $45^{\circ} \mathrm{N}$ against the overflow proxy density described in section 9. Here, we use the AMOC transports from depth space for consistency with the previous studies. In both panels, the majority of the models (12) are clustered together between $36.85-37.00 \mathrm{~kg}$ $\mathrm{m}^{-3}$ with no clear relationship between their AMOC transports and overflow densities. We note that with its overflow parameterization, NCAR has one of the densest overflow waters with one of the largest AMOC transports.

We acknowledge that there are many caveats with this overflow vs. AMOC analysis - we list a few here. First, to re-stress, our overflow density is a rather crude approximation intended to capture the overflow water densities far downstream of the sills, after most entrainment has taken place. The representation of the overflows, the bottom topography in their vicinity, and treatment of bottom flows vary quite significantly among the models. For example, NCAR uses the overflow parameterization documented in Danabasoglu et al. (2010); the Denmark Strait sill depth was deepened in AWI; some models (e.g., GFDL-MOM, KIEL, MIT, NOCS) use par- 
tial bottom cells; some models (e.g., ACCESS, CERFACS, MRI-F) employ various bottom boundary layer parameterizations; or models adapt combinations of these. Our results are also affected by the groups' choices of different density increments when they compute AMOC in density space. Another possible explanation for the lack of any clear relationship between AMOC transports and overflow densities in the present set of models in contrast with some earlier studies is that these previous studies were primarily concerned with sensitivities to some forcing choices in a given model whereas we consider different models here.

We finally focus on possible links between the March-mean sea-ice cover in the LS region and the previously discussed $\operatorname{LS} \theta, S$, and density biases as well as the MLDs. These relationships are presented in Fig. 20, using scatter plots. While we recognize that there are considerable spreads in all the panels, we make the following general remarks. As expected, the models with colder (warmer) upper-oceans have more (less) extensive ice cover in the LS with a correlation coefficient of -0.86 . Models having less extensive sea-ice cover generally show salty biases. In addition to advective salt fluxes associated with AMOC itself, such positive $S$ biases may result from increased evaporation due to positive $\theta$ biases in models with less ice cover, exposing a broader ocean surface to colder atmospheric temperatures. We calculate the observational sea-ice area for the LS region for the $1988-2007$ period as $2.3 \times 10^{5}$ $\mathrm{km}^{2}$. Thus, the models bracket this value with eight of them below and ten of them above the observational estimate. FSU emerges as an outlier with a sea-ice area that is 3.5 times larger than in observations. The scatter plot of the LS sea-ice area against the LS MLD (Fig. 20, bottom left) shows that as the ice cover diminishes, the LS MLD tends to get deeper. Interestingly, the models with a MLD close to the observationally-based estimate have much more extensive sea-ice cover than in observations with the exception of INMOM. To close the loop between the variables 
considered in this study, the final set of scatter plots (bottom middle and right) show the LS sea-ice area against the AMOC transports at $26.5^{\circ}$ and $45^{\circ} \mathrm{N}$. The plots confirm the general tendency of the simulations to have a stronger AMOC transport with smaller LS sea-ice cover with similar $(-0.77$ and -0.74$)$ correlation coefficients at both latitudes. This is consistent with previous work which showed that sea-ice coverage in the LS is a key factor controlling winter water mass transformation rates and deep western boundary current strength (Yeager and Jochum, 2009).

\section{Summary and Conclusions}

We have presented an analysis of the North Atlantic Ocean solutions with a focus on the mean state of the AMOC and related variables from eighteen different models participating in the CORE-II effort. The associated variability study is the subject of a companion paper. It is extremely pleasing to have such large and diverse worldwide involvement in this endeavor, representing major modeling groups and a variety of ocean and sea-ice models. In addition to the traditional level (depth) coordinate ocean models, the participation of isopycnal and hybrid coordinate models, as well as of models with mass (pressure) and terrain following (sigma) coordinates in the vertical and of the first unstructured finite element ocean model, greatly enhanced the value of this model inter-comparison effort. Furthermore, the participation of a data assimilation model (i.e., MRI-A) also offers the opportunity to identify differences between free-running model simulations and state estimation products.

As in the preceding CORE-I study (Griffies et al., 2009), we find that our starting hypothesis, namely that global ocean - sea-ice models integrated using the same inter-annually varying atmospheric forcing data sets will produce qualitatively similar mean and variability in their simulations, is not generally satisfied for the mean states in the North Atlantic. The solutions reveal significant differences among the models. 
Not surprisingly, the model solutions also differ from available observations, but there are exceptions to this generalization with some models showing good agreement with observations for some diagnostics. For example, the RAPID AMOC profile, including its maximum transport, is captured well in the upper $2000 \mathrm{~m}$ in NCAR, and some other models reproduce the maximum observed AMOC transport reasonably well. However, this transport is underestimated in the majority of the models. Moreover, all of the models have difficulties with the representation of the AABW, and they all tend to underestimate MHT.

The differences in the solutions do not suggest an obvious grouping of the models based on their ocean model lineage. For example, the NEMO family of models have significant differences in their AMOC, MLD, etc. depictions. No grouping of solution properties based on model vertical coordinate representations is obvious, either. Thus, we conclude that the differences in solutions among the models are primarily due to the groups' use of different subgrid scale parameterizations and parameter choices as well as to differences in vertical and horizontal grid resolutions in the ocean models. Use of a wide variety of sea-ice models along with diverse snow and sea-ice albedo treatments also contributes to differences in the solutions. Such diversity in the ocean - sea-ice configurations produces differences in surface buoyancy and momentum fluxes among the models particularly through differences in their SSTs, despite identical atmospheric forcing data sets. We note that there are undoubtedly biases in these CORE-II IAF data sets, but the present analysis does not appear to expose any clear issues with forcing related to the North Atlantic.

Our analysis indicates that the larger AMOC transports tend to be associated with deeper MLDs, resulting from increased salt content in the LS region. These positive $S$ biases occur in conjunction with reduced sea-ice cover in the LS, likely due to positive $\theta$ biases. Such positive $\theta$ and $S$ biases along with positive density 
and MLD biases in the LS region appear to be needed by the models to match the observed AMOC transports at $26.5^{\circ} \mathrm{N}$. The $\theta$ and $S$ biases may result from advection of positive heat and salt flux anomalies (from the south) by AMOC itself, surface buoyancy fluxes, sea-ice related mechanisms, or a combination of these. In addition to the hydrographic properties and associated DWF in the LS region, the Nordic Seas overflows can also affect AMOC transports, but our study does not indicate any clear relationship between AMOC transports and an overflow proxy density. We caution, however, that the representation of overflows and the bottom topography in their vicinity vary quite significantly among the models and that our analysis is crude.

Regarding restoring salt fluxes, we do not find any particular links between the LS $S$ biases and the strength (or time scale) of surface salinity restoring used by the models. For example, KIEL and BERGEN have comparable positive $S$ biases despite their use of 1500 and 300 days, respectively, for their restoring time scales. Similarly, the negative $S$ biases are rather similar in MIT and CMCC with restoring time scales of 1500 and 365 days, respectively. There are no apparent connections between the AMOC transport magnitudes and the surface salinity restoring strength among the models, either, even though such a relationship can exist in a given model as discussed in Appendix C, e.g., stronger restoring results in weaker AMOC transports in NCAR - in contrast with Behrens et al. (2013) where stronger restoring produces larger AMOC transports.

Based on the diagnostics employed here, the majority of the models appear suitable for use in North Atlantic studies. Although all of the models will undoubtedly benefit from further improvements, a few require some dedicated development effort. Considering that INMOM represents a preliminary attempt at using a sigma coordinate model in a global configuration, its solutions appear acceptable in some 
measures, e.g., MHT, upper-ocean $\theta$ and $S$ biases, while there are indications of larger issues in some other diagnostics, e.g., MLD, zonal-mean $\theta$ and $S$ biases. Its subgrid scale physics can certainly be improved by including a better mesoscale eddy parameterization, and more effort is needed to interpret its solutions and biases. Coarse model resolution, parameter choices in the ocean model, and the sea-ice model are likely responsible for the Nordic Seas fresh bias and deep MLDs in the LS in ICTP. Addressing the cold and fresh bias and associated extensive sea-ice cover problems in the LS, among others, may lead to improvements in AMOC and MHT distributions in FSU. Indeed, efforts are already underway to improve HYCOM solutions by considering a new configuration of the model that advects $\theta-S$ along with a different sea-ice model and reference pressure (Rainer Bleck and Shan Sun, 2013, personal communication). Early results from this heat and salt conserving HYCOM version show much promise, including an improved representation of AMOC. Although providing a deeper understanding of model biases and suggesting remedies for addressing them are beyond the scope of this study, one of the basic goals of the CORE-II effort is to provide a common framework for inter-comparison of the model results and stimulate discussions and collaborations among the participating groups. We believe that such efforts are already underway as each group assesses their contributions relative to both observations and those of the other groups as in the HYCOM example. Finally, we note that the CORE-II framework may also be adopted by the data assimilation community in their future inter-comparison projects.

The CORE-II experimental protocol was intended to reflect a compromise between the affordability of the simulations by a broad group of researchers and the usability of the resulting solutions for scientific purposes. We believe that such a balance has been achieved as evidenced by large participation and the fidelity of the 
simulations.

\section{Acknowledgments}

NCAR is sponsored by the U. S. National Science Foundation (NSF). The CCSM and CESM are supported by the NSF and the U. S. Department of Energy. S. G. Yeager was supported by the NOAA Climate Program Office under Climate Variability and Predictability Program grant NA09OAR4310163. ACCESS modeling work has been undertaken as part of the Australian Climate Change Science Program, funded jointly by the Department of Climate Change and Energy Efficiency, the Bureau of Meteorology and CSIRO, and was supported by the National Computational Infrastructure facility at the Australian National University. AWI is a member of the Helmholtz Association of German Research Centers. Q. Wang and D. Sidorenko are funded by the Helmholtz Climate Initiative REKLIM (Regional Climate Change) project. The BERGEN contribution is supported by the Research Council of Norway through the EarthClim (207711/E10) and NOTUR/NorStore projects, as well as the Centre for Climate Dynamics at the Bjerknes Centre for Climate Research. The CMCC contribution received funding from the Italian Ministry of Education, University, and Research and the Italian Ministry of Environment, Land, and Sea under the GEMINA project. P. G. Fogli thanks W. G. Large, J. Tribbia, M. Vertenstein, G. Danabasoglu, and D. Bailey for their support and help in bringing NEMO into the CESM framework while vising NCAR. E. Fernandez was supported by the BNPParibas foundation via the PRECLIDE project under the CNRS research convention agreement 30023488. We thank M. Harrison and R. Hallberg of GFDL for assistance with defining the GFDL-GOLD configuration, and P. R. Gent, M. Holland, and F. Bryan of NCAR for suggestions on an earlier version of the manuscript. Finally, we thank both the international CLIVAR and U.S. CLIVAR projects for patiently 
sponsoring WGOMD over the years as COREs were developed.

\section{Appendix A. Contributing Models (in alphabetical order)}

\section{Appendix A.1. ACCESS}

ACCESS-OM is the ocean and sea-ice component of the Australian Community Climate and Earth System Simulator Coupled Model (ACCESS-CM; Bi et al., 2013a). ACCESS-OM comprises the NOAA/GFDL MOM4p1 ocean code (Griffies, 2009) and the Los Alamos National Laboratory (LANL) CICE4.1 sea-ice code (Hunke and Lipscomb, 2008), coupled via the CERFACS OASIS3.25 software framework (Valcke, 2006). ACCESS-OM and its performance under a CORE NYF experiment are described by Bi et al. (2013b). Details of the performance of the ocean and sea-ice components of ACCESS-OM in coupled experiments submitted to CMIP5 are given by Marsland et al. (2013) and Uotila et al. (2013), respectively.

The ocean and sea-ice components share a common horizontal orthogonal discretization having nominally $1^{\circ}$ resolution (360 zonal by 300 meridional grid cells) with the following refinements: a tripolar grid (Murray, 1996) north of $65^{\circ} \mathrm{N}$; equatorial meridional grid refinement to $1 / 3^{\circ}$ within a band from $10^{\circ} \mathrm{S}$ to $10^{\circ} \mathrm{N}$; and cosine dependent (Mercator) grid cells south of $30^{\circ} \mathrm{S}$ to the Antarctic coast. The vertical discretization (50 layers with 20 in the top $200 \mathrm{~m}$ ) uses the $z^{*}$ geopotential coordinate (Adcroft and Campin, 2004) and partial grid cells at the bottom (Adcroft et al., 1997). Conservative temperature (McDougall, 2003) is the model's prognostic temperature field (results presented here use diagnosed potential temperature). For the case of static instability ACCESS-OM uses explicit convection following Rahmstorf (1993). The mixed layer is represented using the K-Profile Parameterization (KPP) scheme (Large et al., 1994) with a critical Richardson number of 0.3. A 
constant background vertical diffusivity $\left(1.0 \times 10^{-5} \mathrm{~m}^{2} \mathrm{~s}^{-1}\right)$ is locally enhanced by the baroclinic abyssal tidal dissipation scheme of Simmons et al. (2004), and the barotropic coastal tidal dissipation scheme of Lee et al. (2006). ACCESS-OM uses the following subgrid scale physics: isoneutral diffusion following Redi (1982); a modified Gent and McWilliams (1990) (GM) scheme following Ferrari et al. (2010) with baroclinic closure of the thickness diffusivity; and a submesoscale mixed layer restratification scheme following Fox-Kemper et al. (2011). Shelf overflows are parameterized following the sigma transport scheme of Beckmann and Döscher (1997), using the downslope mixing scheme from Griffies (2009).

The sea-ice model computes internal ice stresses by an Elastic-Viscous-Plastic (EVP) dynamics scheme (Hunke and Dukowicz, 1997), employs a layered thermodynamic scheme, uses an incremental linear remapping for estimating the ice advection, and redistributes the ice between thickness categories through ridging and rafting schemes by assuming an exponential redistribution function. Sea-ice is divided into five thickness categories with four vertical ice layers and one snow layer in each category. The ice salinity is 4 psu.

\section{Appendix A.2. AWI}

Finite Element Sea-ice Ocean Model (FESOM) is the ocean - sea-ice component of the coupled Earth System Model which is currently under development at the Alfred Wegener Institute for Polar and Marine Research (AWI). The ocean module is an unstructured-mesh model based on finite element methods and hydrostatic primitive equations (Danilov et al., 2004; Wang et al., 2008; Timmermann et al., 2009). It allows for variable mesh resolution without traditional nesting, so multiscale simulations can be conveniently conducted.

FESOM uses $z$-coordinates and finite element discretization with continuous lin- 
ear basis functions on the A-grid. A projection method is used for solving the free surface equation, so there is no mode splitting of barotropic velocity in the model. A flux-corrected-transport advection scheme is used in tracer equations. The KPP scheme is used for vertical mixing parameterization. Both the ocean and ice modules are discretized on the same triangular surface meshes, allowing direct exchange of fluxes and fields between the two components.

The North Pole is displaced over Greenland to avoid singularity. The horizontal model resolution is nominal $1^{\circ}$ in the bulk of the global domain, with the North Atlantic sub-polar gyre region and global coastal regions refined to $25 \mathrm{~km}$. Along the equatorial band the resolution is $1 / 3^{\circ}$. In the vertical 46 levels are used, with 10 $\mathrm{m}$ layer thicknesses within the upper $100 \mathrm{~m}$ depth. The bottom topography at the Denmark Strait is deepened to $900 \mathrm{~m}$, giving two cross-sill active grid points below $600 \mathrm{~m}$. Biharmonic viscosity is scaled with the third power of the grid resolution, and the neutral diffusivity and GM skew diffusivity are scaled with the grid resolution. The river runoff flux is distributed around the river mouths with a linear function within $400 \mathrm{~km}$ distance.

\section{Appendix A.3. BERGEN}

The BERGEN contribution uses the ocean and sea-ice components of the Norwegian Earth System Model (NorESM; Bentsen et al., 2013). This model system is based on the Community Earth System Model (CESM) version 1.0.4 with the same sea-ice component and the same application of atmospheric forcing, but with a different ocean component.

The ocean component, NorESM-O, described in Bentsen et al. (2013), originates from the Miami Isopycnal Coordinate Ocean Model (MICOM; Bleck and Smith, 1990; Bleck et al., 1992), inheriting its mass conserving formulation, C-grid dis- 
cretization, leap-frog time stepping for tracers and the inviscid baroclinic dynamics, forward-backward time-stepping for the barotropic equations, and momentum equations discretized in a potential vorticity/enstrophy conserving manner. The background diapycnal diffusivity is latitude dependent and increases gradually poleward from a minimum value of $10^{-7} \mathrm{~m}^{2} \mathrm{~s}^{-1}$ at the equator. The functional latitude dependence is inspired by Gregg et al. (2003) with values of $10^{-5} \mathrm{~m}^{2} \mathrm{~s}^{-1}$ and $1.54 \times 10^{-5}$ $\mathrm{m}^{2} \mathrm{~s}^{-1}$ at latitudes of $30^{\circ}$ and $60^{\circ}$, respectively. Further, the background diffusivity is constrained with an upper limit of $\sim 10^{-6} \mathrm{~m}^{2} \mathrm{~s}^{-1}$ when sea-ice is present. Shear driven diapycnal mixing follows Large et al. (1994) but with enhanced maximum diffusivity near the ocean floor to provide more realistic mixing in gravity currents. Diapycnal mixing is also driven by a fraction of the energy extracted from the mean flow by the bottom drag (Legg et al., 2006). Tidally driven diapycnal mixing follows the parameterization by Simmons et al. (2004) where the estimated conversion of tidal energy to internal waves by Jayne (2009) is used. The ocean model does not support mass exchange through the surface, thus fluxes of fresh water are converted to a virtual salt flux. The sea-ice model, in the configuration used in this study, is unaltered from the CESM version described in Appendix A.17, which is based on version 4 of the LANL sea-ice model (CICE4; Hunke and Lipscomb, 2008)

The ocean and sea-ice components share the same tripolar grid with a $1^{\circ}$ resolution along the equator. The grid cells are optimized for isotropy except in the equatorial region where the meridional resolution approaches $0.25^{\circ}$. In the Southern Hemisphere the grid singularity is at the South Pole, while the two grid singularities in the Northern Hemisphere are located in Canada and Siberia. The ocean model is configured with 51 isopycnic layers referenced at $2000 \mathrm{db}$. The surface mixed layer is divided into two non-isopycnic layers. 
Appendix A.4. CERFACS

CERFACS-ORCA1 is used as the ocean component of CNRM-CM5, the Earth System Model assembled by Météo-France and CERFACS for CMIP5. It is a $1^{\circ}$ model configuration of the version 3.2 of the Nucleus for European Modelling of the Ocean (NEMO) framework. As many aspects of the CERFACS setup are very similar to the NOCS version detailed in Appendix A.18, we list only the differences from NOCS-ORCA1.

There are 42 vertical levels, monotonically increasing from $10 \mathrm{~m}$ near the surface to $300 \mathrm{~m}$ in the abyssal ocean. The three-waveband scheme of Lengaigne et al. (2007) is run with a constant chlorophyll value of $0.005 \mathrm{~g} \mathrm{Chl} \mathrm{L}^{-1}$. The base value of vertical diffusivity is $1.2 \times 10^{-5} \mathrm{~m}^{2} \mathrm{~s}^{-1}$ only poleward of $15^{\circ}$ of latitude. Between $15^{\circ}-5^{\circ} \mathrm{S}$ and $5^{\circ}-15^{\circ} \mathrm{N}$, it is linearly ramped down to the constant value of $1.2 \times 10^{-6}$ $\mathrm{m}^{2} \mathrm{~s}^{-1}$ in the equatorial band of $5^{\circ} \mathrm{S}-5^{\circ} \mathrm{N}$, following Gregg et al. (2003). A spatially varying geothermal heat flux through the ocean floor with a global mean value of 86.4 $\mathrm{mW} \mathrm{s}{ }^{-2}$ (Emile-Geay and Madec, 2009) is applied. The discretized version of the isoneutral diffusion and the GM eddy advection do not use the triad formalism. In addition, a higher diffusivity of $1 \times 10^{4} \mathrm{~m}^{2} \mathrm{~s}^{-1}$ is used in the Döscher and Beckmann (2000) bottom boundary layer scheme.

\section{Appendix A.5. CMCC}

The CMCC contribution uses the CESM framework, but the CESM ocean component has been replaced with the NEMO version 3.3 (Madec, 2008). Almost all aspects of the ocean model configuration are identical to those of the NOCS version described in Appendix A.18. The exceptions are: i) the vertical grid has 46 levels with 10 levels in the upper $100 \mathrm{~m}$; and ii) the discretized version of the isoneutral diffusion and the GM eddy advection do not use the triad formalism. 
The sea-ice model CICE is the same as the one used in the CESM model (Holland et al., 2012). It runs on the same horizontal grid as the ocean while using an Arakawa B-grid. The exchange of vector fields has been carefully designed in order to properly handle the different velocity points (at the cell grid corners in the B-grid and in the middle of the cell edges in the C-grid). The other details of the ocean - sea-ice interface follow the CESM approaches except for the exchange of freshwater and salt fluxes due to sea-ice freezing and melting which follows Tartinville et al. (2001). The model time step is 1 hour and the coupling time step between the ocean and the sea-ice is 6 hours. The sea-ice model was initialized from a previous simulation. The ocean model allows water to be exchanged across the ocean surface.

\section{Appendix A.6. CNRM}

The major difference from the CERFACS framework described in Appendix A.4 is that the sea-ice component used by CNRM-NEMO is Gelato5, not LIM2. Gelato5 considers four ice thickness categories $(0-0.3 \mathrm{~m}, 0.3-0.8 \mathrm{~m}, 0.8-3 \mathrm{~m}$, and over $3 \mathrm{~m})$. Each category has 10 vertical layers with enhanced resolution near the top of the slab. The salinity of sea-ice varies in time, based on a scheme adapted from Vancoppenolle et al. (2009). The vertical heat diffusion coefficient is a function of ice temperature and salinity, following Pringle et al. (2007). Hence, the vertical heat diffusion equation is solved by an iterative scheme. Snow aging through densification and albedo decrease are represented by a simple snow scheme (Salas-Mélia, 2002). Sea-ice dynamics is represented by the EVP scheme (Hunke and Dukowicz, 1997), and advection is based on an incremental remapping scheme described in Hunke and Lipscomb (2002). Convergence processes, which can lead to transitions between the ice categories through sea-ice rafting or ridging are represented following Thorndike et al. (1975). A more complete description of the whole ocean - sea-ice component is 
provided by Voldoire et al. (2013). In addition, the CNRM configuration of NEMO differs from the CERFACS version only by the horizontal eddy viscosity coefficient. It is set to $1 \times 10^{4} \mathrm{~m}^{2} \mathrm{~s}^{-1}$ in CNRM-NEMO, consistent with the value used in the CNRM-CM5.1 model (Voldoire et al., 2013).

\section{Appendix A.7. FSU}

The FSU contribution uses a modified Community Climate System Model version 3 (CCSM3) framework where the HYCOM version 2.2 (Bleck, 2002; Chassignet et al., 2003; Halliwell, 2004) is employed as the ocean component in its $S$ - density advection formulation. This configuration is referred to as GLB1x3. The horizontal grid (320 cells in the zonal direction and 384 in the meridional direction) and topography are identical to that of the CCSM3 Parallel Ocean Program (POP) except that HYCOM uses staggered Arakawa-C grid while POP uses Arakawa-B grid. GLB1x3 is configured with 32 hybrid layers (depth or potential density) with density target ranging from 28.10 to $37.25 \mathrm{~kg} \mathrm{~m}^{-3}$. The model continually checks whether or not grid points lie on their reference isopycnals and, if not, tries to move them vertically toward the latter (Bleck, 2002). However, the grid points are not allowed to migrate when this would lead to excessive crowding of coordinate surfaces. Thus, in the mixed layer or in shallow water, vertical grid points are geometrically constrained to remain at a fixed pressure while being allowed to join and follow their reference isopycnals over the adjacent deep ocean. Therefore, HYCOM behaves like a pressure coordinate model in the mixed layer or other unstratified regions, like an isopycnic coordinate model in stratified regions, and like a conventional terrain-following model in very shallow and / or unstratified oceanic regions (Chassignet et al., 2003, 2006). The sea-ice model employed by GLB1x3 is the same version of Community Sea-Ice Model (CSIM) as used in CCSM3. 
The initial temperature and salinity are given by the Polar Science Center Hydrographic Climatology version 3 (PHC3). The HYCOM code advects salinity and density using a second order flux corrected transport scheme. The model baroclinic and barotropic time steps are $2160 \mathrm{~s}$ (leap-frog) and $36 \mathrm{~s}$ (explicit), respectively. The model uses the KPP mixed layer sub-model (Large et al., 1994). Interface height smoothing - corresponding to Gent and McWilliams (1990) - is applied through a biharmonic operator, with a mixing coefficient determined by the grid spacing (in $\mathrm{m})$ times a constant velocity scale of $0.05 \mathrm{~m} \mathrm{~s}^{-1}$. For regions where the coordinate surfaces align with constant pressure (mostly in the upper ocean mixed layer), the GM parameterization is not used, and lateral diffusion is oriented along pressure surfaces rather than rotated to neutral directions. No parameterization has been implemented for overflows.

\section{Appendix A.8. GFDL-GOLD}

The ocean component of the GFDL-GOLD configuration employs the Generalized Ocean Layer Dynamics (GOLD) isopycnal code originally developed by Hallberg (1995) with a nominal $1^{\circ}$ horizontal resolution refined to $1 / 3^{\circ}$ meridionally at the equator. The model includes two mixed layers, two buffer layers, and 59 interior isopycnal layers defined according to potential density referenced to 2000 dbar. The configuration is identical to that used as part of the earth system model ESM2G as detailed by Dunne et al. (2012). The GFDL-GOLD configuration uses the same seaice model as the GFDL-MOM configuration. Further details of how GFDL-GOLD was configured for the CORE simulations follow that of the GFDL-MOM with two exceptions. First, GFDL-GOLD inserts the river runoff to the nearest ocean grid point. No further horizontal spreading is used. The model enhances energy available for turbulent mixing at points where river water enters the ocean, so that river 
water is in effect mixed over the upper ocean in a manner similar to GFDL-MOM. Second, GFDL-GOLD uses a surface salinity restoring of 50 days over $50 \mathrm{~m}$, which is six times stronger than the GFDL-MOM configuration. The stronger restoring in GFDL-GOLD was found necessary to retain a stable AMOC.

\section{Appendix A.9. GFDL-MOM}

The ocean component of the GFDL-MOM configuration employs the Modular Ocean Model (MOM) code from Griffies (2012) configured using a B-grid staggering with the same grid resolution and bathymetry as the CM2.1 ocean component documented by Griffies et al. (2005) and Gnanadesikan et al. (2006), which was also used for the NYF simulations of Griffies et al. (2009). This grid configuration was also used in the ESM2M earth system model of Dunne et al. (2012). The grid has a nominal $1^{\circ}$ horizontal resolution (refined meridionally to $1 / 3^{\circ}$ at the equator) and a tripolar grid poleward of $65^{\circ} \mathrm{N}$. The vertical grid uses 50 levels, with 22 in the upper $220 \mathrm{~m}$. The vertical coordinate is the rescaled geopotential coordinate $z^{*}$ from Stacey et al. (1995) and Adcroft and Campin (2004).

GFDL-MOM time steps the tracer and velocity fields using a staggered two-level scheme documented in Griffies et al. (2005) and Griffies (2004). This scheme conserves scalar fields to within computational round-off error, with such conservation particularly important for studies of global mean sea level (see corresponding COREII study from Griffies et al. (2013) for discussion). Further details of the numerical methods and physical parameterizations of the ocean are provided in Griffies et al. (2005) and Dunne et al. (2012). There is one exception to the physical parameterizations discussed in these published papers, whereby the GFDL-MOM CORE-II simulation employs a version of the Lee et al. (2006) coastal tide mixing scheme that corrects a bug, with the bug correction greatly reducing the mixing from this 
scheme towards more physically relevant values. Details of this bug and its correction are documented in chapter 20 of Griffies (2012). The sea-ice component used in the GFDL-MOM configuration is detailed in Delworth et al. (2006), with slight modifications towards more realistic ice albedos given by Dunne et al. (2012).

In these CORE-II simulations, GFDL-MOM employs a climatological chlorophyll data-set for attenuating shortwave radiation into the upper ocean. The data-set is based on an updated version of that produced in Sweeney et al. (2005), using the optical scheme from Manizza et al. (2005) for defining the shortwave attenuation.

\section{Appendix A.10. GISS}

modelER is the ocean component of the coupled NASA GISS modelE (Russell et al., 1995, 2000; Liu et al., 2003). Here, an early version of the revised E2-R code is run in stand-alone mode (Kelley et al., 2013). It employs a mass coordinate that approximates to pressure with a vertical resolution of 32 layers, ranging from about $12 \mathrm{~m}$ at the surface to about $200 \mathrm{~m}$ in the abyssal ocean, and a horizontal resolution of $1.25^{\circ}$ in longitude and $1^{\circ}$ in latitude. The model is a fully dynamic, non-Boussinesq, mass-conserving free surface ocean model. The version used here employs a linear upstream scheme for the horizontal advection of tracers and a centered difference scheme in the vertical. A $1800 \mathrm{~s}$ time step is used for tracer evolution.

The model uses a subgrid scale parameterization to represent exchanges with unresolved straits and open ocean for up to 12 straits, e.g., the Gibraltar, Hormuz, and Nares Straits. All ocean variables are fluxed through these straits as a function of the end-to-end pressure gradients, balanced against a drag proportional to the width of the straits. The latter serves as a tuning parameter to get reasonable fluxes.

modelER uses the GISS vertical mixing scheme (Canuto et al., 2010) which models diapycnal mixing throughout the whole depth of the ocean, including turbulence 
generated by convection and shear in the mixed layer, double-diffusive effects, mixing due to internal waves in the interior of the ocean, and mixing due to tidal interactions with topography near the ocean bottom. Mesoscale eddies are represented by the GM scheme coded with the skew flux formulation (Griffies, 1998) with a new threedimensionally varying surface-enhanced mesoscale diffusivity based on a theoretical prediction of the surface eddy kinetic energy (Canuto et al., 2013).

Sea-ice dynamics, thermodynamics, and ocean - sea-ice coupling are represented as in the CMIP5 modelE configuration (Schmidt et al., 2013), albeit with ice on the ocean model grid rather than that of the atmosphere. Surface turbulent fluxes over sea-ice are calculated using the CORE prescription of transfer coefficients.

\section{Appendix A.11. ICTP}

The ICTP-MOM ocean - sea-ice model is a coarse resolution version of the GFDLMOM model. The model uses the $z^{*}$-coordinate ocean code MOM4p1 documented by Griffies (2009) and the GFDL Sea Ice Simulator (SIS) sea-ice model (see more details in Delworth et al., 2006). The model grid uses 180 cells in the zonal direction $\left(2^{\circ}\right), 96$ latitudinal cells ( $1^{\circ}$ at the equator), and 30 vertical levels with partial step bottom topography. The model updates the tracer and baroclinic velocity with a $9600 \mathrm{~s}$ time step for both inviscid dynamics and dissipative physics. Mesoscale eddy-induced transports are parameterized following the boundary-value problem approach of Ferrari et al. (2010), in which the variable eddy-induced advection coefficient is bounded between 600 and $1400 \mathrm{~m}^{2} \mathrm{~s}^{-1}$. Neutral diffusivity (Redi, 1982) has a value of $800 \mathrm{~m}^{2} \mathrm{~s}^{-1}$. The ocean model uses background vertical diffusivity values following Bryan and Lewis (1979), with values of $0.3 \times 10^{-4}$ and $1.4 \times 10^{-4} \mathrm{~m}^{2} \mathrm{~s}^{-1}$ in the upper and deep ocean, respectively. Submesoscale and overflow mixing schemes are not implemented in this model. 
Appendix A.12. INMOM

The Institute of Numerical Mathematics (INM) Ocean Model (INMOM) is the ocean component of the INM Earth Climate Model (INMCM4.0; Volodin et al., 2010). INMOM is a sigma-coordinate ocean model. It uses a displaced North Pole where the grid pole is placed in Taimyr Peninsula. There are 360 zonal and 340 meridional grid cells, corresponding to $1^{\circ}$ and $0.5^{\circ}$ resolution, respectively. In the vertical, it employs 40 non-uniform sigma levels. The tracer equations use isopycnal diffusion with a constant mixing coefficient of $100 \mathrm{~m}^{2} \mathrm{~s}^{-1}$, but no additional parameterization for mesoscale eddies is used. Vertical mixing is parameterized with the Pacanowski and Philander (1981) scheme. The sea-ice model is described in Yakovlev (2009) and contains many aspects of Hunke and Dukowicz (1997) and Briegleb et al. (2004).

\section{Appendix A.13. KIEL}

The Kiel ocean model configuration ORCA05 is based on the NEMO code (version 3.1.1; Madec, 2008) and belongs to the DRAKKAR framework (The DRAKKAR Group, 2007). It uses a global ocean setup coupled with a Hibler-type sea-ice model (LIM2; Fichefet and Maqueda, 1997) in a tripolar grid configuration with a nominal $0.5^{\circ}$ horizontal resolution and 46 levels in the vertical (Biastoch et al., 2008). The layer thicknesses vary from $6 \mathrm{~m}$ at the surface to about $250 \mathrm{~m}$ in the deep ocean. For the bottom cell, a partial cell approach is used which, in combination with advanced advection schemes, leads to an improved circulation (Barnier et al., 2006).

The turbulent vertical mixing is simulated with a 1.5-level turbulent kinetic energy scheme (Blanke and Delecluse, 1993). Momentum equations use a bi-Laplacian horizontal viscosity. The parameterizations of isoneutral diffusion and the GM eddy advection for tracers use the same formulation and parameters as in NOCS described 
in Appendix A.18. For tracer advection, a total variance dissipation scheme (Zalesak, 1979) is employed.

\section{Appendix A.14. MIT}

The MIT simulation uses the Massachusetts Institute of Technology general circulation model (MITgcm; Marshall et al., 1997; Adcroft et al., 2004). Aside from the CORE-II forcing and mixing parameters used here, the model setup is from the latest Estimating the Circulation and Climate of the Ocean (ECCO) framework and it is used to improve upon the estimates of Forget (2010) and Wunsch and Heimbach (2007). However, none of the ECCO optimized forcing and mixing is used in the present simulations.

In the vertical, the grid consists of 50 depth levels, with $10 \mathrm{~m}$ grid spacing near the ocean surface, and partial step bottom topography. In the horizontal, the socalled latitude-longitude-cap grid is used. Nominal grid spacing is $1^{\circ}$. While the grid follows longitude and latitude lines at mid-latitudes, it turns into a quadripolar mesh over the Arctic, where the 4 model grid poles are conveniently placed on land. Vertical mixing is parameterized by a background diffusivity of $10^{-5} \mathrm{~m}^{2} \mathrm{~s}^{-1}$, a basic convective mixing scheme, and the schemes of Gaspar et al. (1990) and Duffy et al. (1999) under sea-ice. Tracers are further mixed along isopycnals (Redi, 1982), and advection by eddies is parameterized according to Gent and McWilliams (1990). The corresponding isopycnal and thickness diffusivities are both $500 \mathrm{~m}^{2} \mathrm{~s}^{-1}$. The sea-ice model is a dynamic / thermodynamic model with a viscous-plastic (VP) rheology following Hibler (1979). The CORE-II surface hydrological forcing is applied as water fluxes, as opposed to virtual salt fluxes. 
Appendix A.15. MRI-A (assimilation, MOVE/MRI.COM)

MOVE/MRI.COM CORE-II version is a global ocean data assimilation system based on the Multivariate Ocean Variational Estimation / Meteorological Research Institute Community Ocean Model (MOVE/MRI.COM; Usui et al., 2006; Fujii et al., 2012). This system uses the same MRI.COM version with identical grid resolution, physical schemes, and parameter settings as in MRI-F described in Appendix A.16.

MOVE/MRI.COM adopts a 3-dimensional variational (3DVAR) analysis scheme based on Fujii and Kamachi (2003), in which coupled temperature - salinity ( $\theta$ and $S$ ) empirical orthogonal function modal decomposition is applied to the background error covariance matrix. In the system, suboptimal $\theta$ and $S$ analysis fields above 1750 $m$ depth for a target month are estimated from the model forecast and observational data through the 3DVAR scheme, and reflected on the model fields by incremental analysis updates (Bloom et al., 1996). The system is further improved by adopting a variational quality control scheme (Fujii et al., 2005), a sequential bias correction scheme (Fujii et al., 2009), and a first-guess-at-appropriate-time scheme (Lorenc and Rawlins, 2005).

In the reanalysis run, only in-situ $\theta$ and $S$ observational profiles (including data from mooring buoys and profiling floats) are assimilated into the model. No satellite data are used to avoid data gaps. The $\theta$ and $S$ profiles are obtained from the World Ocean Data 2009 (Boyer et al., 2009) and the Global Temperature and Salinity Profile Program (GTSPP) database (Hamilton, 1994). The system also blends a monthly $\theta$ and $S$ climatology based on the WOA09 (Locarnini et al., 2010; Antonov et al., 2010) into the model forecast before it is used in the 3DVAR scheme to suppress the deviation of the model fields from the climatology. This procedure is roughly equivalent to relaxation with a restoring time of 100 months.

The MOVE/MRI.COM is run only for 70 years, starting from model year 231 of 
the MRI-F integration. The first ten years of this integration is treated as a spinup phase during which a stronger blending of observed climatology into the model forecast (equivalent to a relaxation time scale of 20 months) than the one applied during the actual integration is used to reduce biases prior to the start of the latter. Thus, the actual MRI-A integration, assimilating data during the 1948-2007 period, begins at model year 241 and essentially corresponds to the fifth forcing cycle.

\section{Appendix A.16. MRI-F (free running, MRI.COM)}

MRI.COM is the ocean - sea-ice component of MRI-CGCM3 (MRI Coupled General Circulation Model version 3; Yukimoto et al., 2011, 2012) and is based on the MRI.COM version 3 (Tsujino et al., 2010, 2011). MRI.COM3 is a free-surface, depthcoordinate ocean - sea-ice model that solves the primitive equations using Boussinesq and hydrostatic approximations. A split-explicit algorithm is used for the barotropic and baroclinic parts of the equations (Killworth et al., 1991). Horizontal resolutions are $1^{\circ}$ in longitude and $0.5^{\circ}$ in latitude. The horizontal grid is tripolar as prescribed by Murray (1996). The model ocean consists of 50 vertical levels with 30 in the upper $1000 \mathrm{~m}$. The vertical levels shallower than $32 \mathrm{~m}$ follow the surface topography as in sigma-coordinate models (Hasumi, 2006). There is a bottom boundary layer (BBL; Nakano and Suginohara, 2002) with a $50 \mathrm{~m}$ thickness. The BBL is only added in the northern North Atlantic (between $50^{\circ}-70^{\circ} \mathrm{N}$ and $60^{\circ} \mathrm{W}-0^{\circ}$ ) and the Southern Ocean around Antarctica (south of $60^{\circ} \mathrm{S}$ ).

The generalized Arakawa scheme as described by Ishizaki and Motoi (1999) is used to calculate the momentum advection terms. The tracer advection scheme is based on conservation of second order moments (Prather, 1986). Mixing along neutral surfaces caused by eddy stirring is parameterized using an iso-neutral mixing coefficient of $1000 \mathrm{~m}^{2} \mathrm{~s}^{-1}$ (Redi, 1982) and the Gent and McWilliams (1990) parameterization with 
a mixing coefficient of $300 \mathrm{~m}^{2} \mathrm{~s}^{-1} \times \sqrt{\text { grid area }} / 100 \mathrm{~km}$ where grid area is in $\mathrm{km}^{2}$. The maximum allowed slope of iso-neutral surfaces is set to $1 / 1000$. The Smagorinsky (1963) horizontal viscosity formulation is applied using a flow-dependent anisotropic tensor (Smith and McWilliams, 2003) to reduce the viscosity in the direction normal to the flow. Vertical mixing is based on a generic length scale model with parameters recommended by Umlauf and Burchard (2003) with a background three-dimensional distribution following Decloedt and Luther (2010).

The sea-ice component is based on Mellor and Kantha (1989). For categorization by thickness, ridging, rheology, and albedo, those of the LANL sea-ice model (CICE; Hunke and Lipscomb (2008)) are adopted with some modifications for albedo. Shortwave radiation is partitioned with a fixed ratio: 0.575 for visible and 0.425 for near infrared. The dry and wet albedos for ice are 0.8 and 0.58 , respectively. Fractional area, snow volume, ice volume, ice energy, and ice surface temperature of each thickness category are transported using the multidimensional positive definite advection transport algorithm (MPDATA) of Smolarkiewicz (1984).

\section{Appendix A.17. NCAR}

The NCAR contribution uses the Parallel Ocean Program version 2 (POP2; Smith et al., 2010) and the sea-ice model version 4 (CICE4; Hunke and Lipscomb, 2008). They are, respectively, the ocean and sea-ice components of the Community Climate System Model version 4 and Community Earth System Model version 1 (CCSM4 and CESM1, respectively; Gent et al., 2011). Here we give brief summaries and refer to Danabasoglu et al. (2012) and Holland et al. (2012) for further details.

POP2 is a level-coordinate model, using the hydrostatic and Boussinesq approximations. A linearized, implicit free-surface formulation is employed. The global integral of the ocean volume remains constant because the freshwater fluxes are 
treated as virtual salt fluxes. The model uses a displaced North Pole grid with a nominal $1^{\circ}$ horizontal resolution. The meridional resolution is increased to $0.27^{\circ}$ near the equator. There are 60 vertical levels, monotonically increasing from $10 \mathrm{~m}$ in the upper ocean to $250 \mathrm{~m}$ in the deep ocean.

A new overflow parameterization of density driven flows (Danabasoglu et al., 2010; Briegleb et al., 2010) is used to represent the Denmark Strait, Faroe Bank Channel, Ross Sea, and Weddell Sea overflows. The model tracer equations use the GM isopycnal transport parameterization in its skew-flux form (Griffies, 1998). The effects of diabatic mesoscale fluxes within the surface diabatic layer are included via a simplified version of the near-boundary eddy flux parameterization of Ferrari et al. (2008), as implemented by Danabasoglu et al. (2008). Both the thickness and isopycnal diffusivity coefficients vary identically in the vertical, following Ferreira et al. (2005) and Danabasoglu and Marshall (2007). In the upper ocean, enhanced diffusivity values are used which can be as large as $3000 \mathrm{~m}^{2} \mathrm{~s}^{-1}$. They diminish to $300 \mathrm{~m}^{2} \mathrm{~s}^{-1}$ by a depth of about $2000 \mathrm{~m}$. In the surface diabatic layer, the horizontal diffusivity coefficient is also set to $3000 \mathrm{~m}^{2} \mathrm{~s}^{-1}$. The restratification effects of finiteamplitude, submesoscale mixed layer eddies are included, using the mixed layer eddy parameterization of Fox-Kemper et al. (2008) and Fox-Kemper et al. (2011). The momentum equations use the anisotropic horizontal viscosity formulation in its generalized form (Smith and McWilliams, 2003; Large et al., 2001; Jochum et al., 2008). The vertical mixing is parameterized using the KPP scheme (Large et al., 1994) as modified by Danabasoglu et al. (2006) with a latitudinally varying background diffusivity. The abyssal tidal mixing parameterization of St. Laurent et al. (2002) and Jayne (2009) is used to represent the deep vertical mixing arising from the breaking of tidally-generated internal waves over rough topography.

CICE4 shares the same horizontal grid as POP2. It includes EVP dynamics 
(Hunke and Dukowicz, 2002), energy-conserving thermodynamics (Bitz and Lipscomb, 1999), and a subgrid-scale ice thickness distribution (ITD; Thorndike et al., 1975). A fundamental improvement in the sea-ice component is the incorporation of a new radiative transfer scheme for the treatment of solar radiation (Briegleb and Light, 2007; Holland et al., 2012). This scheme calculates multiple scattering of solar radiation in sea-ice using a delta-Eddington approximation with inherent (i.e., microscopic) optical properties that specify scattering - absorption properties for snow, sea-ice, ponds, and included absorbers. The resulting surface albedo and absorbed shortwave flux are computed using this new radiative transfer scheme. Hence the surface albedos are not directly tuned and instead the inherent optical properties of snow, bare sea-ice, and melt ponds are adjusted within two standard deviations of the observations taken during the Surface Heat Budget of the Arctic (SHEBA) experiment in 1997-1998.

\section{Appendix A.18. NOCS}

We note that an expanded description of the NEMO framework is only provided here to serve as a reference for other models using the same framework.

NOCS-ORCA1 is the $1^{\circ}$ model configuration of the NEMO 3.4 framework being used at the National Oceanography Centre Southampton (NOCS). It is a $z$-level Boussinesq global coupled ocean - sea-ice model. NOCS-ORCA1 includes the ocean circulation model OPA (Madec, 2008) coupled to the Louvain-la-Neuve Ice Model sea-ice model LIM2 (Timmermann et al., 2005), but with EVP instead of VP ice rheology (Hunke and Dukowicz, 1997) on the C-grid (Bouillon et al., 2009). The horizontal mesh is tripolar (Timmermann et al., 2005; Hewitt et al., 2011), based on a $1^{\circ}$ Mercator grid, but with additional refinement of the meridional grid to $1 / 3^{\circ}$ near the equator. North of $20^{\circ} \mathrm{N}$ the grid starts to deviate from Mercator as a result 
of the tripolar grid, but does not differ significantly until $60^{\circ} \mathrm{N}$. Over the Arctic Ocean, the model resolution is about $50 \mathrm{~km}$. Model level thicknesses are about $1 \mathrm{~m}$ near the surface, increasing to about $200 \mathrm{~m}$ at $6000 \mathrm{~m}$ depth with 19 levels in the upper $50 \mathrm{~m}$ and 25 levels in the upper $100 \mathrm{~m}$. Topography is represented with partial cells (Barnier et al., 2006). A linear free-surface formulation is employed (Roullet and Madec, 2000), where lateral fluxes of volume, tracers and momentum are calculated using fixed reference ocean surface height. Temperature and salinity are advected with the total variance dissipation scheme (Cravatte et al., 2007), a secondorder, two-step monotonic scheme with moderate numerical diffusion. An energy and enstrophy conserving scheme (Le Sommer et al., 2009) is used for momentum.

Precipitation and evaporation are effected by volume input through the ocean surface; therefore, they affect the sea surface height as a volume flux and the salinity as a concentration / dilution term. Salinity is also restored by volume input. The global mean of freshwater budget is set to zero at each model time step. Ice melting and freezing instead drive salt fluxes through the ocean surface calculated assuming constant ice (6 psu) and ocean (34.7 psu) salinities in order to conserve salt during the ice freezing / melting cycle.

Shortwave radiation is attenuated using the chlorophyll-dependent three-waveband (RGB) scheme of Lengaigne et al. (2007) together with an observed (seasonally and spatially varying) chlorophyll climatology (SeaWiFS, averaged 1999-2005). Momentum and tracers are mixed vertically using a turbulent kinetic energy (TKE) scheme (Madec, 2008) based on the model of Gaspar et al. (1990). It also includes a Langmuir cell parameterization (Axell, 2002), a surface wave breaking parameterization (Mellor and Blumberg, 2004), and uses an energetically consistent time and space discretization (Burchard, 2002; Marsaleix et al., 2008). Base values of vertical diffusivity and viscosity are $1.2 \times 10^{-5}$ and $1.2 \times 10^{-4} \mathrm{~m}^{2} \mathrm{~s}^{-1}$, respectively. Tidal mixing is 
parameterized following Simmons et al. (2004), using an internal wave energy field derived from the output of the barotropic global ocean tide model MOG2D-G (Carrère and Lyard, 2003). In addition, the Koch-Larrouy et al. (2007) parameterization for tidal mixing is used in the Indonesian area.

Lateral diffusivity is parameterized by an iso-neutral Laplacian operator with a coefficient of $1000 \mathrm{~m}^{2} \mathrm{~s}^{-1}$ at the Equator decreasing with the reduction of the grid spacing with latitude - it becomes $<500 \mathrm{~m}^{2} \mathrm{~s}^{-1}$ poleward of $60^{\circ}$ latitude. A spatially varying field of the GM eddy advection coefficient is calculated as a function of local Rossby radius and Eady eddy-growth rate (cf. Held and Larichev, 1996). Both isoneutral diffusion and the GM eddy advection are implemented with a triad formalism (Griffies et al., 1998; Griffies, 1998). Within the surface mixed-layer, lateral diffusion is along slopes linearly decreasing with depth from the isoneutral slope immediately below the mixed layer to zero (flat) at the surface. These linearly varying slopes are also used to calculate the GM skew-fluxes: this is equivalent to a GM eddy-induced velocity that is uniform through the mixed layer (Treguier et al., 1997). This approach, used in OPA since 1999 (Madec, pers. comm.), is a simplified version of the approach recommended by Danabasoglu et al. (2008).

Lateral viscosity is parameterized by a horizontal Laplacian operator with free slip boundary condition and an eddy viscosity coefficient of $2 \times 10^{4} \mathrm{~m}^{2} \mathrm{~s}^{-1}$ except in the tropics where it reduces to $1000 \mathrm{~m}^{2} \mathrm{~s}^{-1}$ (except along western boundaries). Finally, the diffusive component of the bottom boundary layer scheme of Döscher and Beckmann (2000) is employed, in which tracers are diffused downslope, using a diffusivity of $1000 \mathrm{~m}^{2} \mathrm{~s}^{-1}$. 


\section{Appendix B. CORE-II IAF Experimental Protocol}

We summarize the protocol for conducting CORE-II IAF experiments here, with further details provided in Griffies et al. (2012).

The ocean models are initialized with zero velocities and the January-mean climatological $\theta$ and $S$ from the Polar Science Center Hydrographic Climatology (PHC2; a blending of the Levitus et al. (1998) data set with modifications in the Arctic Ocean based on Steele et al. (2001)). More recent $\theta$ and $S$ data sets can also be used. The sea-ice models are generally initialized from a state available from other, existing simulations. Because the CORE-II IAF experiments are run no less than 300 years, fine details of the initial conditions are not crucial.

The surface fluxes of heat, freshwater / salt, and momentum are determined using the CORE-II IAF atmospheric data sets, the model's prognostic SST and surface currents, and the bulk formulae described in Large and Yeager (2004, 2009). As the forcing data-sets have been developed using the formulae described in these references, we recommend using the same bulk formulae. There is no restoring term applied to SSTs. In contrast, a form of sea surface salinity (SSS) restoring may be used to prevent unbounded local salinity trends (see Appendix C for details of SSS restoring used by the groups). This restoring can be applied as either a salt flux or a converted water flux - the latter is for models that employ fresh water fluxes. However, the former method is preferred even for models that employ fresh water fluxes to maintain simple diagnostic control over the total water budget without any confusion from water fluxes from restoring. A modified version of the PHC2 monthlymean SSS climatology which includes salinity enhancements along the Antarctic coast due to Doney and Hecht (2002) is recommended as the restoring field.

In contrast with the river runoff data used in Griffies et al. (2009), the new 
runoff data are not pre-spread. Therefore, the user must choose how to insert river water into the ocean. For example, in AWI, the runoff flux is distributed around the river mouths with a linear function within $400 \mathrm{~km}$ distance. In NCAR, river runoff is spread substantially prior to applying it as a flux into the uppermost grid cell with a newer smoothing algorithm than was used in Large and Yeager (2004), yielding far less spreading. GFDL-MOM simulations choose to apply two passes of a Laplacian (1-2-1) filter in the horizontal at each time step to spread the river runoff outward from the river insertion point, resulting in a rather small spread. In addition, as detailed in Griffies et al. (2005), river runoff is inserted to the GFDLMOM simulations over the upper four grid cells (roughly $40 \mathrm{~m}$ ). This insertion is meant to parameterize tidal mixing near river mouths, and it may serve a similar purpose to the horizontal spreading applied by NCAR. In so doing, it helps to mix the fresh water throughout the upper four model grid cells, thus reducing the tendency for the simulation to produce a highly stratified fresh cap at the river mouths.

The ocean - sea-ice coupled model is run for no less than 5 repeating cycles of the 60-year forcing. Upon reaching the end of 2007, the forcing is returned to 1948. Analysis of the ocean fields during the 5th cycle provides the basis for comparing to other simulations. We note that the 60-year repeat cycling introduces an unphysical jump in the forcing from 2007 back to 1948 with the ocean state in 1948 identical to that of the end state of the previous cycle. Nevertheless, no agreeable alternative has been proposed and tested.

To aid in assessing the models' mixing processes, ventilation rates, deep water formation, and circulation characteristics under CORE-II IAF forcing, we recommend that the simulations include ideal age tracer and chlorofluorocarbons (CFCs). The ideal age tracer (Thiele and Sarmiento, 1990) is set to zero in the model surface layer (level) at each time step, and ages at 1 year per year below. It evolves accord- 
ing to the same advection - diffusion equation in the ocean interior just as a passive tracer. Regions of low ventilation have the oldest waters while the younger waters indicate recent contact with the ocean surface. For a proper comparison of model ideal age distributions, we recommend that the ideal age be initialized with zero at the beginning of the 300-year simulations (five forcing cycles).

The CFC-11 and CFC-12 have been increasingly utilized in evaluating ocean models largely due to i) a good observational data base (the World Ocean Circulation Experiment, WOCE, upon which Global Ocean Data Analysis Project, GLODAP, Key et al. (2004) is largely based), ii) their well-known atmospheric concentrations, and iii) because they are inert in the ocean. The surface concentrations of CFC-12 and CFC-11 are available starting from 1931 and 1938, respectively. The associated fluxes should be calculated following the Ocean Carbon Model Inter-comparison Project (OCMIP-2) protocols (Dutay et al., 2002). However, instead of the protocol specified fields, the CORE-II IAF data sets should be used in the flux equations.

There is a mismatch between the CFC and CORE-II IAF data start dates. At NCAR, the following approach is used. Assuming a 300-year simulation, we introduce the CFC-12 and CFC-11 surface fluxes at the beginning of model years 224 and 231, respectively, in the fourth forcing cycle. Both CFCs are initialized with zero. These model years correspond to calendar years 1991 and 1998, respectively, for the surface fluxes of heat, salt, and momentum in the IAF cycle, while they correspond to calendar year 1931 for CFC-12 and calendar year 1938 for CFC-11 surface fluxes. However, by the beginning of the fifth cycle corresponding to model year 241 and calendar year 1948, all surface fluxes become synchronous, i.e., the calendar years for the atmospheric data used in all surface flux calculations are the same during the fifth cycle. Another option is to simply introduce both CFCs at the beginning of the fifth cycle, i.e., in year 1948. Because CFC concentrations are rather small during 
the previous years, this represents a reasonable approach.

\section{Appendix C. Hydrological Forcing and Salinity Restoring}

As discussed in Griffies et al. (2009), the ocean - sea-ice coupled systems lack many of the feedbacks present in a fully coupled framework due to the absence of an active atmospheric component. In addition, the lack of any appreciable local feedbacks between SSS and freshwater fluxes can lead to unbounded local salinity trends that can occur in response to inaccuracies in precipitation. These two factors necessitate restoring (or relaxation) of model SSS (SSS model) to an observed climatology $\left(\mathrm{SSS}_{\text {data }}\right)$ in ocean - sea-ice coupled simulations. The CORE-II IAF protocol described in Appendix B does not specify a particular recipe for such restoring and it is left to the modelers to choose their optimal restoring procedure.

Such SSS restoring remains part of the art, rather than the science, of ocean sea-ice climate modeling. SSS restoring is applied using a restoring salt flux of

$$
F=V_{\text {piston }}\left(\mathrm{SSS}_{\text {data }}-\mathrm{SSS}_{\text {model }}\right)=V_{\text {piston }} \Delta \mathrm{SSS}
$$

to the top ocean model grid cell. For example, when $\mathrm{SSS}_{\text {model }}$ is smaller than $\mathrm{SSS}_{\text {data }}$, then a positive restoring salt flux is added. Unfortunately, the model solutions exhibit substantial sensitivities to the strength of the piston velocity $\left(V_{\text {piston }}\right)$ - or equivalently to the magnitude of the restoring time scale for a given length scale, e.g., Behrens et al. (2013). It is highly desirable that the selection of a restoring time scale for a particular model is based on quantitative measures, involving comparisons of model solutions with available observations. Often times, this decision also incorporates subjective calls involving, for example, judgments on unknown AMOC variability or making sure that the model produces a stable AMOC. 
An example of the sensitivity of the model AMOC simulations to the restoring time scale is provided in Fig. 21. The figure shows several annual-mean AMOC maximum transport time series at $26.5^{\circ} \mathrm{N}$ from a preliminary version of the NCAR model in comparison with the RAPID data (Cunningham et al., 2007). The model time series are obtained using different SSS restoring time scales: 30 days (30D); 1 year $(1 \mathrm{Y}) ; 4$ years $(4 \mathrm{Y})$; and infinity $(\mathrm{NO})$, i.e., no restoring, all with respect to a $50 \mathrm{~m}$ length scale. The restoring time scale has a substantial influence on the mean AMOC maximum transport which increases monotonically with weaker restoring from 14.1 Sv in 30D to 20.9 Sv in NO - both over the 60-year period. Not surprisingly, weaker restoring leads to larger salinity, and hence density, biases compared to observations in the model deep water formation regions in the northern North Atlantic (not shown). Despite these differences in the AMOC mean at this latitude, the restoring time scale does not appear to impact the characteristics of AMOC interannual to decadal variability appreciably (see also Behrens et al. (2013)). The 4Y simulation fortuitously matches the RAPID data. We note that this metric by itself is not sufficient to justify using a 4-year restoring time scale and additional metrics, such as northward heat transport, $\theta$ and $S$ differences from observations, and the ACC transport at Drake Passage, should be considered. During this exploratory investigation, we re-confirmed that the 4-year SSS restoring time scale that has been in use at NCAR since Large et al. (1997) produces solutions that, in general, compare more favorably with observations than the ones obtained with the other restoring time scales.

We present a summary of the surface hydrological forcing and SSS restoring details used by the participating groups in Table 2. Most of the groups apply real fresh water fluxes instead of a virtual salt flux. The NEMO-based models convert SSS restoring to a fresh water flux. All the other models apply SSS restoring as a 
salt flux. The restoring time scales vary considerably between the groups, but they can be gathered into three categories as follows:

- weak restoring with time scales of about 4 years: FSU, GISS, KIEL, MIT, and NCAR,

- moderate restoring with time scales of 9 - 12 months: AWI, BERGEN, CERFACS, CMCC, CNRM, GFDL-MOM, ICTP, INMOM, MRI-A, and MRI-F, NOCS,

- strong restoring with time scales of 50 - 150 days: ACCESS, GFDL-GOLD.

In all models, the SSS restoring is applied globally and under ice covered regions - the latter with the exception of ICTP and KIEL. However, in ten of the models, the mismatch between $\mathrm{SSS}_{\text {model }}$ and $\mathrm{SSS}_{\text {data }}$ is limited to 0.5 psu, i.e., $|\Delta \mathrm{SSS}| \leq 0.5$ psu, to avoid extremely large salt fluxes of either sign that may occur, for example, in the vicinity of western boundary currents that are not realistically represented in coarse resolution simulations. The main idea is to minimize any spurious weakening of AMOC due to possible northward transport of too much fresh water that can be added to the model without such a limit. Some groups which use narrow river runoff spreading also choose to eliminate restoring at grid cells receiving river runoff so that freshening due to runoff would not be compensated by overly salty values found in the restoring field.

To ensure that there is no accumulation of salt due to the restoring fluxes, most of the groups remove the globally integrated salt content arising from restoring at each time step. We note that this is a global correction, impacting the magnitude and even the sign of local restoring fluxes. 
Finally, given the evolving model SSTs, there is no guarantee that precipitation (P) plus runoff (R) minus evaporation (E) will balance to zero so that the ocean - sea-ice total water content - or salt content for those models using virtual salt fluxes - will not change. All groups use some sort of normalization to enforce such a constraint. These normalizations impact the surface ocean globally; they are nonlocal. Examples include i) multiplication of $\mathrm{P}+\mathrm{R}$ by a factor based on the global salinity change in the ocean over the previous year to bring the salinity change towards zero as in NCAR (Large et al., 1997), and ii) enforcing globally integrated $\mathrm{P}+\mathrm{R}-\mathrm{E}=0$ at each time step as in, e.g., CMCC, GFDL-MOM, GFDL-GOLD, and MIT. Operationally, in CMCC, GFDL-MOM, and GFDL-GOLD, the global mean of $\mathrm{P}-\mathrm{E}+\mathrm{R}$ is subtracted from $\mathrm{P}-\mathrm{E}$; the runoff is not modified. So in effect, the global area integrated $\mathrm{P}-\mathrm{E}$ will be equal and opposite in sign to the global area integrated runoff. Additionally, water can be exchanged with the sea-ice, yet this exchange is not considered for purposes of the global normalization used in these models.

\section{Appendix D. Calculations of Zonal Averages and Transports}

In this Appendix, we briefly summarize how the zonal averages and transports (or integrals) are computed by the participating groups. The latter concerns calculations of AMOC and MHT.

Due to its regular longitude - latitude grid, GISS is the only model that does not require any additional regridding to obtain true zonal averages and integrals. In AWI, FSU, INMOM, MRI-A, and MRI-F, variables are first interpolated to regular longitude - latitude grids and then zonal operations are performed. In NCAR, a binning approach is used for transports where horizontal divergences of volume and heat calculated on the model grid are summed within specified latitude bands onto a regular longitude - latitude grid. Zonal averages in NCAR are computed using a 
volume-weighted average (or horizontal area-weighted average because the vertical thicknesses are the same for a given vertical level) of a field where the average is over the model grid cells intersecting the latitude band, and the horizontal area for the weighting is the area of intersection of the model grid cell with the latitude band.

In ACCESS, GFDL-GOLD, GFDL-MOM, and ICTP, the model grids are truly zonal south of $65^{\circ} \mathrm{N}$. Similarly, the model grids are truly zonal south of $38.5^{\circ}$ and $56^{\circ} \mathrm{N}$ in BERGEN and MIT, respectively. Thus, these models do not necessitate any regridding south of these latitudes. Further north, the zonal operations are performed along model grid lines, despite their deviations from constant latitude lines.

All zonal calculations are done along the distorted grid lines in NEMO-based models, i.e., CERFACS, CMCC, CNRM, KIEL, and NOCS. The grid distortion is rather small at low latitudes. For example, latitude varies by about $0.03^{\circ}$ along a model grid line (a line of constant model latitude index) near $26.9^{\circ} \mathrm{N}$ in the Atlantic Basin. However, the distortion gradually increases to $>2^{\circ}$ by about $60^{\circ} \mathrm{N}$, e.g., the minimum and maximum latitudes are $60.1^{\circ}$ and $62.5^{\circ} \mathrm{N}$ along a grid line. The nominal latitude is specified as the maximum latitude along a grid line. North of $60^{\circ} \mathrm{N}$, the grid distortions become larger, making such zonal averages and transports less meaningful.

In the vertical, BERGEN, FSU, GFDL-GOLD, and INMOM use regridding or binning to map from model vertical coordinates to depth levels. In GISS, the zonal operations are done in mass levels as their depths vary only slightly with time, i.e., by $<1 \%$.

We believe that calculations of zonal integrations and averages along model grid lines are acceptable for our present purposes because serious grid distortions from true zonal averages are expected to occur only at high latitudes where AMOC and 
MHT are relatively small. However, we note that proper calculations of AMOC and MHT at these high latitudes are important for studies involving Arctic Ocean and sea-ice where even small transports matter significantly.

\section{Appendix E. Impacts of Neptune Parameterization}

A comparison experiment was performed of a NEMO run identical to the NOCS contribution except that a simplified version of the Neptune parameterization of unresolved eddy - topographic interactions (Eby and Holloway, 1994) was used, following Holloway and Wang (2009). The horizontal velocity field is relaxed towards a topographically determined, steady, Neptune velocity field

$$
u^{\mathrm{Nept}}=-\frac{1}{H} \frac{\partial \psi^{\mathrm{Nept}}}{\partial y} \quad, \quad v^{\mathrm{Nept}}=\frac{1}{H} \frac{\partial \psi^{\mathrm{Nept}}}{\partial x}
$$

derived from a transport stream function

$$
\psi^{\mathrm{Nept}}=-f L^{2} H
$$

Here $H$ is the ocean depth, $f$ the Coriolis parameter, and $L$ is a latitude-dependent length that scales smoothly from $12 \mathrm{~km}$ at the equator down to $3 \mathrm{~km}$ at the poles. To avoid excessively strong flow in shallow waters, $\mathbf{u}^{\text {Nept }}$ is scaled linearly down to zero as $H$ shallows from 200 to $100 \mathrm{~m}$.

The resulting $\psi^{\text {Nept }}$ is quite significant, ranging from $-27 \mathrm{~Sv}$ at $30^{\circ} \mathrm{N}$ to $-13.9 \mathrm{~Sv}$ at $60^{\circ} \mathrm{N}$ and $-5.2 \mathrm{~Sv}$ at the North Pole, and has a major impact on the solutions in NOCS. Specifically, the cyclonic topographic flow thus excited in the Greenland Sea, LS, and subpolar gyre brings down cool fresh water (and ice) from the Greenland current into the LS. This quenches winter convection in the LS, reducing winter 
MLDs to 100-200 m, and freshens and cools the whole subpolar gyre. This freshening and cooling even penetrates into the western subtropical gyre.

This Neptune experiment has a much weaker MHT, with a maximum of only 0.42 PW compared with the 0.69 PW in the standard NOCS contribution. However, the maximum AMOC differs little. Figure 22a shows the differences (Neptune standard) in temperature flux along a quasi-zonal section at $26.5^{\circ} \mathrm{N}$, near where the maximum MHT is achieved, for the last year of the run. These differences are similar to the annual-mean differences in Fig. 22b of $v$ (meridional velocity) times the average of the temperatures between the Neptune and standard experiments, implying that they are driven by changes in the flow rather than in the temperature. This suggests that Neptune reduces the integrated MHT because the cyclonic boundary current weakens northward transport in the Gulf Stream, where the water is warm, and strengthens northward transport along the eastern edge, where the water is cool.

Indeed, the plots of the AMOC in Fig. 22c show that the overturning circulation differs little, but the plot of the difference in the cumulative vertically integrated heat transport (Fig. 22d) shows how the weaker zonally integrated heat transports with Neptune in the upper $1000 \mathrm{~m}$ reduce the total MHT by about 0.3 PW. Again, this cumulative heat flux difference (blue line) is largely due to changes in the velocity field (green line).

Our experience with the Neptune parameterization appears to be consistent with that of Roubicek et al. (1995). Despite some improvements of the mid-latitude jet separation location, they find that the strong cyclonic circulation produced by the parameterization dominates the barotropic circulation in idealized, wind-driven experiments with large topographic slopes. Using a biharmonic implementation of the Neptune parameterization in an eddying global model, Maltrud and Holloway (2008) report only marginal improvements in the Gulf Stream and Arctic Ocean solutions 
with no obvious degradations elsewhere. In contrast, Holloway and Wang (2009) (see also Holloway et al., 2007) show improvements of the Arctic Ocean solutions with this parameterization in comparison with those obtained with frictional parameterizations. In light of these mixed results, we concur with the above studies in their suggestions for refinements of the Neptune parameterization for both coarse and eddy permitting / resolving applications.

\section{Appendix F. List of Major Acronyms}

- ACCESS: Australian Community Climate and Earth System Simulator

- AWI: Alfred Wegener Institute

- CCSM: Community Climate System Model

- CERFACS: Centre Européen de Recherche et de Formation Avancée en Calcul Scientifique

- CESM: Community Earth System Model

- CICE: Sea ice model

- CLIVAR: Climate Variability and Predictability

- CM: Coupled model

- CMCC: Centro Euro-Mediterraneo sui Cambiamenti Climatici

- CMIP5: Coupled Model Inter-comparison Project phase 5

- CNRM: Centre National de Recherches Météorologiques

- CORE: Coordinated Ocean-ice Reference Experiments 


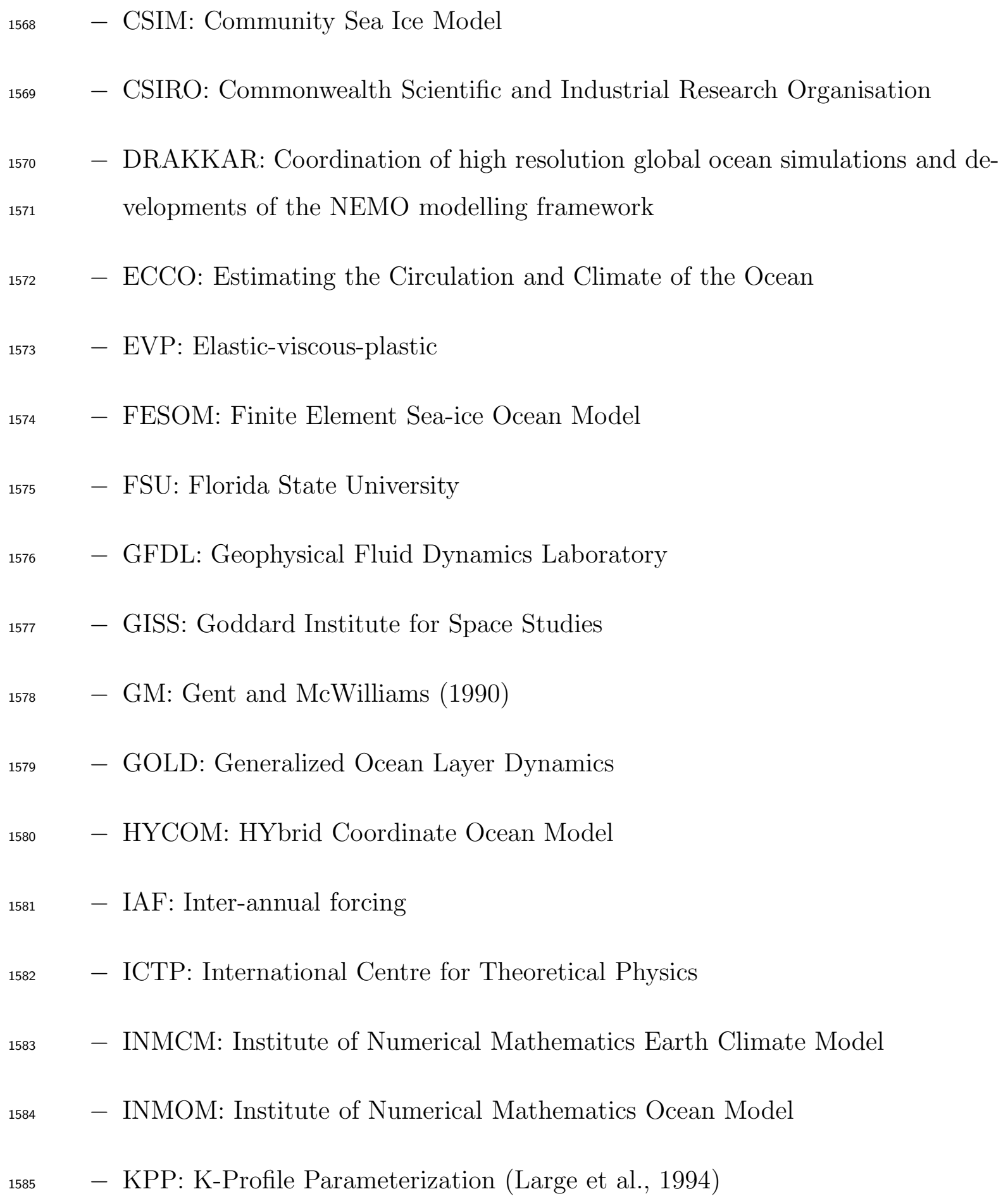




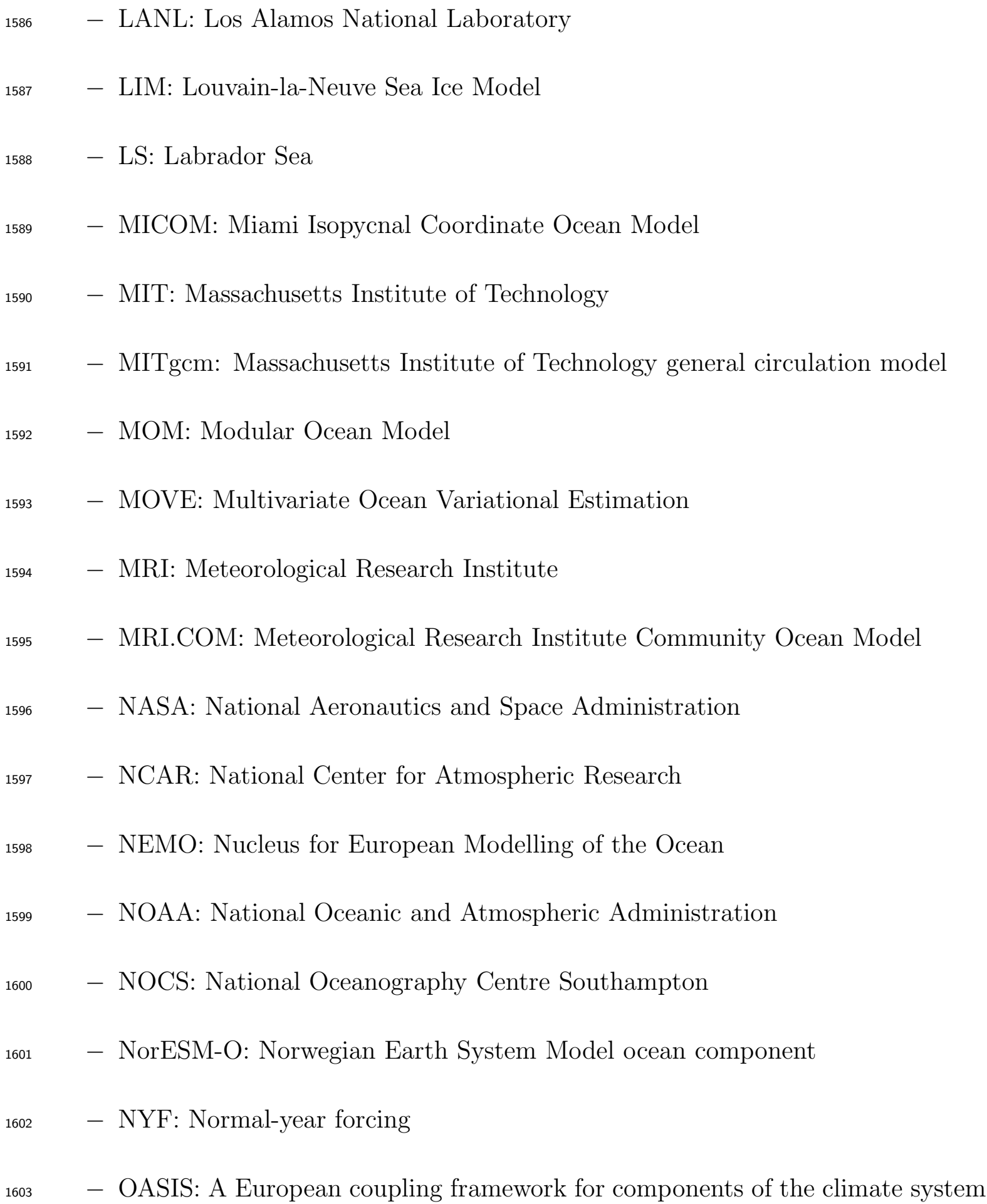




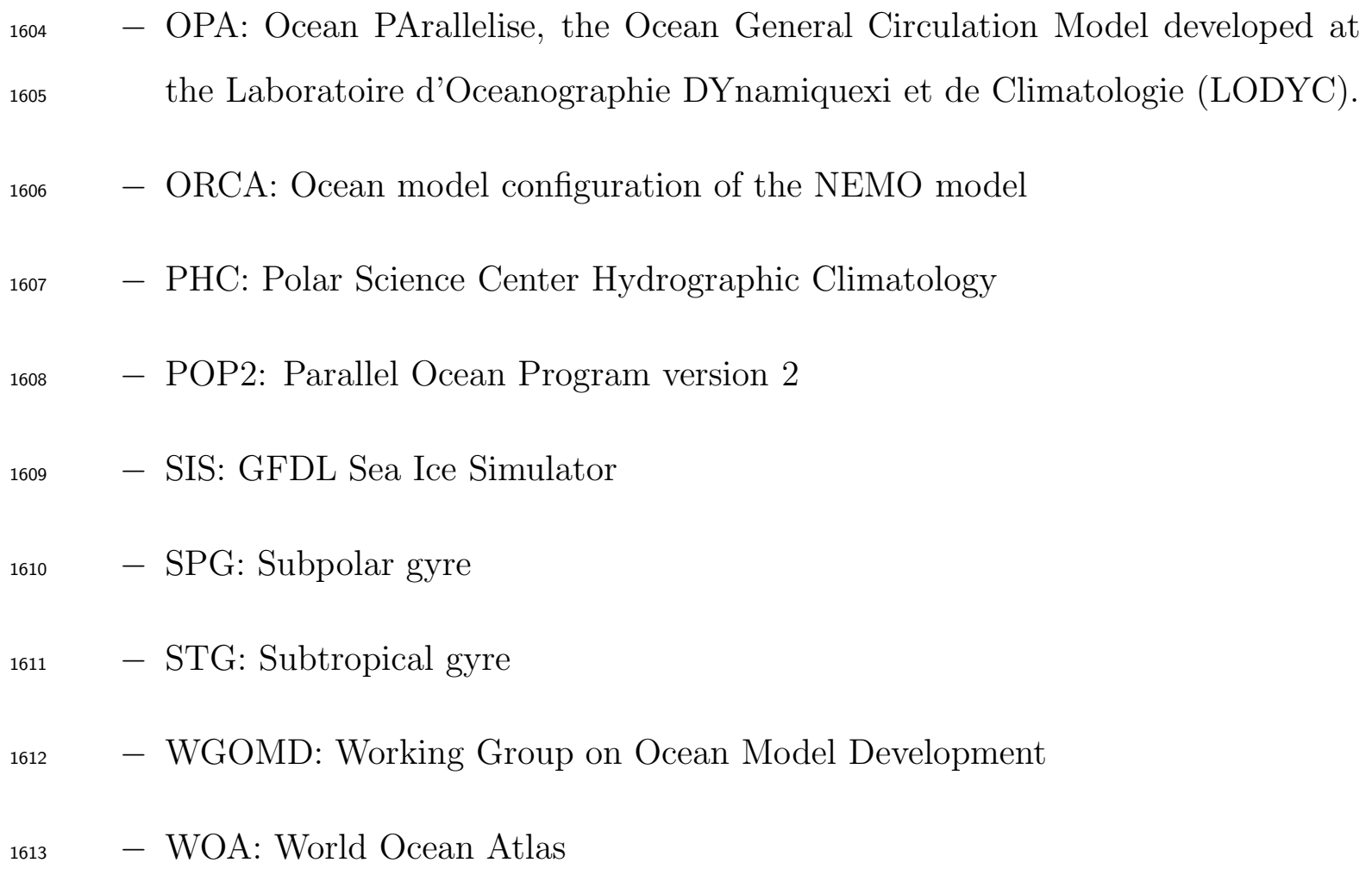




\section{References}

Adcroft, A., Campin, J.-M., 2004. Rescaled height coordinates for accurate representation of free-surface flows in ocean circulation models. Ocean Modelling 7, 269-284.

Adcroft, A., Hill, C., Campin, J., Marshall, J., Heimbach, P., 2004. Overview of the formulation and numerics of the MIT GCM. In: Proc. ECMWF Seminar Series on Numerical Methods: Recent Developments in Numerical Methods for Atmosphere and Ocean Modelling. pp. 139-149.

Adcroft, A., Hill, C., Marshall, J., 1997. Representation of topography by shaved cells in a height coordinate ocean model. Mon. Weather Rev. 125, 2293-2315.

Antonov, J. I., Seidov, D., Boyer, T. P., Locarnini, R. A., Mishonov, A. V., Garcia, H. E., Baranova, O. K., Zweng, M. M., Johnson, D. R., 2010. World Ocean Atlas 2009, volume 2: Salinity. U. S. Government Printing Office, Washington, D. C., NOAA Atlas NESDIS 69, p. 184.

Axell, L. B., 2002. Wind-driven internal waves and Langmuir circulations in a numerical ocean model of the southern Baltic Sea. J. Geophys. Res. 107, 3204.

Barnier, B., Madec, G., Penduff, T., Molines, J., Treguier, A., Sommer, J. L., Beckmann, A., Biastoch, A., Böning, C., Dengg, J., Derval, C., Durand, E., Gulev, S., Remy, E., Talandier, C., Theetten, S., Maltrud, M., McClean, J., Cuevas, B. D., 2006. Impact of partial steps and momentum advection schemes in a global ocean circulation model at eddy permitting resolution. Ocean Dyn. 56, 543-567.

Beckmann, A., Döscher, R., 1997. A method for improved representation of dense 
water spreading over topography in geopotential-coordinate models. J. Phys. Oceanogr. 27, 581-591.

Behrens, E., Biastoch, A., Böning, C. W., 2013. Spurious AMOC trends in global ocean sea-ice models related to subarctic freshwater forcing. Ocean Modelling(in press).

Bentsen, M., Bethke, I., Debernard, J. B., Iversen, T., Kirkevag, A., Seland, O., Drange, H., Roelandt, C., Seierstad, I. A., Hoose, C., Kristjansson, J. E., 2013. The Norwegian Earth System Model, NorESM1-M. Part 1: Description and basic evaluation of the physical climate. Geosci. Model Dev. 6, 687-720.

Bi, D., Dix, M., Marsland, S. J., O'Farrell, S., Rashid, H., Uotila, P., Hirst, A. C., Kowalczyk, E., Golebiewski, M., Sullivan, A., Hailin, Y., Hanna, N., Franklin, C., Sun, Z., Vohralik, P., Watterson, I., Zhou, X., Fiedler, R., Collier, M., Ma, Y., Noonan, J., Stevens, L., Uhe, P., Zhu, H., Hill, R., Harris, C., Griffies, S., Puri, K., 2013a. The ACCESS Coupled Model: Description, control climate and preliminary validation. Aust. Met. Oceanogr. J. 63, 41-64.

Bi, D., Marsland, S. J., Uotila, P., O’Farrell, S., Fiedler, R., Sullivan, A., Griffies, S. M., Zhou, X., Hirst, A. C., 2013b. ACCESS OM, the ocean-sea ice core of the ACCESS Coupled Model. Aust. Met. Oceanog. J. 63, 213-232.

Biastoch, A., Böning, C. W., Getzlaff, J., Molines, J.-M., Madec, G., 2008. Causes of interannual - decadal variability in the meridional overturning circulation of the mid-latutude North Atlantic Ocean. J. Climate 21, 6599-6615.

Bitz, C. M., Lipscomb, W. H., 1999. An energy-conserving thermodynamic sea ice model for climate study. J. Geophys. Res. 104, 15669-15677. 
Blanke, B., Delecluse, P., 1993. Variability of the tropical Atlantic Ocean simulated by a general circulation model with two different mixed -layer physics. J. Phys. Oceanogr. 23, 1363-1388.

Bleck, R., 2002. An oceanic general circulation model framed in hybrid isopycnicCartesian coordinates. Ocean Modelling 4, 55-88.

Bleck, R., Rooth, C., Hu, D., Smith, L. T., 1992. Salinity-driven thermocline transients in a wind- and thermohaline-forced isopycnic coordinate model of the North Atlantic. J. Phys. Oceanogr. 22, 1486-1505.

Bleck, R., Smith, L. T., 1990. A wind-driven isopycnic coordinate model of the north and equatorial Atlantic Ocean. 1. Model development and supporting experiments. J. Geophys. Res. 95, 3273-3285.

Bloom, S. C., Takacs, L. L., DaSilva, A. M., Ledvina, D., 1996. Data assimilation using incremental analysis updates. Mon. Wea. Rev. 124, 1256-1271.

Böning, C. W., Bryan, F. O., Holland, W. R., Döscher, R., 1996. Deep-water formation and meridional overturning in a high-resolution model of the North Atlantic. J. Phys. Oceanogr. 26, 1142-1164.

Böning, C. W., Dieterich, C., Barnier, B., Jia, Y. L., 2001. Seasonal cycle of the meridional heat transport in the subtropical North Atlantic: a model intercomparison in relation to observations near $25^{\circ} \mathrm{N}$. Prog. Oceanogr. 48, 231-253.

Bouillon, S., Morales-Maqueda, M. Á., Legat, V., Fichefet, T., 2009. An elasticviscous-plastic sea ice model formulated on Arakawa B and C grids. Ocean Modelling 27, 174-184. 
Boyer, T. P., Antonov, J. I., Baranova, O. K., Garcia, H. E., Johnson, D. R., Locarnini, R. A., Mishonov, A. V., O’Brien, T. D., Seidov, D., Smolyar, I. V., Zweng, M. M., 2009. World Ocean database 2009. U. S. Government Printing Office, Washington, D. C., NOAA Atlas NESDIS 66, p. 216.

Briegleb, B. P., Bitz, C. M., Hunke, E. C., Lipscomb, W. H., Holland, M. M., Schramm, J. L., Moritz, R. E., 2004. Scientific description of the sea-ice component in the Community Climate System Model, version three. NCAR Tech. Note NCAR/TN-463+STR, National Center for Atmospheric Research, Boulder, Colorado.

Briegleb, B. P., Danabasoglu, G., Large, W. G., 2010. An overflow parameterization for the ocean component of the Community Climate System Model. NCAR Tech. Note NCAR/TN-481+STR.

Briegleb, B. P., Light, B., 2007. A Delta-Eddington multiple scattering parameterization for solar radiation in the sae ice component of the Community Climate System Model. NCAR Tech. Note NCAR/TN-472+STR.

Bryan, F. O., Böning, C. W., Holland, W. R., 1995. On the midlatitude circulation in a high-resolution model of the North Atlantic. J. Phys. Oceanogr. 25, 289-305.

Bryan, K., Lewis, L. J., 1979. A water mass model of the world ocean. J. Geophys. Res. 84, 2503-2517.

Bryden, H., Imawaki, S., 2001. Ocean heat transport. In: Siedler, G., Church, J., Gould, J. (Eds.), Ocean circulation and climate. Vol. 77 of International Geophysical Series. Academic Press, pp. 317-336. 
Burchard, H., 2002. Energy-conserving discretisation of turbulent shear and buoyancy production. Ocean Modelling 4, 347-361.

Canuto, V. M., Dubovikov, M. S., Leboissetier, A., 2013. Mesoscales parameterization. Part I: The diabatic regime(in preparation).

Canuto, V. M., Howard, A. M., Cheng, Y., Muller, C. J., Leboissetier, A., Jayne, S. R., 2010. Ocean turbulence III: New GISS vertical mixing scheme. Ocean Modelling 34, 70-91.

Carrère, L., Lyard, F., 2003. Modelling the barotropic response of the global ocean to atmospheric wind and pressure forcing - comparisons with observations. Geophys. Res. Lett. 30, 1275.

Cavalieri, D., Parkinson, C., Gloersen, P., Zwally, H. J., 1996, updated yearly. Sea ice concentrations from Nimbus-7 SMMR and DMSP SSM/I-SSMIS passive microwave data, 1979-2000. National Snow and Ice Data Center, Boulder, Colorado, USA, digital media.

Chassignet, E., Hurlburt, H., Smedstad, O., Halliwell, G., Wallcraft, A., Metzger, E., Blanton, B., Lozano, C., Rao, D., Hogan, P., Srinivasan, A., 2006. Generalized vertical coordinates for eddy-resolving global and coastal forecasting. Oceanography $19,20-31$.

Chassignet, E. P., Smith, L. T., Halliwell, G. T., Bleck, R., 2003. North Atlantic simulations with the Hybrid Coordinate Ocean Model (HYCOM): Impact of the vertical coordinate choice, reference pressure, and thermobaricity. J. Phys. Oceanogr. $33,2504-2526$. 
Cravatte, S., Madec, G., Izumo, T., Menkes, C., Bozec, A., 2007. Progress in the 3-D circulation of the eastern equatorial Pacific in a climate ocean model. Ocean Modelling 17, 28-48.

Cunningham, S. A., Kanzow, T., Rayner, D., Baringer, M. O., Johns, W. E., Marotzke, J., Longworth, H. R., Grant, E. M., Hirschi, J. J.-M., Beal, L. M., Meinen, C. S., Bryden, H. L., 2007. Temporal variability of the Atlantic meridional overturning circulation at $26.5^{\circ} \mathrm{N}$. Science $317,935-938$.

Dai, A., Qian, T., Trenberth, K., Milliman, J., 2009. Changes in continental freshwater discharge from 1948-2004. J. Climate 22, 2773-2791.

Dai, A., Trenberth, K. E., 2002. Estimates of freshwater discharge from continents: Latitudinal and seasonal variations. J. Hydrometeorology 3, 660-687.

Danabasoglu, G., Bates, S. C., Briegleb, B. P., Jayne, S. R., Jochum, M., Large, W. G., Peacock, S., Yeager, S. G., 2012. The CCSM4 ocean component. J. Climate 25, 1361-1389.

Danabasoglu, G., Ferrari, R., McWilliams, J. C., 2008. Sensitivity of an ocean general circulation model to a parameterization of near-surface eddy fluxes. J. Climate 21, $1192-1208$.

Danabasoglu, G., Large, W. G., Briegleb, B. P., 2010. Climate impacts of parameterized Nordic Sea overflows. J. Geophys. Res. 115, C11005.

Danabasoglu, G., Large, W. G., Tribbia, J. J., Gent, P. R., Briegleb, B. P., McWilliams, J. C., 2006. Diurnal coupling in the tropical oceans of CCSM3. J. Climate 19, 2347-2365. 
Danabasoglu, G., Marshall, J., 2007. Effects of vertical variations of thickness diffusivity in an ocean general circulation model. Ocean Modelling 18, 122-141.

Danabasoglu, G., Yeager, S. G., Bailey, D., Behrens, E., Bentsen, M., Bi, D., Biastoch, A., Böning, C., Bozec, A., Canuto, V. M., Cassou, C., Chassignet, E., Danilov, S., Diansky, N., Drange, H., Farneti, R., Fernandez, E., Fogli, P. G., Forget, G., Fujii, Y., Griffies, S. M., Gusev, A., Heimbach, P., Howard, A., Jung, T., Kelley, M., Large, W. G., Leboissetier, A., Lu, J., Marsland, S. J., Masina, S., Navarra, A., Nurser, A. J. G., Pirani, A., Salas y Mélia, D., Samuels, B. L., Scheinert, M., Sidorenko, D., Treguier, A.-M., Tsujino, H., Uotila, P., Valcke, S., Voldoire, A., Wang, Q., 2013. North Atlantic simulations in Coordinated Oceanice Reference Experiments phase II (CORE-II). Part II: Variability. Ocean Modelling(in preparation).

Danilov, S., Kivman, G., Schroter, J., 2004. A finite element ocean model: principles and evaluation. Ocean Modelling 6, 125-150.

de Boyer Montégut, C., Madec, G., Fischer, A. S., Lazar, A., Iudicone, D., 2004. Mixed layer depth over the global ocean: An examination of profile data and a profile-based climatology. J. Geophys. Res. 109, C12003.

Decloedt, T., Luther, D. S., 2010. On a simple empirical parameterization of topography-catalyzed diapycnal mixing in the abyssal ocean. J. Phys. Oceanogr. $40,487-508$.

Delworth, T. L., Broccoli, A. J., Rosati, A., Stouffer, R. J., Balaji, V., Beesley, J. A., Cooke, W. F., Dixon, K. W., Dunne, J., Dunne, K. A., Durachta, J. W., Findell, K. L., Ginoux, P., Gnanadesikan, A., Gordon, C., Griffies, S. M., Gudegel, R., Harrison, M. J., Held, I. M., Hemler, R. S., Horowitz, L. W., Klein, S. A., Knutsen, 
T. R., Kushner, P. J., Langenhorst, A. L., Lee, H.-C., Lin, S. J., Lu, L., Malyshev, S. L., Milly, P., Ramaswamy, V., Russel, J., Schwarxkopf, M. D., Shevliakova, E., Sirutis, J., Spelman, M., Stern, W. F., Winton, M., Wittenberg, A. T., Wyman, B., Zeng, F., Zhang, R., 2006. GFDL's CM2 global coupled climate models. Part I: Formulation and simulation characteristics. J. Climate 19, 643-674.

Doney, S. C., Hecht, M. W., 2002. Antarctic bottom water formation and deepwater chlorofluorocarbon distributions in a global ocean climate model. J. Phys. Oceanogr. 32, 1642-1666.

Doney, S. C., Yeager, S., Danabasoglu, G., Large, W. G., McWilliams, J. C., 2007. Mechanisms governing interannual variability of upper-ocean temperature in a global ocean hindcast simulation. J. Phys. Oceanogr. 37, 1918-1938.

Döscher, R., Beckmann, A., 2000. Effects of a bottom boundary layer parameterization in a coarse-resolution model of the North Atlantic Ocean. J. Atmos. Ocean Tech. 17, 698-707.

Döscher, R., Redler, R., 1997. The relative importance of northern overflow and subpolar deep convection for the North Atlantic thermohaline circulation. J. Phys. Oceanogr. 27, 1894-1902.

Duffy, P. B., Eby, M., Weaver, A. J., 1999. Effects of sinking of salt rejected during formation of sea ice on results of an ocean-atmosphere-sea ice climate model. Geophys. Res. Lett. 26, 1739-1742.

Dunne, J. P., John, J. G., Hallberg, R. W., Griffies, S. M., Shevliakova, E. N., Stouffer, R. J., Krasting, J. P., Sentman, L. A., Milly, P. C. D., Malyshev, S. L., Adcroft, A. J., Cooke, W., Dunne, K. A., Harrison, M. J., Levy, H., Samuels, 
B. L., Spelman, M., Winton, M., Wittenberg, A. T., Phillips, P. J., Zadeh, N., 2012. GFDLs ESM2 global coupled climate-carbon Earth System Models Part I: Physical formulation and baseline simulation characteristics. J. Climate 25, 66466665 .

Dutay, J.-C., Bullister, J. L., Doney, S. C., Orr, J. C., Najjar, R., Caldeira, K., Campin, J.-M., Drange, H., Follows, M., Gao, Y., Gruber, N., Hecht, M. W., Ishida, A., Joos, F., Lindsay, K., Madec, G., Maier-Reimer, E., Marshall, J. C., Matear, R. J., Monfray, P., Mouchet, A., Plattner, G.-K., Sarmiento, J., Schlitzer, R., Slater, R., Totterdell, I. J., Weirig, M.-F., Yamanaka, Y., Yool, A., 2002. Evaluation of ocean model ventilation with CFC-11: Comparison of 13 global ocean models. Ocean Modelling 4, 89-120.

Eby, M., Holloway, G., 1994. Sensitivity of a large-scale ocean model to a parameterization of topographic stress. J. Phys. Oceanogr. 24, 2577-2587.

Emile-Geay, J., Madec, G., 2009. Geothermal heating, diapycnal mixing and the abyssal circulation. Ocean Sci. 5, 281-325.

Ferrari, R., Griffies, S. M., Nurser, A. J. G., Vallis, G. K., 2010. A boundary-value problem for the parameterized mesoscale eddy transport. Ocean Modelling 32, 143-156.

Ferrari, R., McWilliams, J. C., Canuto, V. M., Dubovikov, M., 2008. Parameterization of eddy fluxes near oceanic boundaries. J. Climate 21, 2770-2789.

Ferreira, D., Marshall, J., Heimbach, P., 2005. Estimating eddy stresses by fitting dynamics to observations using a residual-mean ocean circulation model and its adjoint. J. Phys. Oceanogr. 35, 1891-1910. 
Fichefet, T., Maqueda, M. A. M., 1997. Sensitivity of a global sea ice model to the treatment of ice thermodynamics and dynamics. J. Geophys. Res. 102 (C6), 12609-12612.

Fischer, J., Schott, F. A., Dengler, M., 2004. Boundary circulation at the exit of the Labrador Sea. J. Phys. Oceanogr. 34, 1548-1570.

Fischer, J., Visbeck, M., Zantopp, R., Nunes, N., 2010. Interannual to decadal variability of outflow from the Labrador Sea. Geophys. Res. Lett. 37, L24610.

Forget, G., 2010. Mapping ocean observations in a dynamical framework: A 2004-06 ocean atlas. J. Phys. Oceanogr. 40, 1201-1221.

Fox-Kemper, B., Danabasoglu, G., Ferrari, R., Griffies, S. M., Hallberg, R. W., Holland, M. M., Maltrud, M. E., Peacock, S., Samuels, B. L., 2011. Parameterization of mixed layer eddies. Part III: Implementation and impact in global ocean climate simulations. Ocean Modelling 39, 61-78.

Fox-Kemper, B., Ferrari, R., Hallberg, R., 2008. Parameterization of mixed layer eddies. Part I: Theory and diagnosis. J. Phys. Oceanogr. 38, 1145-1165.

Fujii, Y., Ishizaki, S., Kamachi, M., 2005. Application of nonlinear constraints in a three-dimensional variational ocean analysis. J. Oceanogr. 61, 655-662.

Fujii, Y., Kamachi, M., 2003. Three dimensional analysis of temperature and salinity in the equatorial Pacific using a variational method with vertical coupled temperature - salinity empirical orthogonal function modes. J. Geophys. Res. 108 (C9), 3297. 
Fujii, Y., Kamachi, M., Matsumoto, S., Ishizaki, S., 2012. Barrier layer and relevant variability of the salinity field in the equatorial Pacific estimated in an ocean reanalysis experiment. Pure Appl. Geophys. 169, 579-594.

Fujii, Y., Nakaegawa, T., Matsumoto, S., Yasuda, T., Yamanaka, G., Kamachi, M., 2009. Coupled climate simulation by constraining ocean fields in a coupled model with ocean data. J. Climate 22, 5541-5557.

Gaspar, P., Grégoris, Y., Lefevre, J., 1990. A simple eddy kinetic energy model for simulations of the oceanic vertical mixing: tests at station Papa and long-term upper ocean study site. J. Geophys. Res. 95, 16179-16193.

Gent, P. R., Danabasoglu, G., Donner, L. J., Holland, M. M., Hunke, E. C., Jayne, S. R., Lawrence, D. M., Neale, R. B., Rasch, P. J., Vertenstein, M., Worley, P. H., Yang, Z.-L., Zhang, M., 2011. The Community Climate System Model version 4. J. Climate 24, 4973-4991.

Gent, P. R., McWilliams, J. C., 1990. Isopycnal mixing in ocean circulation models. J. Phys. Oceanogr. 20, 150-155.

Gnanadesikan, A., Dixon, K. W., Griffies, S. M., Balaji, V., Beesley, J. A., Cooke, W. F., Delworth, T. L., Gerdes, R., Harrison, M. J., Held, I. M., Hurlin, W. J., Lee, H.-C., Liang, Z., Nong, G., Pacanowski, R. C., Rosati, A., Russell, J., Samuels, B. L., Song, S. M., , Spelman, M. J., Stouffer, R. J., Sweeney, C. O., Vecchi, G., Winton, M., Wittenberg, A. T., Zeng, F., Zhang, R., 2006. GFDL's CM2 global coupled climate models - Part 2: The baseline ocean simulation. J. Climate 19, 675-697. 
Gregg, M., Sanford, T., Winkel, D., 2003. Reduced mixing from the breaking of internal waves in equatorial waters. Nature 422, 513-515.

Griffies, S., Gnanadesikan, A., Pacanowski, R., Larichev, V., Dukowicz, J., Smith, R., 1998. Isoneutral diffusion in a z-coordinate ocean model. J. Phys. Oceanogr. $28,805-830$.

Griffies, S. M., 1998. The Gent-McWilliams skew flux. J. Phys. Oceanogr. 28, 831841.

Griffies, S. M., 2004. Fundamentals of Ocean Climate Models. Princeton University Press, Princeton, USA, 518+xxxiv pages.

Griffies, S. M., 2009. Elements of MOM4p1. GFDL Ocean Group Tech. Report No. 6, Princeton, NJ.

Griffies, S. M., 2012. Elements of the Modular Ocean Model (MOM): 2012 release. GFDL Ocean Group Technical Report No. 7, Princeton, NJ.

Griffies, S. M., Biastoch, A., Böning, C., Bryan, F., Danabasoglu, G., Chassignet, E. P., England, M. H., Gerdes, R., Haak, H., Hallberg, R. W., Hazeleger, W., Jungclaus, J., Large, W. G., Madec, G., Pirani, A., Samuels, B. L., Scheinert, M., Gupta, A. S., Severijns, C. A., Simmons, H. L., Treguier, A. M., Winton, M., Yeager, S., Yin, J., 2009. Coordinated Ocean-ice Reference Experiments (COREs). Ocean Modelling 26, 1-46.

Griffies, S. M., Gnanadesikan, A., Dixon, K. W., Dunne, J. P., Gerdes, R., Harrison, M. J., Rosati, A., Russell, J. L., Samuels, B. L., Spelman, M. J., Winton, M., Zhang, R., 2005. Formulation of an ocean model for global climate simulations. Ocean Science 1, 45-79. 
Griffies, S. M., Winton, M., Samuels, B., Danabasoglu, G., Yeager, S., Marsland, S., Drange, H., Bentsen, M., 2012. Datasets and protocol for the CLIVAR WGOMD Coordinated Ocean sea-ice Reference Experiments (COREs). WCRP Report No. $21 / 2012$.

Griffies, S. M., Yin, J., Durack, P. J., Goddard, P., Bates, S. C., Behrens, E., Bentsen, M., Bi, D., Biastoch, A., Böning, C., Bozec, A., Cassou, C., Chassignet, E., Danabasoglu, G., Danilov, S., Domingues, C., Drange, H., Farneti, R., Fernandez, E., Greatbatch, R. J., Holland, D. M., Ilicak, M., Lu, J., Marsland, S. J., Mishra, A., Lorbacher, K., Nurser, A. J. G., Salas y Mélia, D., Palter, J. B., Samuels, B. L., Schröter, J., Schwarzkopf, F. U., Sidorenko, D., Treguier, A.-M., Tseng, Y.-H., Tsujino, H., Uotila, P., Valcke, S., Voldoire, A., Wang, Q., Winton, M., Zhang, X., 2013. An assessment of global and regional sea level in a suite of interannual core-ii simulations. Ocean Modelling(in preparation).

Hallberg, R. W., 1995. Some aspects of the circulation in ocean basins with isopycnals intersecting the sloping boundaries. PhD Thesis, University of Washington Oceanography, Seattle, USA.

Halliwell, G. R., 2004. Evaluation of vertical coordinate and vertical mixing algorithms in the HYbrid-Coordinate Ocean Model (HYCOM). Ocean Modelling 7, $285-322$.

Hamilton, D., 1994. GTSPP builds an ocean temperature - salinity database. Earth System Monitor 4, 4-5.

Hasumi, H., 2006. CCSR Ocean Component Model (COCO) version 4.0. Center for Climate System Research CCSR Report No. 25. 
Hatun, H., Sando, A. B., Drange, H., Hansen, B., Valdimarsson, H., 2005. Influence of the Atlantic subpolar gyre on the thermohaline circulation. Science 309, 18411844.

Held, I. M., Larichev, V. D., 1996. A scaling theory for horizontally homogeneous, baroclinically unstable flow on a $\beta$-plane. J. Atmos. Sci. 53, 946-952.

Hewitt, H. T., Copsey, D., Culverwell, I. D., Harris, C. M., Hill, R. S. R., Keen, A. B., McLaren, A. J., Hunke, E. C., 2011. Design and implementation of the infrastructure of HadGEM3: the next-generation Met Office climate modelling system. Geosci. Model Dev. 4, 223-253.

Hibler, W., 1979. A dynamic thermodynamic sea ice model. J. Phys. Oceanogr. 9, $815-846$.

Holland, M. M., Bailey, D. A., Briegleb, B. P., Light, B., Hunke, E., 2012. Improved sea ice shortwave radiation physics in CCSM4: The impact of melt ponds and aerosols on Arctic sea ice. J. Climate 25, 1413-1430.

Holland, W. R., 1973. Baroclinic and topographic influences on the transport in western boundary currents. Geophys. Fluid Dyn. 4, 187-210.

Holloway, G., Dupont, F., Golubeva, E., Häkkinen, S., Hunke, E., Jin, M., Karcher, M., Kauker, F., Maltrud, M., Morales Maqueda, M. A., Maslowski, W., Platov, G., Stark, D., Steele, M., Suzuki, T., Wang, J., Zhang, J., 2007. Water properties and circulation in Arctic Ocean models. J. Geophys. Res. 112, C04S03.

Holloway, G., Wang, Z., 2009. Representing eddy stress in an Arctic Ocean model. J. Geophys. Res. 114, C06020. 
Hunke, E. C., Dukowicz, J. K., 1997. An elastic-viscous-plastic model for sea ice dynamics. J. Phys. Oceanogr. 27, 1849-1867.

Hunke, E. C., Dukowicz, J. K., 2002. The elastic-viscous-plastic sea ice dynamics model in general orthogonal curvilinear coordinates on a sphere - Incorporation of metric terms. Mon. Wea. Rev. 130, 1848-1865.

Hunke, E. C., Lipscomb, W. H., 2002. CICE: The Los Alamos sea ice model, documentation and software user's manual, version 3. Los Alamos National Laboratory Tech. Rep. LA-CC-98-16, Los Alamos, NM.

Hunke, E. C., Lipscomb, W. H., 2008. CICE: The Los Alamos sea ice model, documentation and software, version 4.0. Los Alamos National Laboratory Tech. Rep. LA-CC-06-012, Los Alamos, NM.

Hurrell, J. W., Visbeck, M., Busalacchi, A., Clarke, R. A., Delworth, T. L., Dickson, R. R., Johns, W. E., Koltermann, K. P., Kushnir, Y., Marshall, D., Mauritzen, C., McCartney, M. S., Piola, A., Reason, C., Reverdin, G., Schott, F., Sutton, R., Wainer, I., Wright, D., 2006. Atlantic climate variability and predictability: A CLIVAR perspective. J. Climate 19, 5100-5121.

Ishizaki, H., Motoi, T., 1999. Reevaluation of the Takano - Onishi scheme for momentum advection on bottom relief ocean models. J. Atmos. Oceanic. Technol. 16, $1994-2010$.

Jayne, S. R., 2009. The impact of abyssal mixing parameterizations in an ocean general circulation model. J. Phys. Oceanogr. 39, 1756-1775.

Jochum, M., Danabasoglu, G., Holland, M., Y.-O.-Kwon, Large, W. G., 2008. Ocean viscosity and climate. J. Geophys. Res. 113, C06017. 
Johns, W., Shay, T., Bane, J., Watts, D., 1995. Gulf Stream structure, transport, and recirculation near $68^{\circ} \mathrm{W}$. J. Geophys. Res. 100, 817-838.

Johns, W. E., Baringer, M. O., Beal, L. M., Cunningham, S. A., Kanzow, T., Bryden, H. L., Hitschi, J. J. M., Marotzke, J., Meinen, C. S., Shaw, B., Curry, R., 2011. Continuous, array-based estimates of Atlantic Ocean heat transport at $26.5^{\circ} \mathrm{N}$. J. Climate 24, 2429-2449.

Kelley, M., Marshall, J., Bleck, R., Campin, J.-M., Canuto, V., Howard, A., Leboissetier, A., Romanou, A., Russell, G., Schmidt, G., Scott, J., Sun, S., 2013. A study of ocean model drift and its dependence on model formulation and mixing parameterizations(in preparation).

Key, R. M., Kozyr, A., Sabine, C. L., Lee, K., Wanninkhof, R., Bullister, J. L., Feely, R. A., Millero, F. J., Mordy, C., Peng, T.-H., 2004. A global ocean carbon climatology: Results from Global Data Analysis Project (GLODAP). Global Biogeochemical Cycles 18, GB4031.

Killworth, P. D., Stainforth, D., Webb, D. J., Paterson, S. M., 1991. The development of a free-surface Bryan - Cox - Semtner ocean model. J. Phys. Oceanogr. 21, 13331348.

Kirtman, B. P., Bitz, C., Bryan, F., Collins, W., Dennis, J., Hearn, N., III, J. L. K., Loft, R., Rousset, C., Siqueira, L., Stan, C., Tomas, R., Vertenstein, M., 2012. Impact of ocean model resolution on CCSM climate simulations. Cli. Dyn. 39, 1303-1328.

Koch-Larrouy, A., Madec, G., Bouruet-Aubertot, P., Gerkema, T., Bessieres, L., 
Molcard, R., 2007. Tidal mixing in the Indonesian Seas and its effect on the tropical climate system. Geophys. Res. Lett. 34, L04604.

Kwok, R., Cunningham, G. F., Wensnahan, M., Rigor, I., Zwally, H. J., Yi, D., 2009. Thinning and volume loss of the Arctic Ocean sea ice cover: 2003-2008. J. Geophys. Res. 114, C07005.

Large, W. G., Danabasoglu, G., Doney, S. C., McWilliams, J. C., 1997. Sensitivity to surface forcing and boundary layer mixing in a global ocean model: Annual-mean climatology. J. Phys. Oceanogr. 27, 2418-2447.

Large, W. G., Danabasoglu, G., McWilliams, J. C., Gent, P. R., Bryan, F. O., 2001. Equatorial circulation in a global ocean climate model with anisotropic horizontal viscosity. J. Phys. Oceanogr. 31, 518-536.

Large, W. G., McWilliams, J. C., Doney, S. C., 1994. Oceanic vertical mixing: A review and a model with a nonlocal boundary layer parameterization. Rev. Geophys. $32,363-403$.

Large, W. G., Yeager, S., 2004. Diurnal to decadal global forcing for ocean and seaice models: The data sets and flux climatologies. NCAR Tech. Note NCAR/TN460+STR.

Large, W. G., Yeager, S. G., 2009. The global climatology of an interannually varying air-sea flux data set. Clim. Dyn. 33, 341-364.

Latif, M., Böning, C., Willebrand, J., Biastoch, A., Dengg, J., Keenlyside, N., Schweckendiek, U., 2006. Is the thermohaline circulation changing? J. Climate 19, 4631-4637. 
Le Sommer, J., Penduff, T., Theetten, S., Madec, G., Barnier, B., 2009. How momentum advection schemes influence current-topography interactions at eddy permitting resolution. Ocean Modelling 29, 1-14.

Lee, H.-C., Rosati, A., Spelman, M., 2006. Barotropic tidal mixing effects in a coupled climate model: Oceanic conditions in the northern Atlantic. Ocean Modelling 3-4, 464-477.

Legg, S., Hallberg, R. W., Girton, J. B., 2006. Comparison of entrainment in overflows simulated by z-coordinate, isopycnal and non-hydrostatic models. Ocean Modelling 11, 69-97.

Lengaigne, M., Menkes, C., Aumont, O., Gorgues, T., Bopp, L., André, J.-M., Madec, G., 2007. Bio-physical feedbacks on the tropical Pacific climate in a coupled general circulation model. Clim. Dyn. 28, 503-516.

Levitus, S., Boyer, T., Concright, M., Johnson, D., O'Brien, T., Antonov, J., Stephens, C., Garfield, R., 1998. World Ocean Database 1998, volume I: Introduction.

Liu, J., Schmidt, G. A., Martinson, D. G., Rind, D., Russell, G. L., Yuan, X., 2003. Sensitivity of sea ice to physical parameterizations in the GISS global climate model. J. Geophys. Res. 108, 3053.

Locarnini, R. A., Mishonov, A. V., Antonov, J. I., Boyer, T. P., Garcia, H. E., Baranova, O. K., Zweng, M. M., Johnson, D. R., 2010. World Ocean Atlas 2009, volume 1: Temperature. U. S. Government Printing Office, Washington, D. C., NOAA Atlas NESDIS 68, p. 184. 
Lohmann, K., Drange, H., Bentsen, M., 2009. A possible mechanism for the strong weakening of the North Atlantic subpolar gyre in the mid-1990s. Geophys. Res. Lett. 36, L15602.

Lorenc, A. C., Rawlins, F., 2005. Why does 4D-Var beat 3D-Var? Q. J. R. Meteorol. Soc. $131,3247-3257$.

Madec, G., 2008. NEMO ocean engine. Technical Report and Note du Pole de mod'elisation Institut Pierre-Simon Laplace (IPSL) 27 ISSN No 1288-1619.

Mahlstein, I., Knutti, R., 2011. Ocean heat transport as a cause for model uncertainty in projected Arctic warming. J. Climate 24, 1451-1460.

Maltrud, M., Holloway, G., 2008. Implementing biharmonic neptune in a global eddying ocean model. Ocean Modelling 21, 22-34.

Manizza, M., Le Quere, C., Watson, A. J., Buitenhuis, E. T., 2005. Bio-optical feedbacks among phytoplankton, upper ocean physics and sea-ice in a global model. Geophys. Res. Lett. 32, L05603.

Marsaleix, P., Auclair, F., Floor, J. W., Herrmann, M. J., Estournel, C., Pairaud, I., Ulses, C., 2008. Energy conservation issues in sigma-coordinate free-surface ocean models. Ocean Modelling 20, 61-89.

Marshall, J., Adcroft, A., Hill, C., Perelman, L., Heisey, C., 1997. A finite-volume, incompressible Navier Stokes model for studies of the ocean on parallel computers. J. Geophys. Res. 102, 5753-5766.

Marsland, S. J., Bi, D., Uotila, P., Fiedler, R., Griffies, S. M., Lorbacher, K., O'Farrell, S., , Sullivan, A., Uhe, P., Zhou, X., Hirst, A. C., 2013. Evaluation 
of ACCESS Climate Model ocean diagnostics in CMIP5 simulations. Aust. Met. Oceanog. J. 63, 101-119.

McDougall, T. J., 2003. Potential enthalpy: a conservative oceanic variable for evaluating heat content and heat fluxes. J. Phys. Oceanogr. 33, 945-963.

Mellor, G., Blumberg, A., 2004. Wave breaking and ocean surface layer thermal response. J. Phys. Oceanogr. 34, 693-698.

Mellor, L. G., Kantha, L., 1989. An ice - ocean coupled model. J. Geophys. Res. 94, $10937-10954$.

Msadek, R., Johns, W. E., Yeager, S. G., Danabasoglu, G., Delworth, T. L., Rosati, A., 2013. The Atlantic meridional heat transport at $26.5^{\circ} \mathrm{N}$ and its relationship with the MOC in the RAPID array and the GFDL and NCAR coupled models. J. Climate 26, 4335-4356.

Munoz, E., Kirtman, B., Weijer, W., 2011. Varied representation of the Atlantic meridional overturning across multidecadal ocean reanalyses. Deep-Sea Res. II 58, $1848-1857$.

Murray, R. J., 1996. Explict generation of orthogonal grids for ocean models. J. Comput. Phys. 126, 251-273.

Nakano, H., Suginohara, N., 2002. Effects of bottom boundary layer parameterization on reproducing deep and bottom waters in a world ocean model. J. Phys. Oceanogr. $32,1209-1227$.

Pacanowski, R. C., Philander, G., 1981. Parameterization of vertical mixing in numerical models of the tropical ocean. J. Phys. Oceanogr. 11, 1442-1451. 
Prather, M. J., 1986. Numerical advection by conservation of second order moments. J. Geophys. Res. 91, 6671-6681.

Pringle, D. J., Eicken, H., Trodahl, H. J., Backstrom, L. G. E., 2007. Thermal conductivity of landfast Antarctic and Arctic sea ice. J. Geophys. Res. 112, C04017.

Rahmstorf, S., 1993. A fast and complete convection scheme for ocean models. Ocean Modelling 101, 9-11.

Redi, M. H., 1982. Oceanic isopycnal mixing by coordinate rotation. J. Phys. Oceanogr. 12, 1154-1158.

Redler, R., Böning, C. W., 1997. Effect of the overflows on the circulation in the subpolar North Atlantic: A regional model study. J. Geophys. Res. 102, 1852918552.

Roubicek, A. J., Chassignet, E. P., Griffa, A., 1995. Topographic stress parameterization in a primitive equation ocean model: Impact on mid-latitude jet separation. In: Muller, P., Henderson, D. (Eds.), Topographic Effects in the Ocean, Proceedings of the 8th Aha Huliko'a Hawaiian Winter Workshop. pp. 239-251.

Roullet, G., Madec, G., 2000. Salt conservation, free surface, and varying levels: a new formulation for ocean general circulation models. J. Geophys. Res. 105, $23927-23942$.

Russell, G. L., Miller, J. R., Rind, D. H., 1995. A coupled atmosphere - ocean model for transient climate change. Atmos. Ocean 33, 683-730.

Russell, G. L., Miller, J. R., Rind, D. H., Ruedy, R. A., Schmidt, G. A., Sheth, S., 2000. Comparison of model and observed regional temperature changes during the past 40 years. J. Geophys. Res. 105, 14891-14898. 
Salas-Mélia, D., 2002. A global coupled sea ice-ocean model. Ocean Modelling 4, 137-172.

Sarkisyan, A. S., Ivanov, V. F., 1971. Joint effect of baroclinicity and bottom relief as an important factor in the dynamics of sea currents. Izv. Acad. Sci., USSR Atmos. Oceanic Phys. 7, 173-178.

Schmidt, G. A., Kelley, M., Nazarenko, L., Ruedy, R., Russell, G. L., Aleinov, I., Bauer, M., Bauer, S., Bhat, M. K., Bleck, R., Canuto, V., Chen, Y., Cheng, Y., Clune, T. L., DelGenio, A., de Fainchtein, R., Faluvegi, G., Hansen, J. E., Healy, R. J., Kiang, N. Y., Koch, D., Lacis, A. A., LeGrande, A. N., Lerner, J., Lo, K. K., Matthews, E. E., Menon, S., Miller, R. L., Oinas, V., Oloso, A., Perlwitz, J., Puma, M. J., Putman, W. M., Rind, D., Romanou, A., Sato, M., Shindell, D. T., Sun, S., Syed, R., Tausnev, N., Tsigaridis, K., Unger, N., Voulgarakis, A., Yao, M.-S., Zhang, J., 2013. Configuration and assessment of the GISS ModelE2 contributions to the CMIP5 archive(in preparation).

Schweckendiek, U., Willebrand, J., 2005. Mechanisms affecting the overturning response in global warming simulations. J. Climate 18, 4925-4936.

Simmons, H. L., Jayne, S. R., St Laurent, L. C., Weaver, A. J., 2004. Tidally driven mixing in a numerical model of the ocean general circulation. Ocean Modelling 6, $245-263$.

Smagorinsky, J., 1963. General circulation experiments with the primitive equations. Mon. Weather Rev. 91, 99-164.

Smith, R. D., Jones, P., Briegleb, B., Bryan, F., Danabasoglu, G., Dennis, J., Dukowicz, J., Eden, C., Fox-Kemper, B., Gent, P., Hecht, M., Jayne, S., Jochum, M., 
Large, W., Lindsay, K., Maltrud, M., Norton, N., Peacock, S., Vertenstein, M., Yeager, S., 2010. The Parallel Ocean Program (POP) reference manual, ocean component of the Community Climate System Model (CCSM). Los Alamos National Laboratory Tech. Rep. LAUR-10-01853, Los Alamos, NM, [Available online at http://www.cesm.ucar.edu/models/cesm1.0/pop2/doc/sci/POPRefManual.pdf].

Smith, R. D., McWilliams, J. C., 2003. Anisotropic horizontal viscosity for ocean models. Ocean Modelling 5, 129-156.

Smolarkiewicz, P. K., 1984. A fully multidimensional positive definite advection transport algorithm with small implicit diffusion. J. Comput. Phys. 54, 325-362.

St. Laurent, L. C., Simmons, H. L., Jayne, S. R., 2002. Estimates of tidally driven enhanced mixing in the deep ocean. Geophys. Res. Lett. 29, 2106.

Stacey, M. W., Pond, S., Nowak, Z. P., 1995. A numerical model of the circulation in Knight Inlet, British Columbia, Canada. J. Phys. Ocenogr. 25, 1037-1062.

Steele, M., Morley, R., Ermold, W., 2001. PHC: A global ocean hydrography with a high quality Arctic Ocean. J. Climate 14, 2079-2087.

Sutton, R. W., Hodson, D. L. R., 2005. Atlantic Ocean forcing of North American and European summer climate. Science 309, 115-118.

Sweeney, C., Gnanadesikan, A., Griffies, S. M., Harrison, M., Rosati, A., Samuels, B., 2005. Impacts of shortwave penetration depth on large-scale ocean circulation and heat transport. J. Phys. Oceanog. 35, 1103-1119.

Tartinville, B., Campin, J. M., Fichefet, T., Goosse, H., 2001. Realistic representation of the surface freshwater flux in an ice-ocean general circulation model. Ocean Modelling 3, 95-108. 
The DRAKKAR Group, 2007. Eddy-permitting ocean circulation hindcasts of past decades. CLIVAR Exchanges 12, 8-10.

Thiele, G., Sarmiento, J. L., 1990. Tracer dating and ocean ventilation. J. Geophys. Res. 95, 9377-9391.

Thorndike, A. S., Rothrock, D. S., Maykut, G. A., Colony, R., 1975. The thickness distribution of sea ice. J. Geophys. Res. 80, 4501-4513.

Timmermann, R., Danilov, S., Schroter, J., Böning, C., Sidorenko, D., Rollenhagen, K., 2009. Ocean circulation and sea ice distribution in a finite element global sea ice - ocean model. Ocean Modelling 27, 114-129.

Timmermann, R., Goosse, H., Madec, G., Fichefet, T., Ethé, C., Dulière, V., 2005. On the representation of high latitude processes in the ORCA-LIM global coupled sea ice-ocean model. Ocean Modelling 8, 175-201.

Treguier, A. M., Held, I. M., Larichev, V. D., 1997. On the parameterization of quasi-geostrophic eddies in primitive equation ocean models. J. Phys. Oceanogr. $27,567-580$.

Tsujino, H., Hirabara, M., Nakano, H., Yasuda, T., Motoi, T., Yamanaka, G., 2011. Simulating present climate of the global ocean - ice system using the Meteorological Research Institute Community Ocean Model (MRI.COM): Simulation characteristics and variability in the Pacific sector. J. Oceanogr. 67, 449-479.

Tsujino, H., Motoi, T., Ishikawa, I., Hirabara, M., Nakano, H., Yamanaka, G., Yasuda, T., Ishizaki, H., 2010. Reference manual for the Meteorological Research Institute Community Ocean Model (MRI.COM) version 3. Tech. Rep. of 
the Meteorological Research Institute 59, Tsukuba, Japan, [Available online at http://www.mri-jma.go.jp/Publish/Technical/index_en.html].

Umlauf, L., Burchard, H., 2003. A generic length-scale equation for geophysical turbulence models. J. Marine Res. 61, 235-265.

Uotila, P., O'Farrell, S., Marsland, S. J., Bi, D., 2013. The sea-ice performance of the Australian climate models participating in the CMIP5. Aust. Met. Oceanogr. J. $63,121-143$.

Usui, N., Ishizaki, S., Fujii, Y., Tsujino, H., Yasuda, T., Kamachi, M., 2006. Meteorological Research Institute Multivariate Ocean Variational Estimation (MOVE) System: Some early results. J. Adv. Space Res. 37, 806-822.

Valcke, S., 2006. OASIS3 user guide (prism 2-5). PRISM-Support Initiative Report 3, Toulouse, France.

Vancoppenolle, M., Fichefet, T., Goosse, H., Bouillon, S., Madec, G., MoralesMaqueda, M. A., 2009. Simulating the mass balance and salinity of Arctic and Antarctic sea ice. 1. Model description and validation. Ocean Modelling 27, 33-53.

Voldoire, A., Sanchez-Gomez, E., y Mélia, D. S., Decharme, B., Cassou, C., Sénési, S., Valcke, S., Beau, I., Alias, A., Chevallier, M., Déqué, M., Deshayes, J., Douville, H., Fernandez, E., Madec, G., Maisonnave, E., Moine, M.-P., Planton, S., SaintMartin, D., Szopa, S., Tyteca, S., Alkama, R., Belamari, S., Braun, A., Coquart, L., Chauvin, F., 2013. The CNRM-CM5.1 global climate model: Description and basic evaluation. Clim. Dyn. 40, 2091-2121.

Volodin, E. M., Dianskii, N. A., Gusev, A. V., 2010. Simulating present-day cli- 
mate with the INMCM4.0 coupled model of the atmospheric and oceanic general circulations. Izvestiya, Atmospheric and Oceanic Phys. 46, 414-431.

Wang, Q., Danilov, S., Schroter, J., 2008. Finite element ocean circulation model based on triangular prismatic elements, with application in studying the effect of topography representation. J. Geophys. Res. 113, C05015.

Wunsch, C., Heimbach, P., 2007. Practical global oceanic state estimation. Physica D 230, 197-208.

Xu, X., Hurlburt, H. E., Schmitz Jr., W. J., Zantopp, R., Fischer, J., Hogan, P. J., 2013. On the currents and transports connected with the Atlantic meridional overturning circulation in the subpolar North Atlantic. J. Geophys. Res. 118, 1-15.

Yakovlev, N. G., 2009. Reproduction of the large-scale state of water and sea-ice in the Arctic Ocean in 1948-2002: Part I. numerical model. Izvestiya, Atmospheric and Oceanic Phys. 45, 357-371.

Yeager, S., Karspeck, A., Danabasoglu, G., Tribbia, J., Teng, H., 2012. A decadal prediction case study: Late Twentieth-century North Atlantic Ocean heat content. J. Climate 25, 5173-5189.

Yeager, S. G., Danabasoglu, G., 2012. Sensitivity of Atlantic meridional overturning circulation variability to parameterized Nordic Sea overflows in CCSM4. J. Climate 25, 2077-2103.

Yeager, S. G., Jochum, M., 2009. The connection between Labrador Sea buoyancy loss, deep western boundary current strength, and Gulf Stream path in an ocean circulation model. Ocean Modelling 30, 207-224. 
Yukimoto, S., Adachi, Y., Hosaka, M., Sakami, T., Yoshimura, H., Hirabara, M., Tanaka, T. Y., Shindo, E., Tsujino, H., Deushi, M., Mizuta, R., Yabu, S., Obata, A., Nakano, H., Koshiro, T., Ose, T., Kitoh, A., 2012. A new global climate model of Meteorological Research Institute: MRI-CGCM3 - Model description and basic performance. J. Meteor. Soc. Japan 90A, 23-64.

Yukimoto, S., Yoshimura, H., Hosaka, M., Sakami, T., Tsujino, H., Hirabara, M., Tanaka, T. Y., Deushi, M., Obata, A., Nakano, H., Adachi, Y., Shindo, E., Yabu, S., Ose, T., Kitoh, A., 2011. Meteorological Research Institute Earth System Model version 1 (MRI-ESM1) - Model description. Tech. Rep. of the Meteorological Research Institute 64, Tsukuba, Japan, [Available online at http://www.mrijma.go.jp/Publish/Technical/index_en.html].

Zalesak, S. T., 1979. Fully multidimensional flux corrected transport algorithms for fluids. J. Comput. Phys. 31, 335-362. 


\section{List of Figures}

1 AMOC annual-mean maximum transport time series at $26.5^{\circ} \mathrm{N}$ for the entire 300-year integration length. The time series are smoothed using a five-point box car filter. The repeating 60-year forcing cycle, corresponding to calendar years 1948-2007, is indicated by the dashed lines in each panel. . . . . . . . . . . . . . . . . . . . 102

2 Root-mean-square (rms) differences (top panels) and correlations (bottom panels) for the AMOC annual-mean maximum transport time series at $26.5^{\circ} \mathrm{N}$ between consecutive forcing cycles. The first ten years of each cycle are excluded from the analysis to avoid large adjustments associated with the jump in forcing from 2007 back to 1948. The MRI-A data assimilation simulation is not included because it is integrated only for one 60-year cycle. . . . . . . . . . . . . . . 103

3 Time-mean AMOC plotted in depth $(\mathrm{km})$ and latitude space. The positive and negative contours indicate clockwise and counter-clockwise circulations, respectively. In MIT, AWI, MRI-F, MRI-A, FSU, BERGEN, and GISS, the AMOC distributions do not include the high latitude North Atlantic and / or Arctic Oceans, and hence are masked. Unless otherwise noted, the time-mean refers to the 20-year means for years 1988-2007, corresponding to simulation years 281-300, in all the figures.104

4 Same as in Fig. 3 except for AMOC plotted in $\sigma_{2}$ density $\left(\mathrm{kg} \mathrm{m}^{-3}\right)$ and latitude space. INMOM distribution is not available. . . . . . . . 105

$5 \quad$ Years 2004-2007 mean AMOC depth profiles at $26.5^{\circ} \mathrm{N}$ from model solutions in comparison with the 4-year mean (April 2004 - March 2008) RAPID data (thick black lines plotted in each panel). . . . . . 106 
6 Time-mean meridional heat transports for the Atlantic Ocean. The black lines denoted by L\&Y09 represent implied time-mean transport calculated by Large and Yeager (2009) with shading showing the implied transport range in individual years for the 1984-2006 period. Direct estimates with their uncertainty ranges from the RAPID data (square; Johns et al., 2011) and from Bryden and Imawaki (2001) (triangle; B\&I01) are also shown. . . . . . . . . . . . . . . . . 107

7 Scatter plot of the maximum AMOC transport against meridional heat transport (MHT), both evaluated at $26.5^{\circ} \mathrm{N}$. The model data are for the time-mean. The solid star denotes the observational AMOC and MHT estimates from the RAPID data. The regression line and correlation coefficient are also shown. . . . . . . . . . . . . . 108

8 Time-mean, 0-700 m average potential temperature model minus observations (Locarnini et al., 2010) difference distributions. The boxed area in the NCAR panel indicates the Labrador Sea analysis region. . 109

9 Time-mean, 0-700 $\mathrm{m}$ average salinity model minus observations (Antonov et al., 2010) difference distributions. . . . . . . . . . . . . . . . . . . . 110

10 Time-mean, 0-700 m average density model minus observations difference distributions. The observational density is based on WOA09 temperature and salinity. . . . . . . . . . . . . . . . 111

11 Time-mean and zonal-mean potential temperature model minus observations (Locarnini et al., 2010) difference distributions for the Atlantic Ocean. In MIT, MRI-F, KIEL, CERFACS, CNRM, MRI-A, FSU, and GISS, the difference distributions do not include the high latitude North Atlantic and / or Arctic Oceans, and hence are masked. 112 
12 Same as in Fig. 11 except for salinity, and observations are from Antonov et al. (2010) . . . . . . . . . . . . . . . . . 113

13 March-mean mixed layer depth (MLD) based on a $\Delta \rho=0.125 \mathrm{~kg}$ $\mathrm{m}^{-3}$ criterion for the northern North Atlantic. The panel to the left of the color bar shows MLD calculated from the WOA09 potential temperature (Locarnini et al., 2010) and salinity (Antonov et al., 2010)

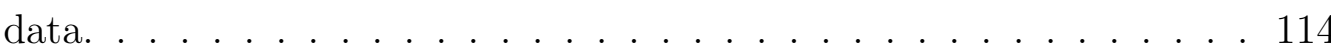

14 Time-mean and zonal-mean ideal age distributions for the Atlantic Ocean. Ideal age is not available from MIT, ACCESS, ICTP, KIEL, CERFACS, CNRM, and FSU. In MRI-F and MRI-A, the distributions do not include the Arctic Ocean, and hence are masked. . . . . . . . 115

15 March-mean sea-ice thickness. The black contour line denotes the 15\% observed sea-ice extent from the updated NSIDC data (Cavalieri et al., 1996, updated yearly). . . . . . . . . . . . . . . 116

16 Scatter plots of the North Atlantic subpolar gyre (SPG) maximum transports against the North Atlantic subtropical gyre (STG) maximum transports (left) and against the overflow proxy density (right). All data are time-mean. Overflow proxy density is not available from INMOM. See text for details of how STG and SPG transports are determined. The overflow proxy density is calculated as the time-mean density of the densest outflow (or southward flow) at $60^{\circ} \mathrm{N}$ as represented by approximately $1 \mathrm{~Sv}$ AMOC transport in density $\left(\sigma_{2}\right)$ space, using Fig. 4. . . . . . . . . . . . . . . . . . . . . . . . 117 
17 Scatter plots of the Labrador Sea (LS) upper-ocean (0-700 m average) potential temperature (left), salinity (middle), and density (right) biases against the AMOC maximum transports at $26.5^{\circ} \mathrm{N}$ (top) and $45^{\circ} \mathrm{N}$ (bottom). Each panel contains the corresponding regression line along with the correlation coefficient. The model data are for the time-mean. The solid stars in the top panels show the 4-year mean RAPID data (April 2004 - March 2008) plotted against no bias. The LS region is bounded by $60^{\circ}-45^{\circ} \mathrm{W}$ and $50^{\circ}-65^{\circ} \mathrm{N}$ and is indicated in Fig. 8. . . . . . . . . . . . . . . . . . . 118

18 Scatter plots of the LS March-mean MLD against the AMOC maximum transports at $26.5^{\circ} \mathrm{N}$ and $45^{\circ} \mathrm{N}$ (top panels) and against the LS upper-ocean (0-700 m average) potential temperature, salinity, and density biases (bottom panels). Each panel contains the corresponding regression line along with the correlation coefficient. Except MLD, the model data are for the time-mean. The solid stars in the top left and bottom panels represent the observationally-based March-mean MLD estimate plotted against the 4-year mean RAPID data (April 2004 - March 2008) and against no bias, respectively. . . . . . . . . . 119

19 Scatter plots of the AMOC maximum transports at $26.5^{\circ} \mathrm{N}$ (left) and $45^{\circ} \mathrm{N}$ (right) against the overflow proxy density described in Fig. 16 . All data are time-mean. Overflow proxy density is not available from INMOM. . . . . . . . . . . . . . . . . . . 120 
20 Scatter plots of the LS March-mean sea-ice area against the LS upperocean (0-700 $\mathrm{m}$ average) potential temperature (top left), salinity (top middle), and density (top right) biases, and against the LS Marchmean MLD (bottom left), AMOC maximum transport at $26.5^{\circ} \mathrm{N}$ (bottom middle), and AMOC maximum transport at $45^{\circ} \mathrm{N}$ (bottom right). Each panel contains the corresponding regression line along with the correlation coefficient. Except MLD and sea-ice area, the model data are for the time-mean. The solid stars in the top panels show observational March-mean sea-ice area plotted against no bias. The solid stars in the lower left and middle panels are for the observational Marchmean sea-ice area plotted against the observationally-based Marchmean MLD and the 4-year mean RAPID data (April 2004 - March 2008), respectively. . . . . . . . . . . . . . . . . . 121

21 AMOC annual-mean maximum transport time series at $26.5^{\circ} \mathrm{N}$ obtained with a preliminary version of the NCAR model using different SSS restoring time scales: 30 days (30D); 1 year (1Y); 4 years (4Y); and infinity (NO), i.e., no restoring. The associated length scale is 50 m. RAPID line represents the observational data from Cunningham et al. (2007). The time series are shown for one forcing cycle. . . . . . 122 
22 a) Difference (Neptune - standard) in northward annual-mean temperature flux along a quasi-zonal section at $26.5^{\circ} \mathrm{N}$ in ${ }^{\circ} \mathrm{C} \mathrm{m} \mathrm{s}^{-1}$. b) Difference in velocity times mean of the temperatures from the two runs in ${ }^{\circ} \mathrm{C} \mathrm{m} \mathrm{s}^{-1}$. c) Zonally integrated meridional flow cumulatively integrated up from the bottom in Sv for the Neptune run (blue line) and standard run (green line). d) Difference in zonally integrated heat transport cumulatively integrated up from the bottom in PW, calculated using the full temperature flux (blue line) and the approximation, using only the difference in velocities (green line). All plots are for year 2007 of the last forcing cycle. . . . . . . . . . . . . . . . . 123 


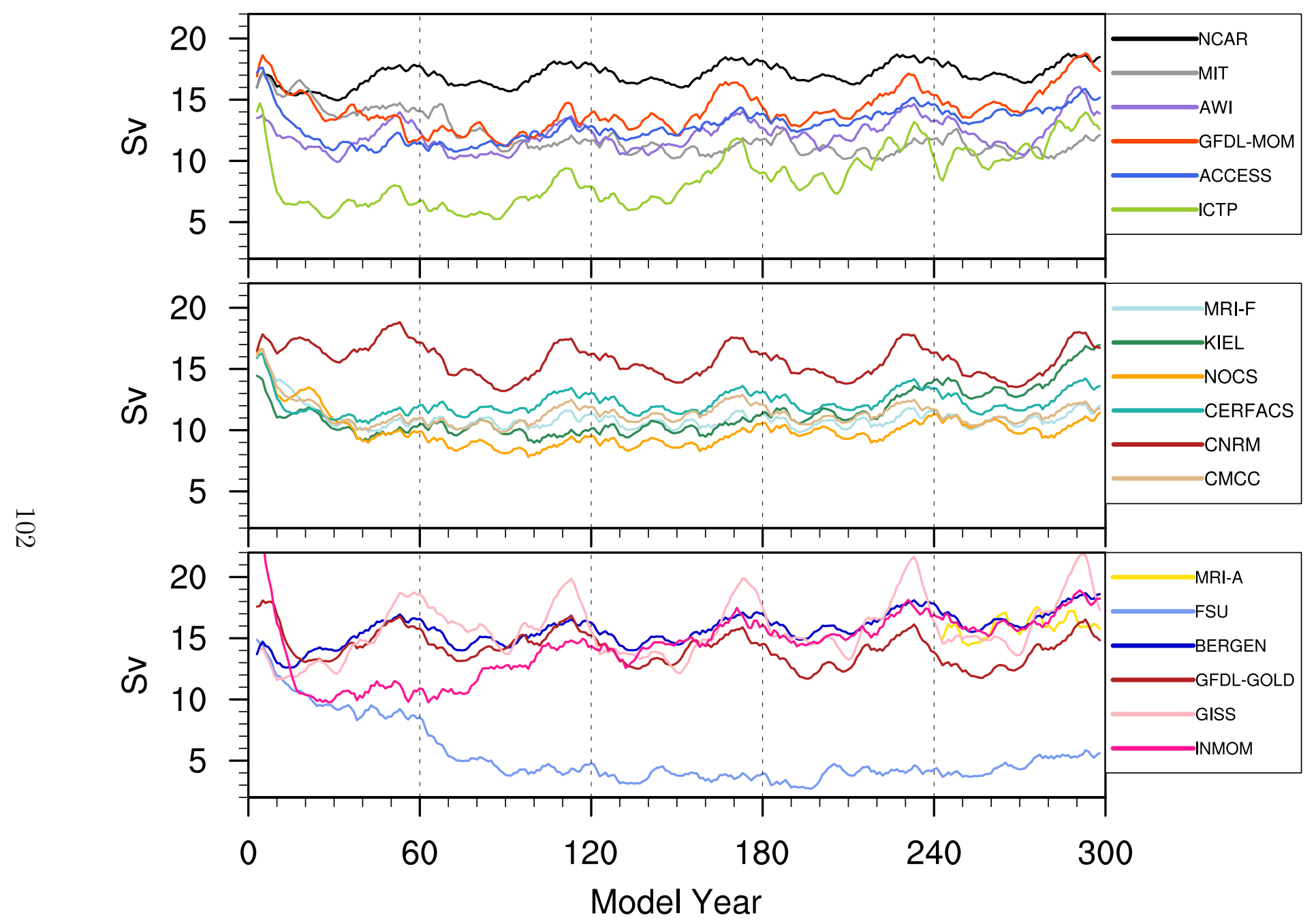

Figure 1: AMOC annual-mean maximum transport time series at $26.5^{\circ} \mathrm{N}$ for the entire 300 -year integration length. The time series are smoothed using a five-point box car filter. The repeating 60-year forcing cycle, corresponding to calendar years 1948-2007, is indicated by the dashed lines in each panel. 

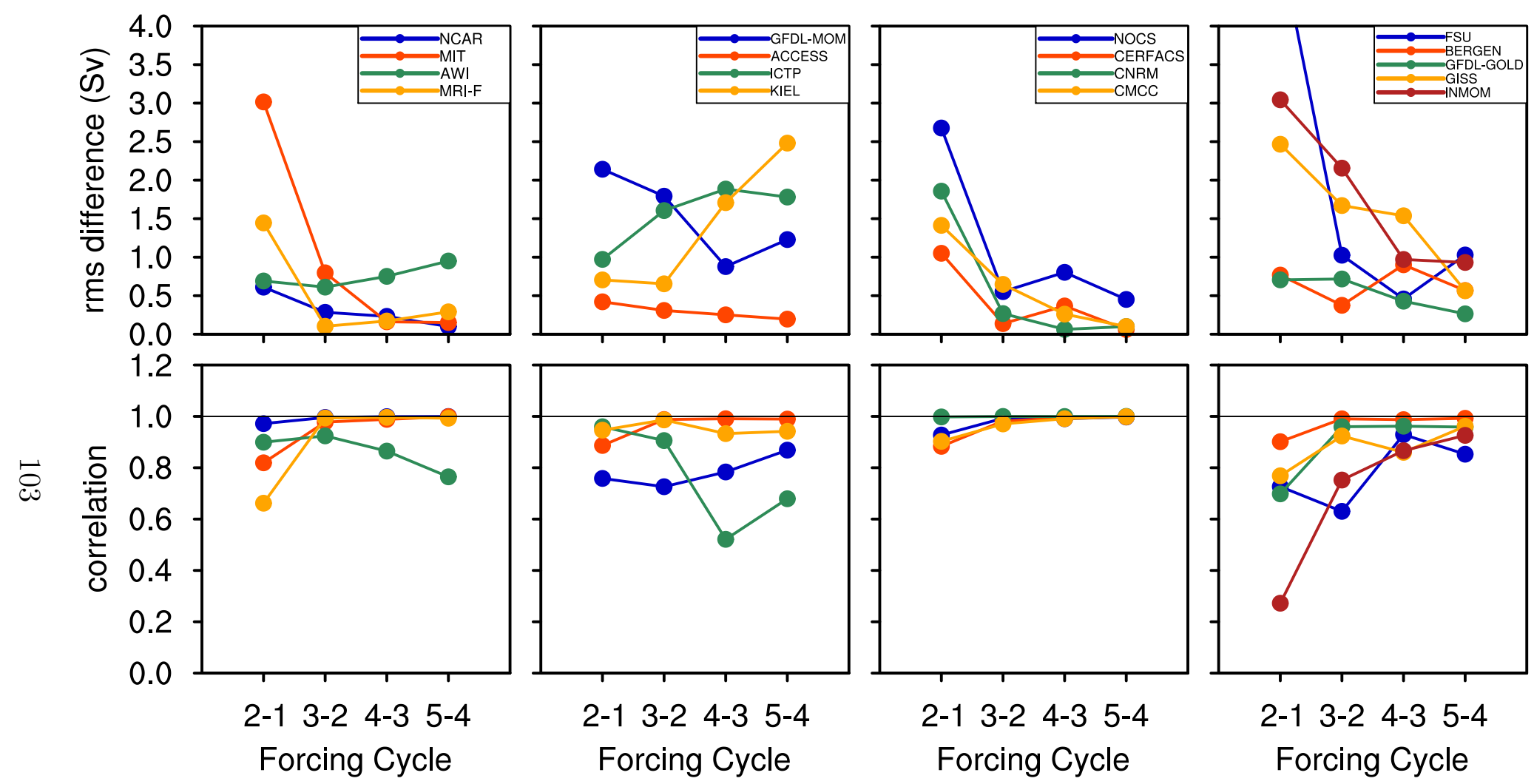

Figure 2: Root-mean-square (rms) differences (top panels) and correlations (bottom panels) for the AMOC annual-mean maximum transport time series at $26.5^{\circ} \mathrm{N}$ between consecutive forcing cycles. The first ten years of each cycle are excluded from the analysis to avoid large adjustments associated with the jump in forcing from 2007 back to 1948. The MRI-A data assimilation simulation is not included because it is integrated only for one 60-year cycle. 


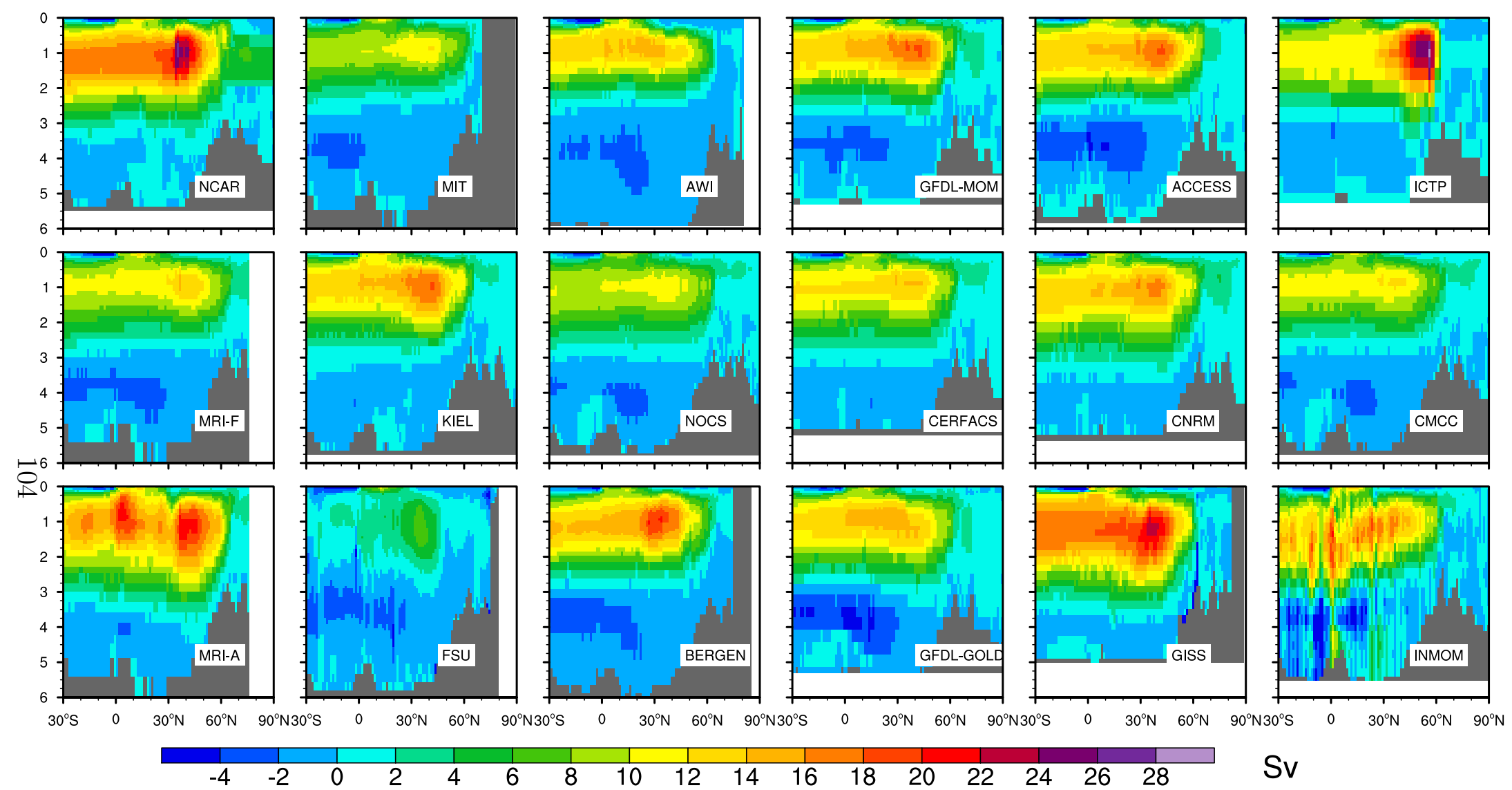

Figure 3: Time-mean AMOC plotted in depth $(\mathrm{km})$ and latitude space. The positive and negative contours indicate clockwise and counter-clockwise circulations, respectively. In MIT, AWI, MRI-F, MRI-A, FSU, BERGEN, and GISS, the AMOC distributions do not include the high latitude North Atlantic and / or Arctic Oceans, and hence are masked. Unless otherwise noted, the time-mean refers to the 20-year means for years 1988-2007, corresponding to simulation years 281-300, in all the figures. 

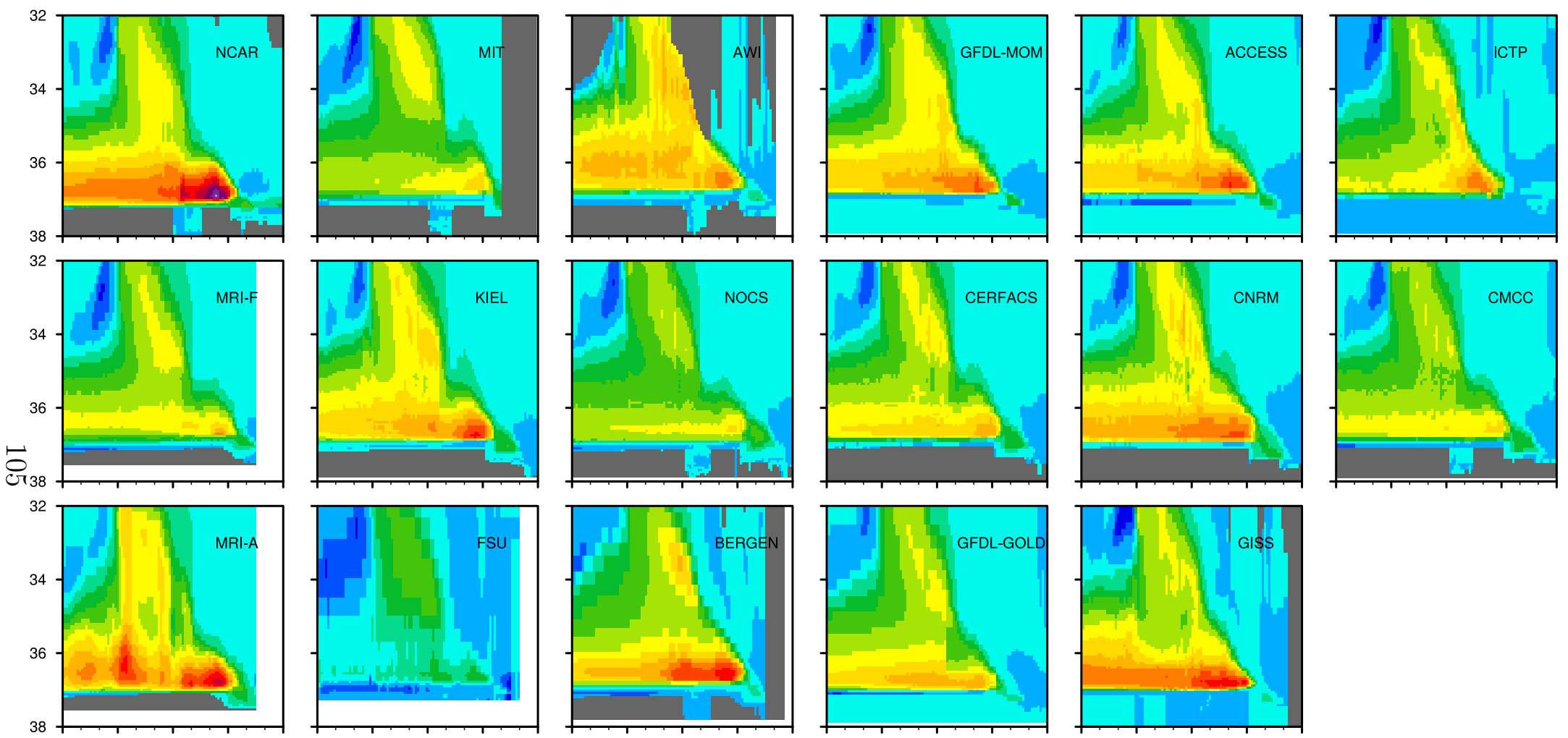

\begin{tabular}{ccccc}
$30^{\circ} \mathrm{S}$ & 0 & $30^{\circ} \mathrm{N}$ & $60^{\circ} \mathrm{N}$ & $90^{\circ} \mathrm{N} 30^{\circ} \mathrm{S}$ \\
\hline
\end{tabular}

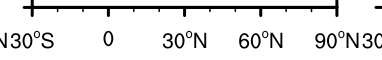

$\begin{array}{llllllllll} & 0 & 30^{\circ} \mathrm{N} & 60^{\circ} \mathrm{N} & 90^{\circ} \mathrm{N} 30^{\circ} \mathrm{S} & 0 & 30^{\circ} \mathrm{N} & 60^{\circ} \mathrm{N} & 90^{\circ} \mathrm{N}\end{array}$

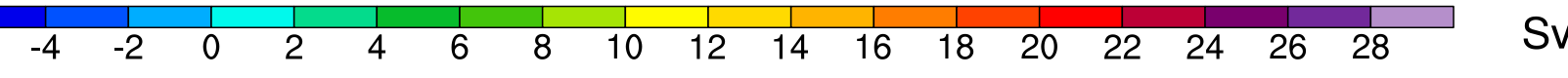

Figure 4: Same as in Fig. 3 except for AMOC plotted in $\sigma_{2}$ density $\left(\mathrm{kg} \mathrm{m}^{-3}\right)$ and latitude space. INMOM distribution is not available. 

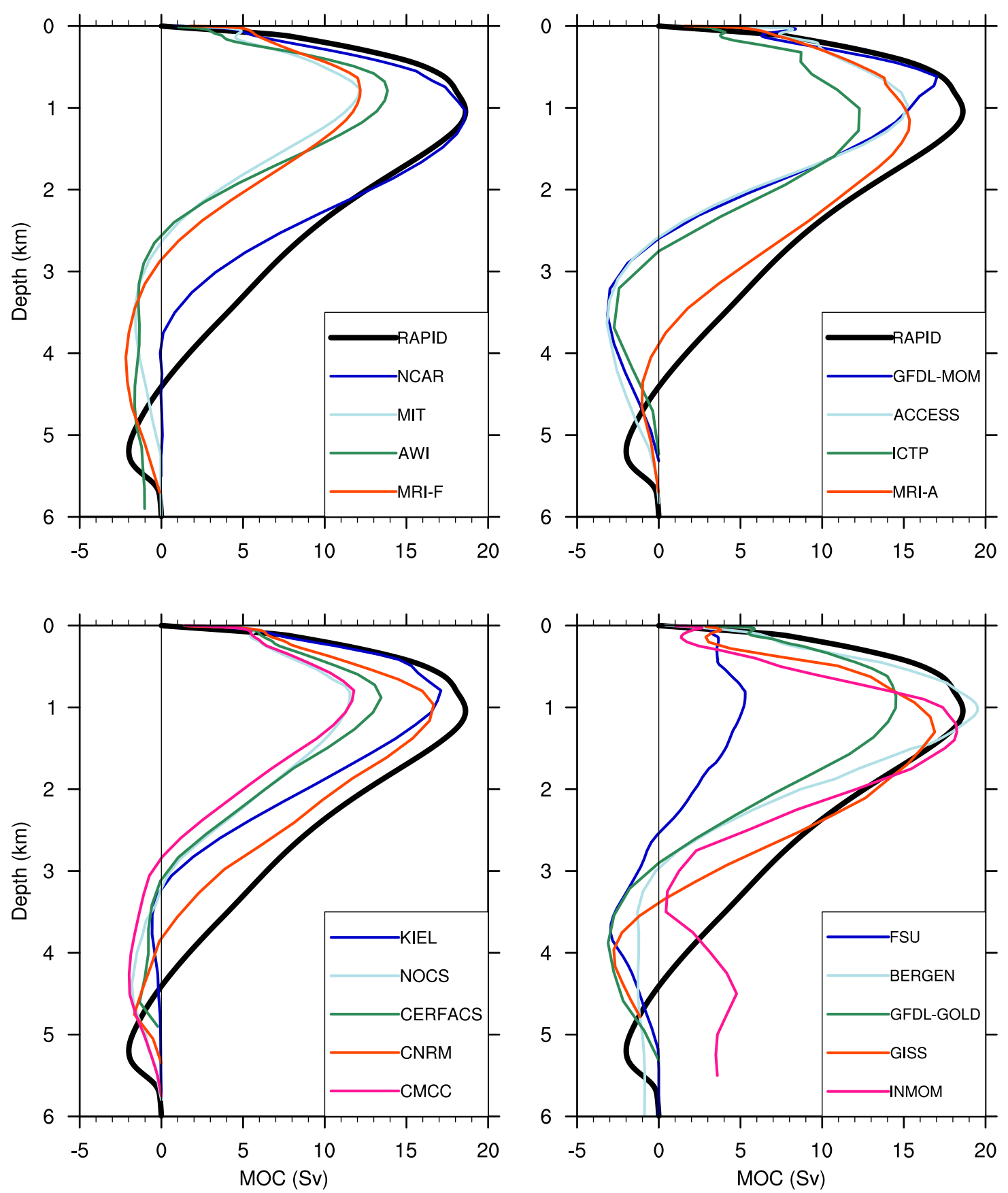

Figure 5: Years 2004-2007 mean AMOC depth profiles at 26.5 $\mathrm{N}$ from model solutions in comparison with the 4-year mean (April 2004 - March 2008) RAPID data (thick black lines plotted in each panel). 

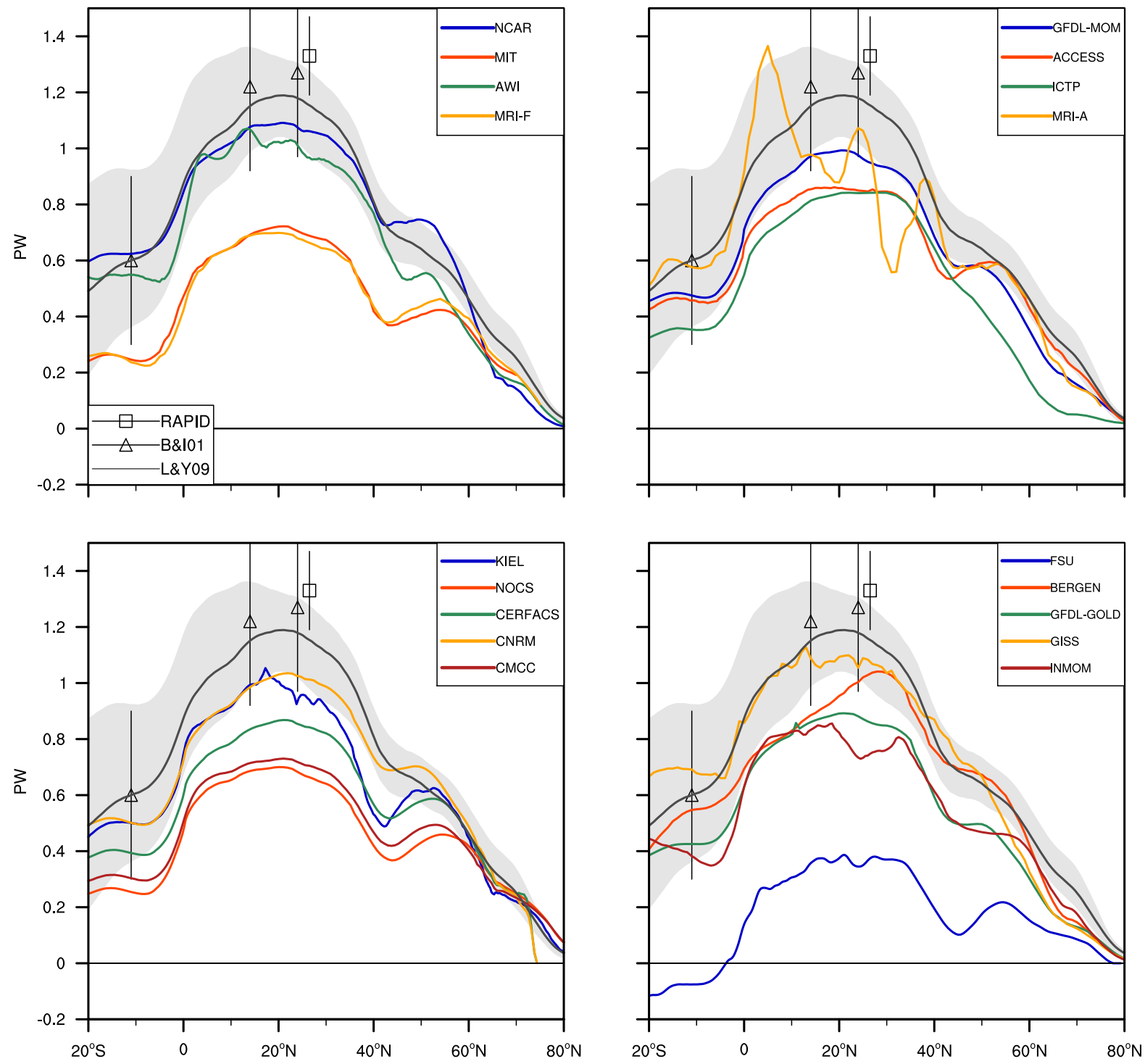

Figure 6: Time-mean meridional heat transports for the Atlantic Ocean. The black lines denoted by L\&Y09 represent implied time-mean transport calculated by Large and Yeager (2009) with shading showing the implied transport range in individual years for the 1984-2006 period. Direct estimates with their uncertainty ranges from the RAPID data (square; Johns et al., 2011) and from Bryden and Imawaki (2001) (triangle; B\&I01) are also shown. 


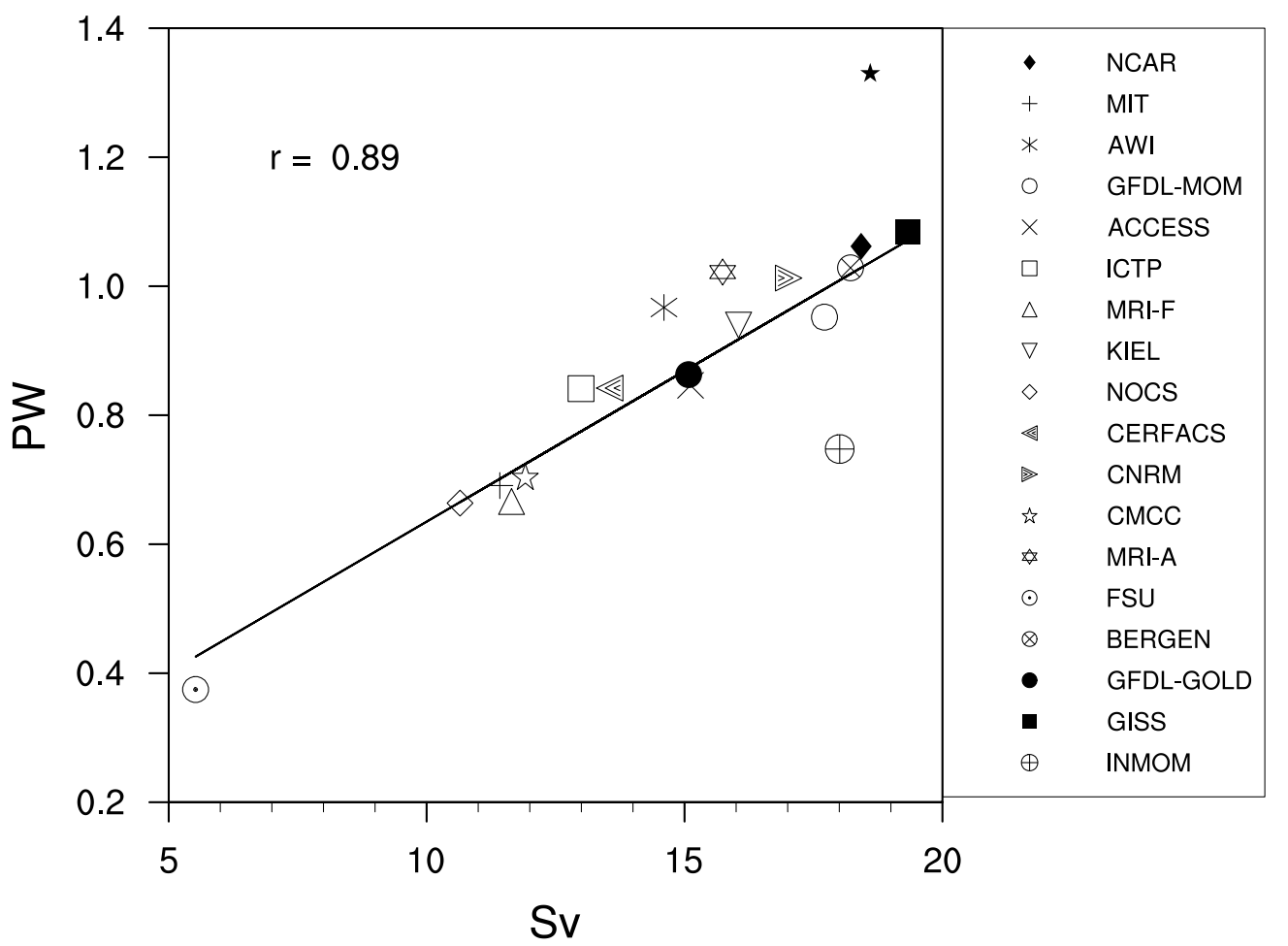

Figure 7: Scatter plot of the maximum AMOC transport against meridional heat transport (MHT), both evaluated at $26.5^{\circ} \mathrm{N}$. The model data are for the time-mean. The solid star denotes the observational AMOC and MHT estimates from the RAPID data. The regression line and correlation coefficient are also shown. 


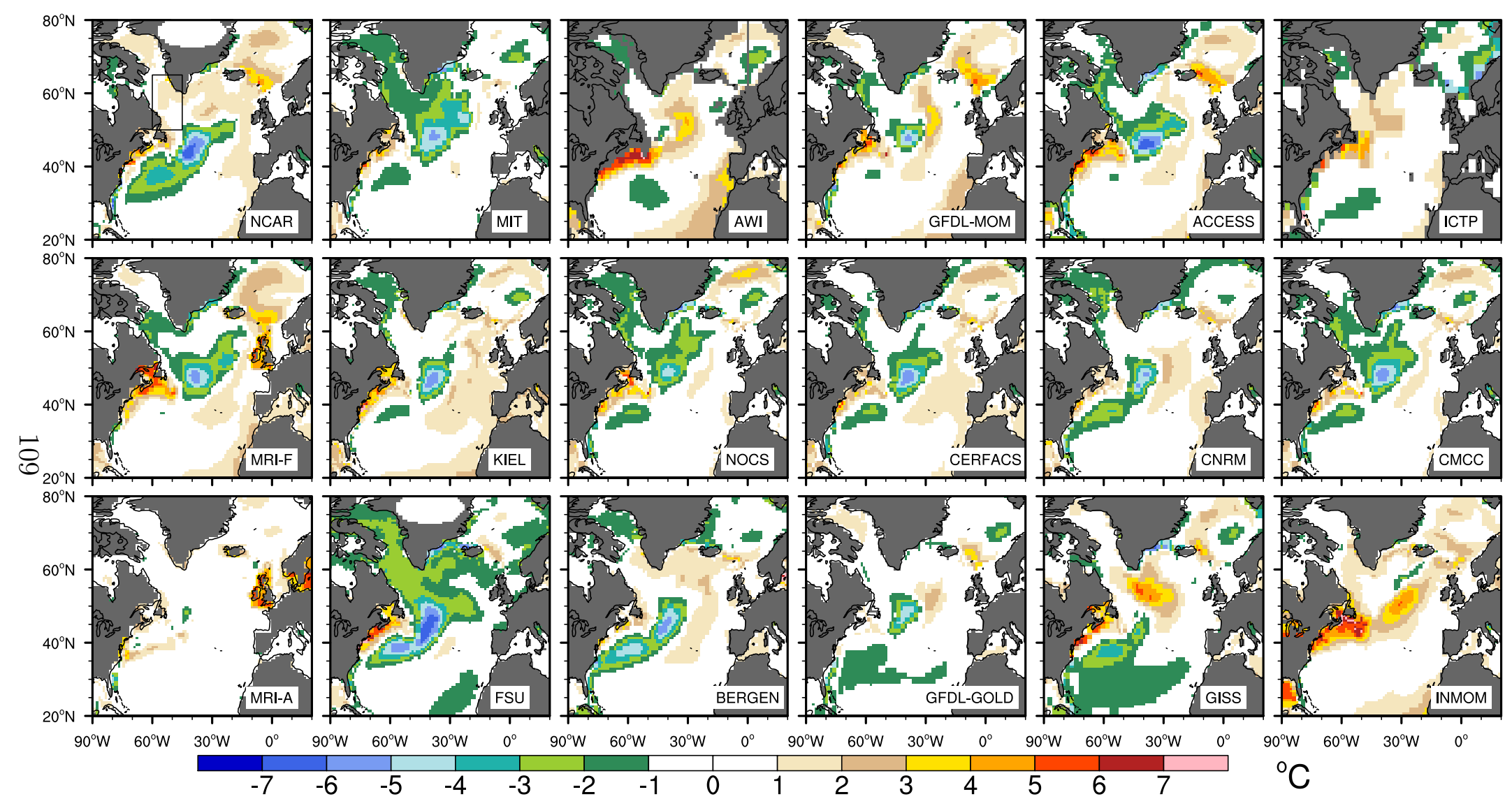

Figure 8: Time-mean, 0-700 m average potential temperature model minus observations (Locarnini et al., 2010) difference distributions. The boxed area in the NCAR panel indicates the Labrador Sea analysis region. 


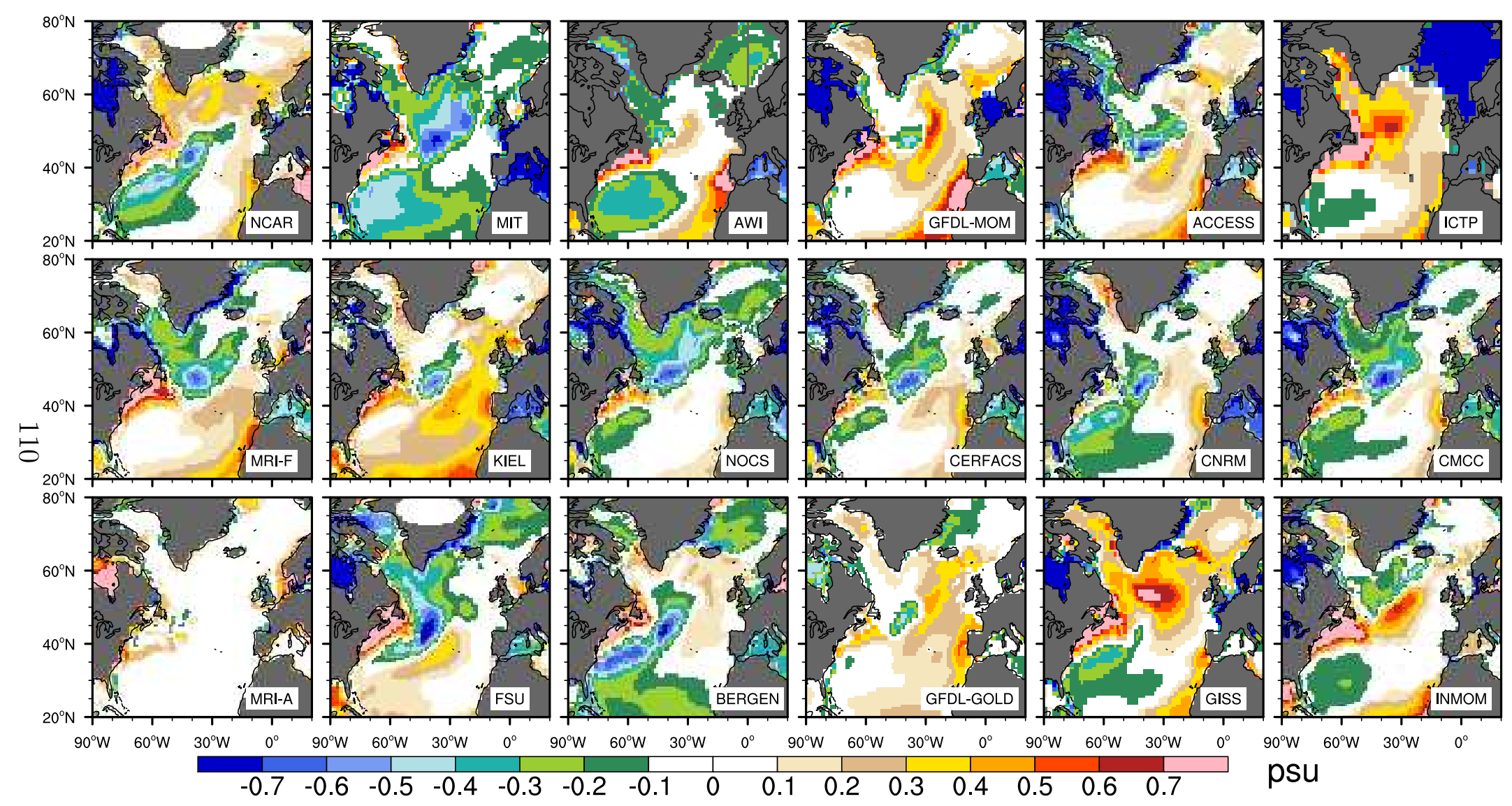

Figure 9: Time-mean, 0-700 m average salinity model minus observations (Antonov et al., 2010) difference distributions. 


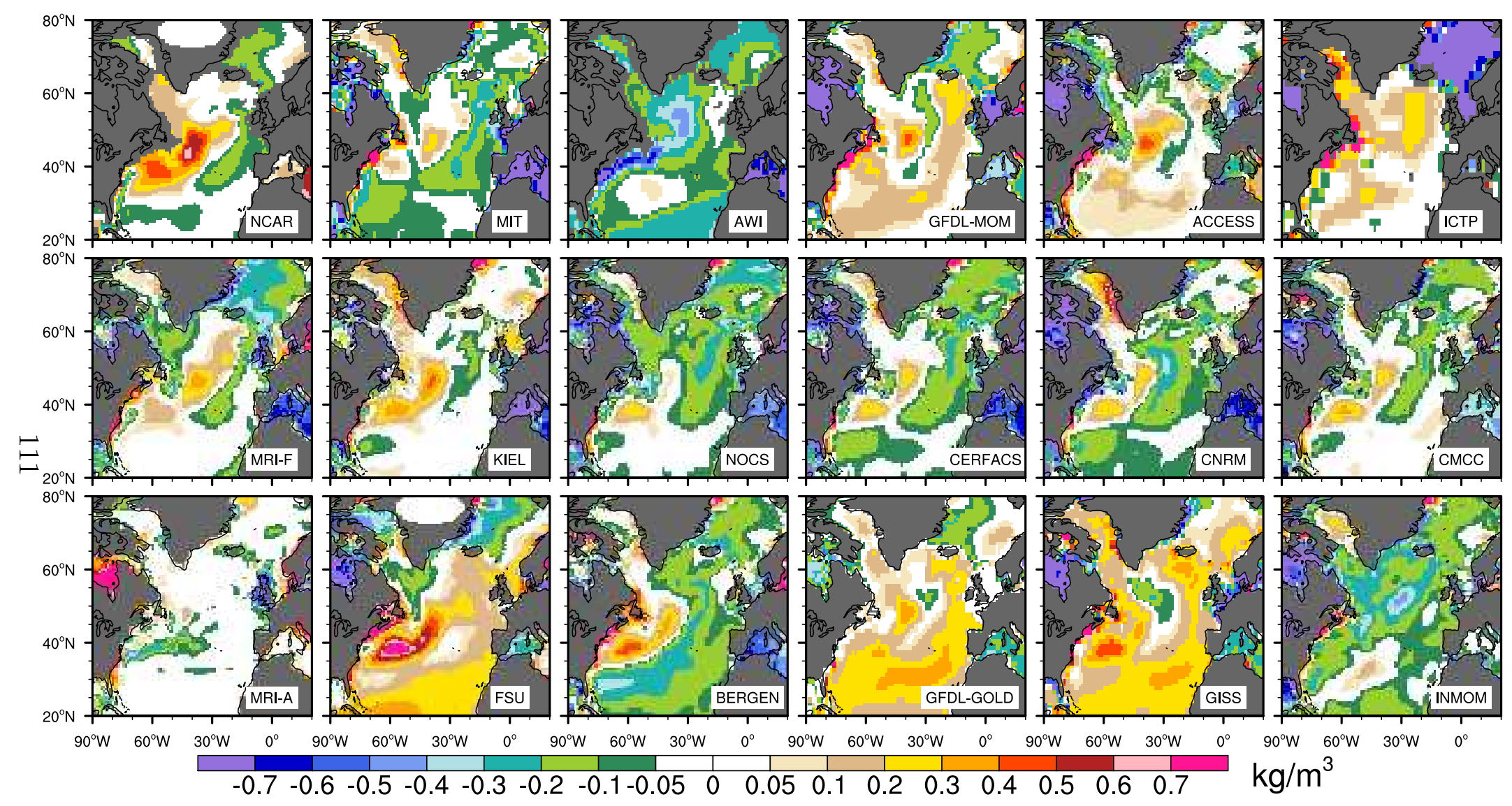

Figure 10: Time-mean, 0-700 $\mathrm{m}$ average density model minus observations difference distributions. The observational density is based on WOA09 temperature and salinity. 


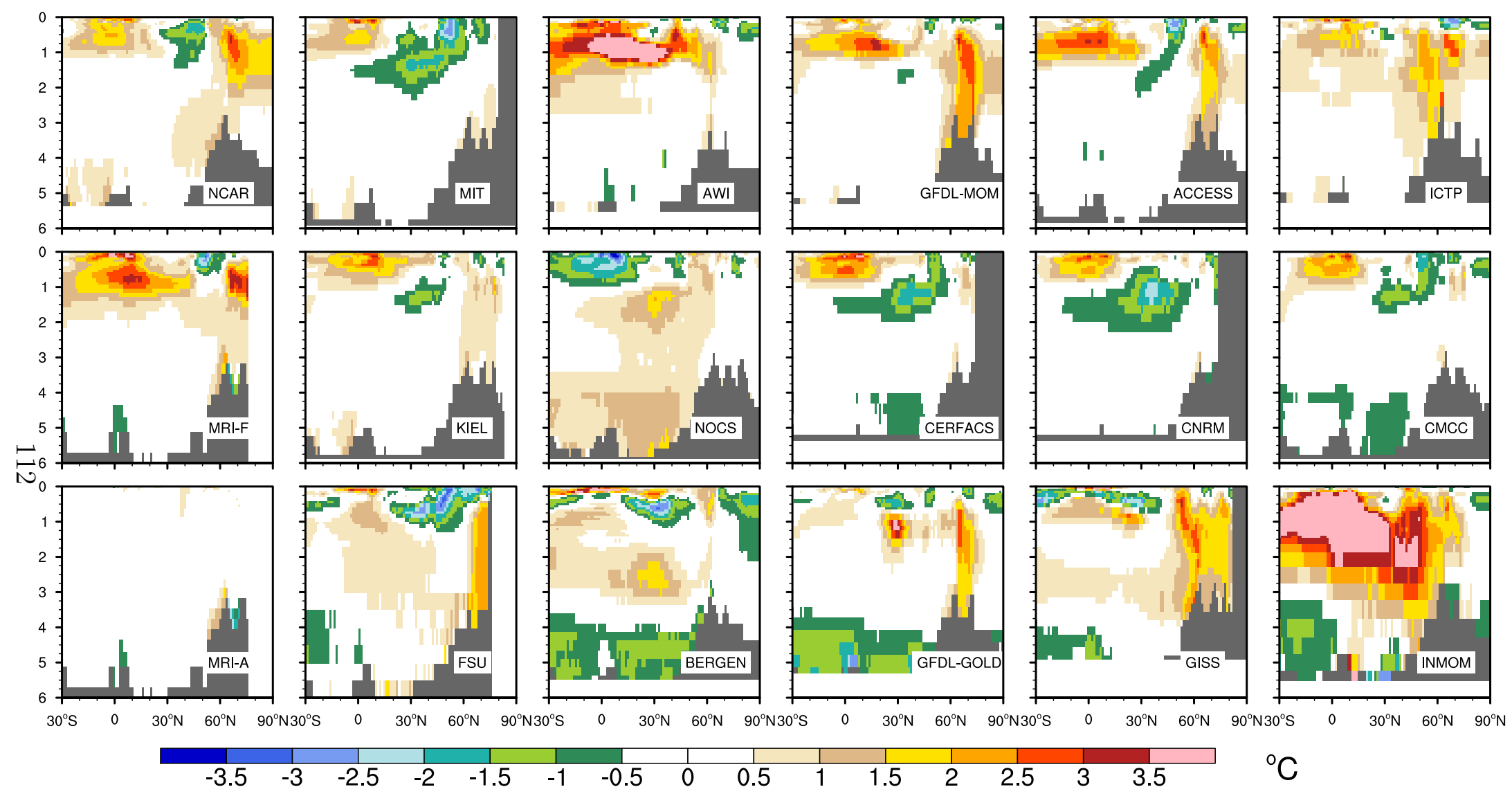

Figure 11: Time-mean and zonal-mean potential temperature model minus observations (Locarnini et al., 2010) difference distributions for the Atlantic Ocean. In MIT, MRI-F, KIEL, CERFACS, CNRM, MRI-A, FSU, and GISS, the difference distributions do not include the high latitude North Atlantic and / or Arctic Oceans, and hence are masked. 


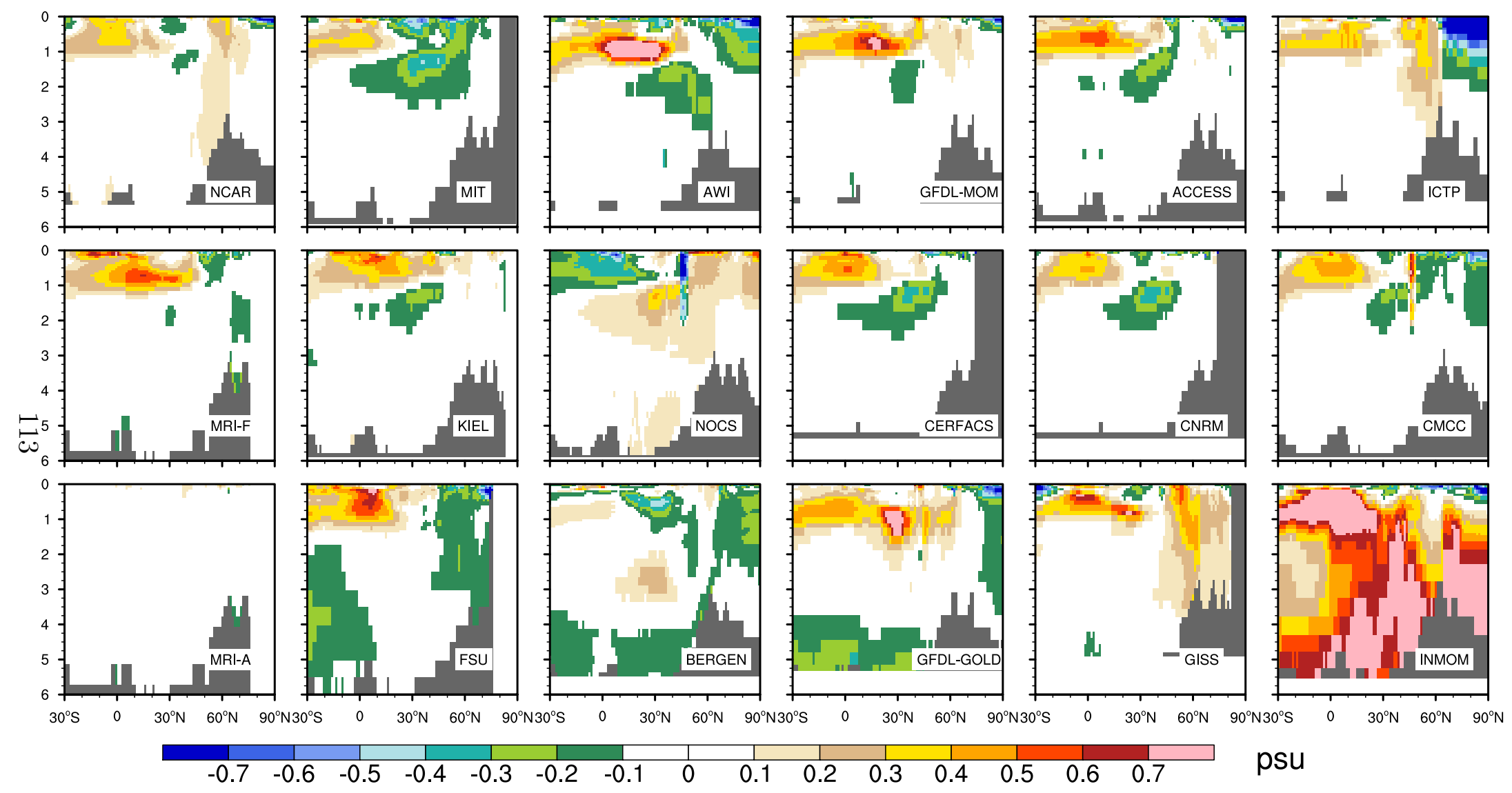

Figure 12: Same as in Fig. 11 except for salinity, and observations are from Antonov et al. (2010) 


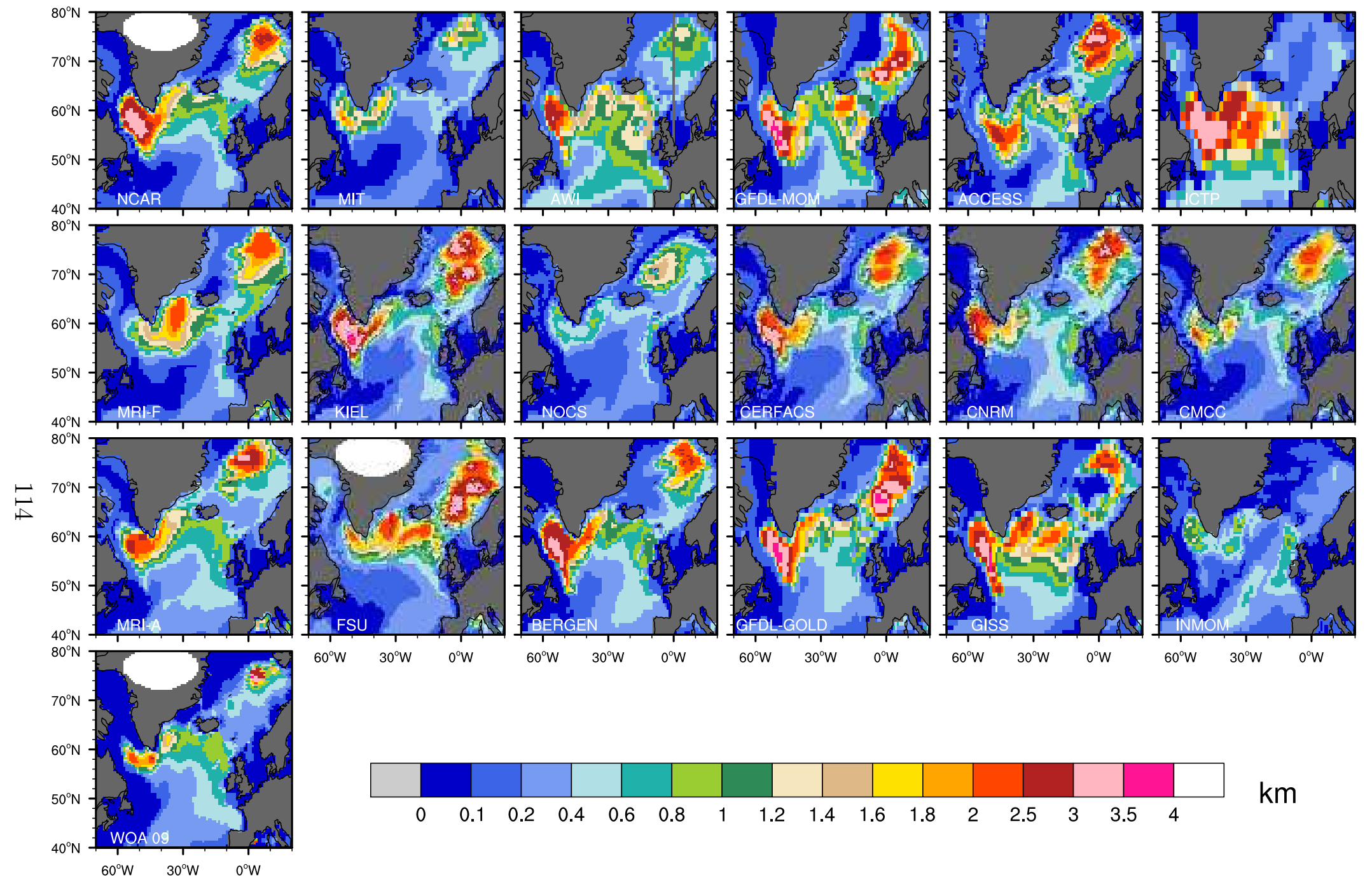

Figure 13: March-mean mixed layer depth (MLD) based on a $\Delta \rho=0.125 \mathrm{~kg} \mathrm{~m}^{-3}$ criterion for the northern North Atlantic. The panel to the left of the color bar shows MLD calculated from the WOA09 potential temperature (Locarnini et al., 2010) and salinity (Antonov et al., 2010) data. 

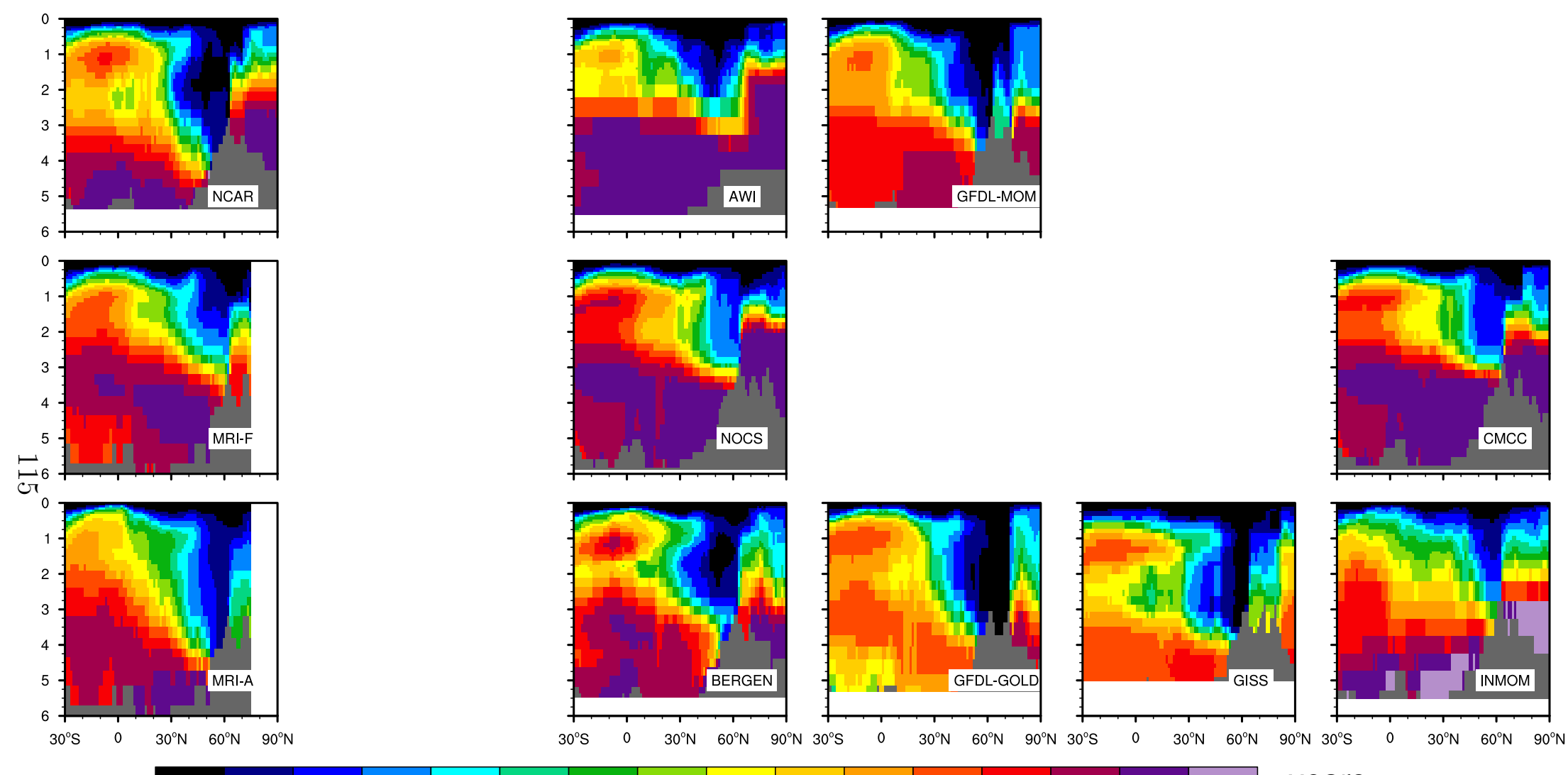

20

$40 \quad 60$

100

160

280300

years

Figure 14: Time-mean and zonal-mean ideal age distributions for the Atlantic Ocean. Ideal age is not available from MIT, ACCESS, ICTP, KIEL, CERFACS, CNRM, and FSU. In MRI-F and MRI-A, the distributions do not include the Arctic Ocean, and hence are masked. 


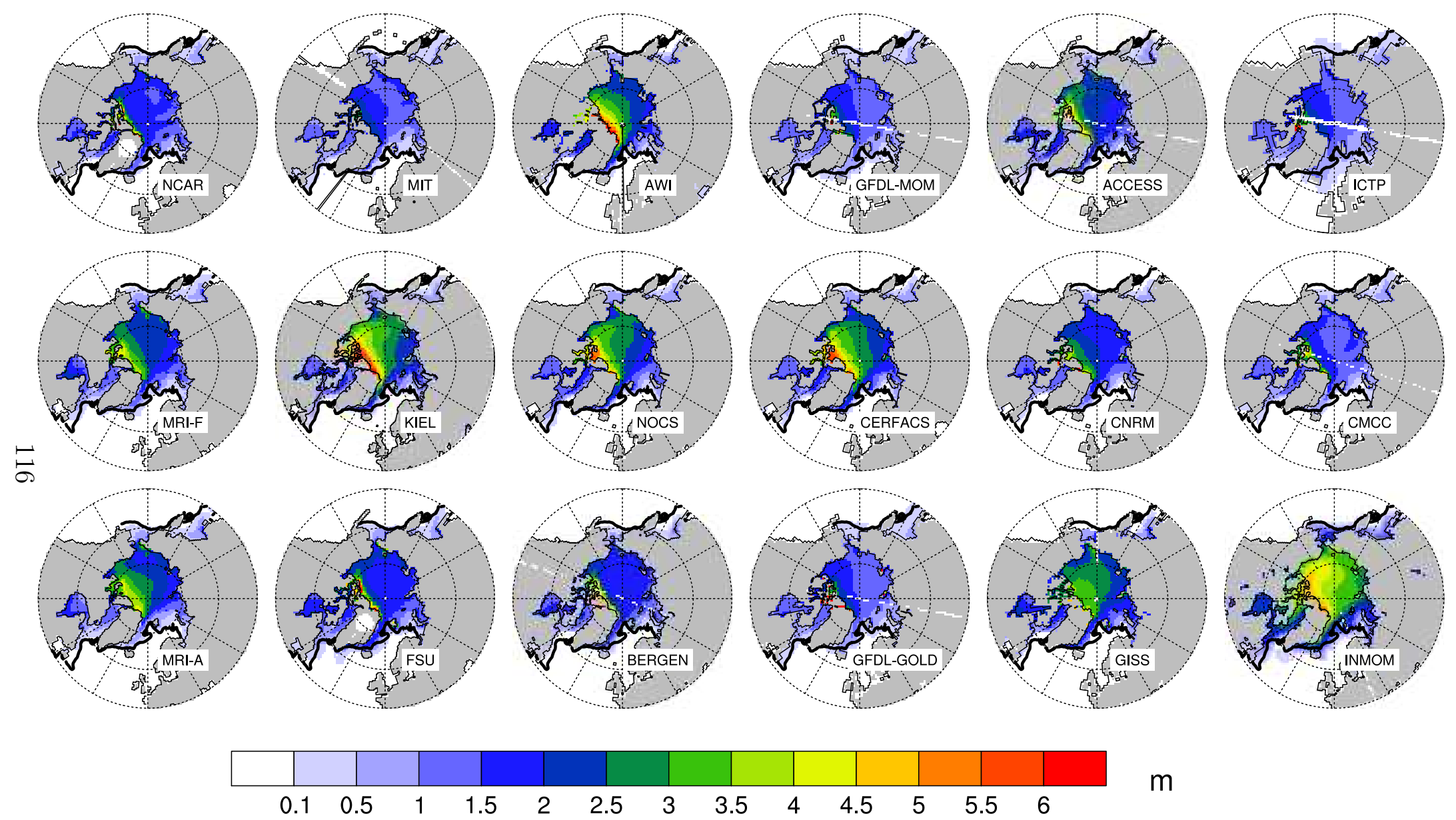

Figure 15: March-mean sea-ice thickness. The black contour line denotes the $15 \%$ observed sea-ice extent from the updated NSIDC data (Cavalieri et al., 1996, updated yearly). 

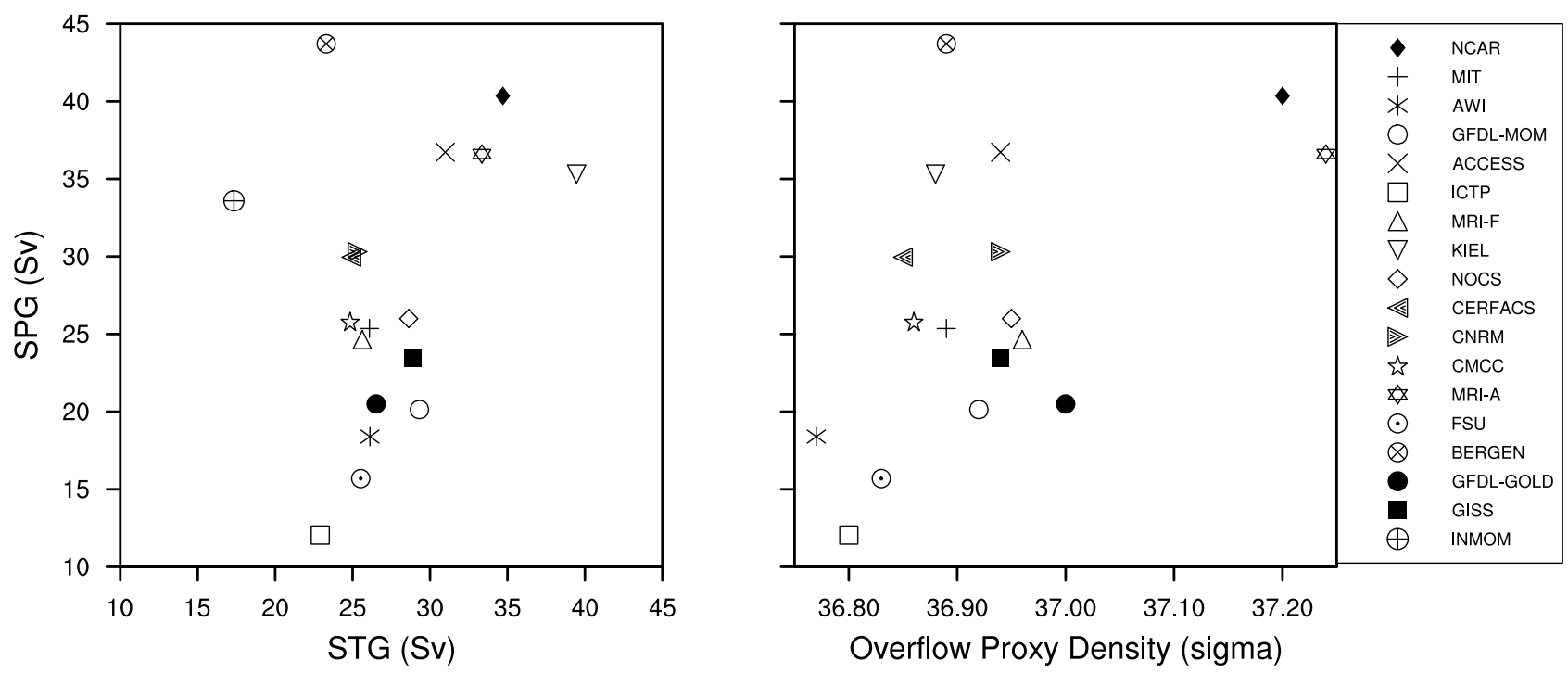

Figure 16: Scatter plots of the North Atlantic subpolar gyre (SPG) maximum transports against the North Atlantic subtropical gyre (STG) maximum transports (left) and against the overflow proxy density (right). All data are time-mean. Overflow proxy density is not available from INMOM. See text for details of how STG and SPG transports are determined. The overflow proxy density is calculated as the time-mean density of the densest outflow (or southward flow) at $60^{\circ} \mathrm{N}$ as represented by approximately $1 \mathrm{~Sv}$ AMOC transport in density $\left(\sigma_{2}\right)$ space, using Fig. 4. 

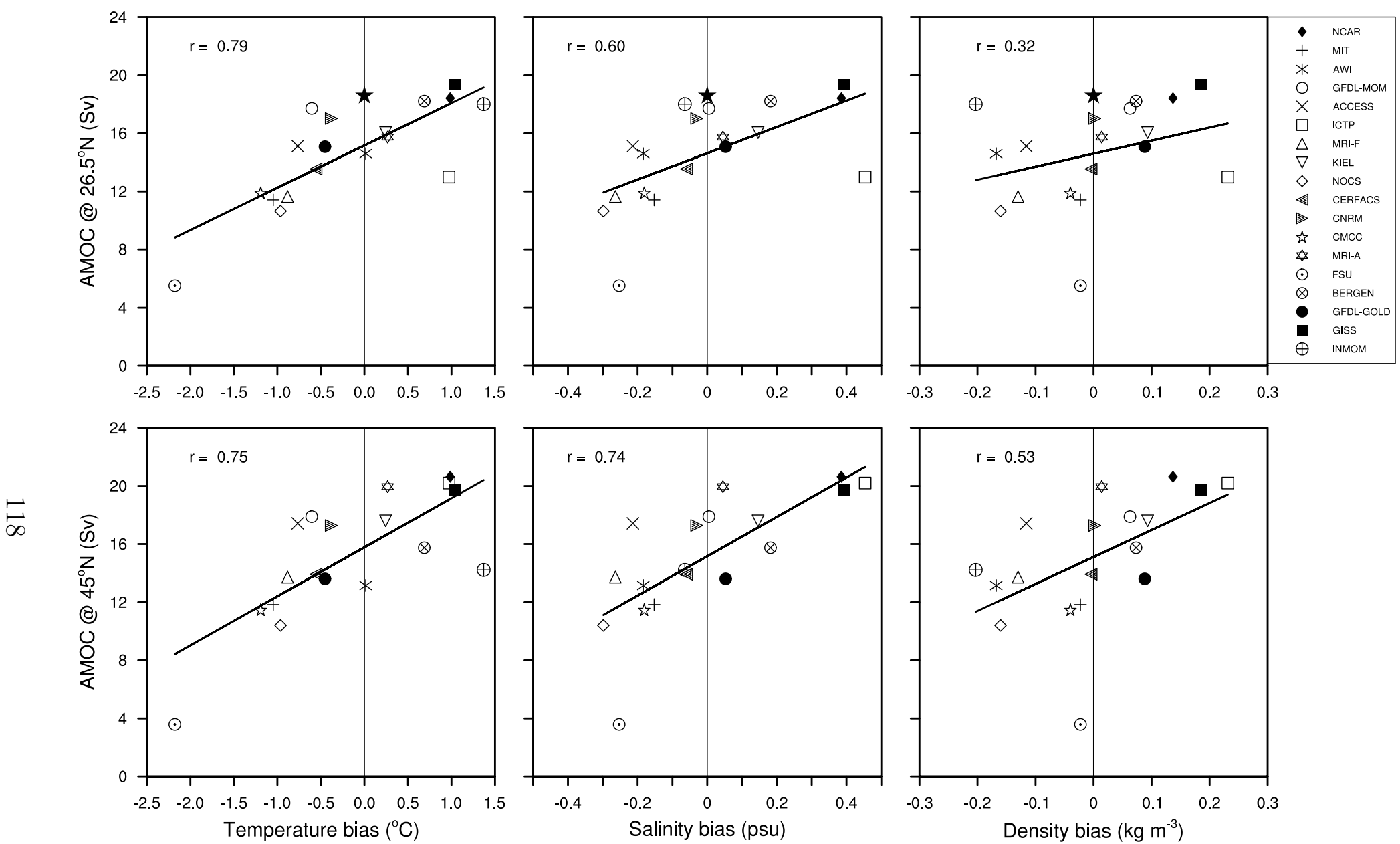

Figure 17: Scatter plots of the Labrador Sea (LS) upper-ocean (0-700 m average) potential temperature (left), salinity (middle), and density (right) biases against the AMOC maximum transports at $26.5^{\circ} \mathrm{N}$ (top) and $45^{\circ} \mathrm{N}$ (bottom). Each panel contains the corresponding regression line along with the correlation coefficient. The model data are for the time-mean. The solid stars in the top panels show the 4-year mean RAPID data (April 2004 - March 2008) plotted against no bias. The LS region is bounded by $60^{\circ}-45^{\circ} \mathrm{W}$ and $50^{\circ}-65^{\circ} \mathrm{N}$ and is indicated in Fig. 8 . 

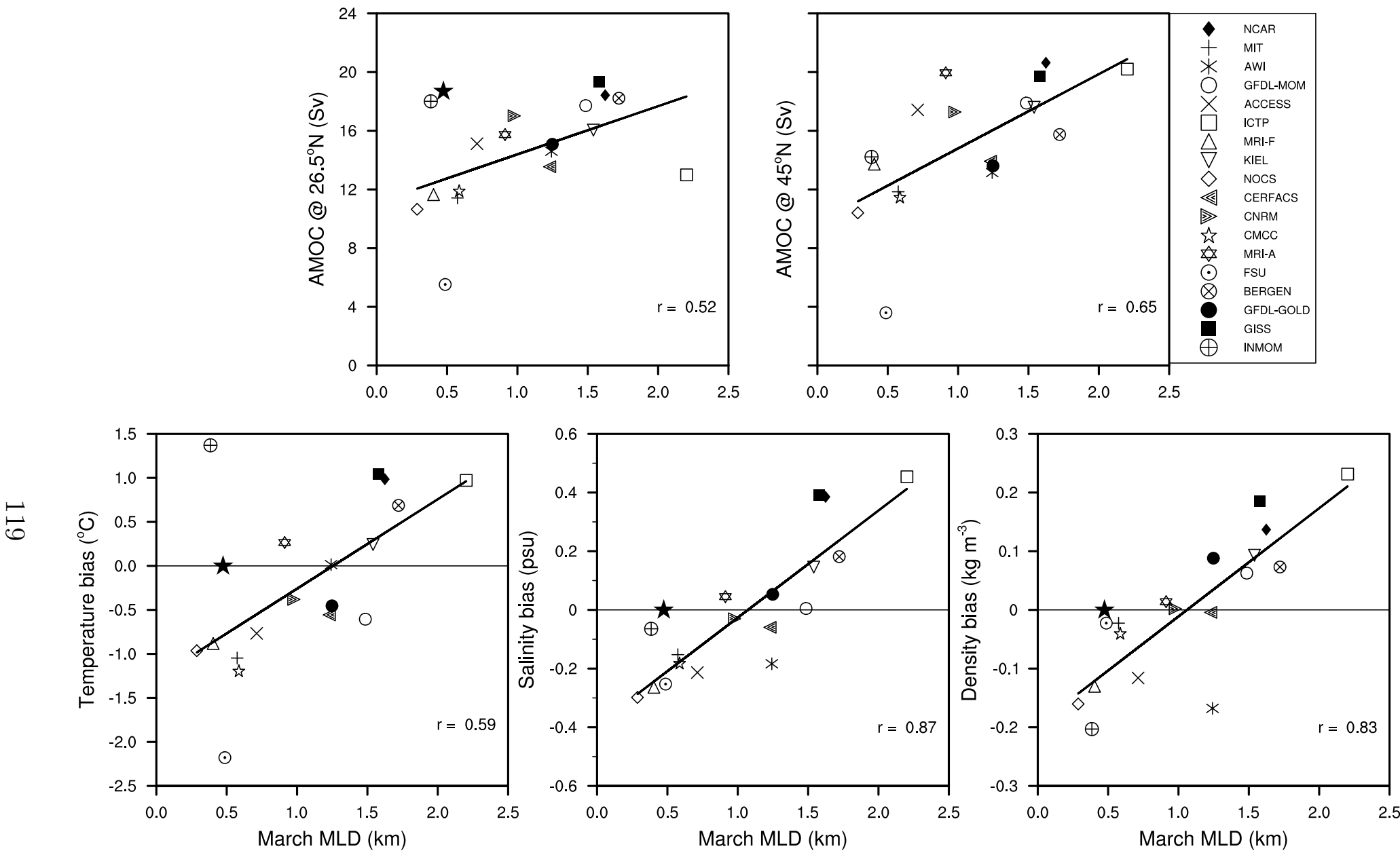

Figure 18: Scatter plots of the LS March-mean MLD against the AMOC maximum transports at $26.5^{\circ} \mathrm{N}$ and $45^{\circ} \mathrm{N}$ (top panels) and against the LS upper-ocean (0-700 m average) potential temperature, salinity, and density biases (bottom panels). Each panel contains the corresponding regression line along with the correlation coefficient. Except MLD, the model data are for the time-mean. The solid stars in the top left and bottom panels represent the observationally-based March-mean MLD estimate plotted against the 4-year mean RAPID data (April 2004 - March 2008) and against no bias, respectively. 

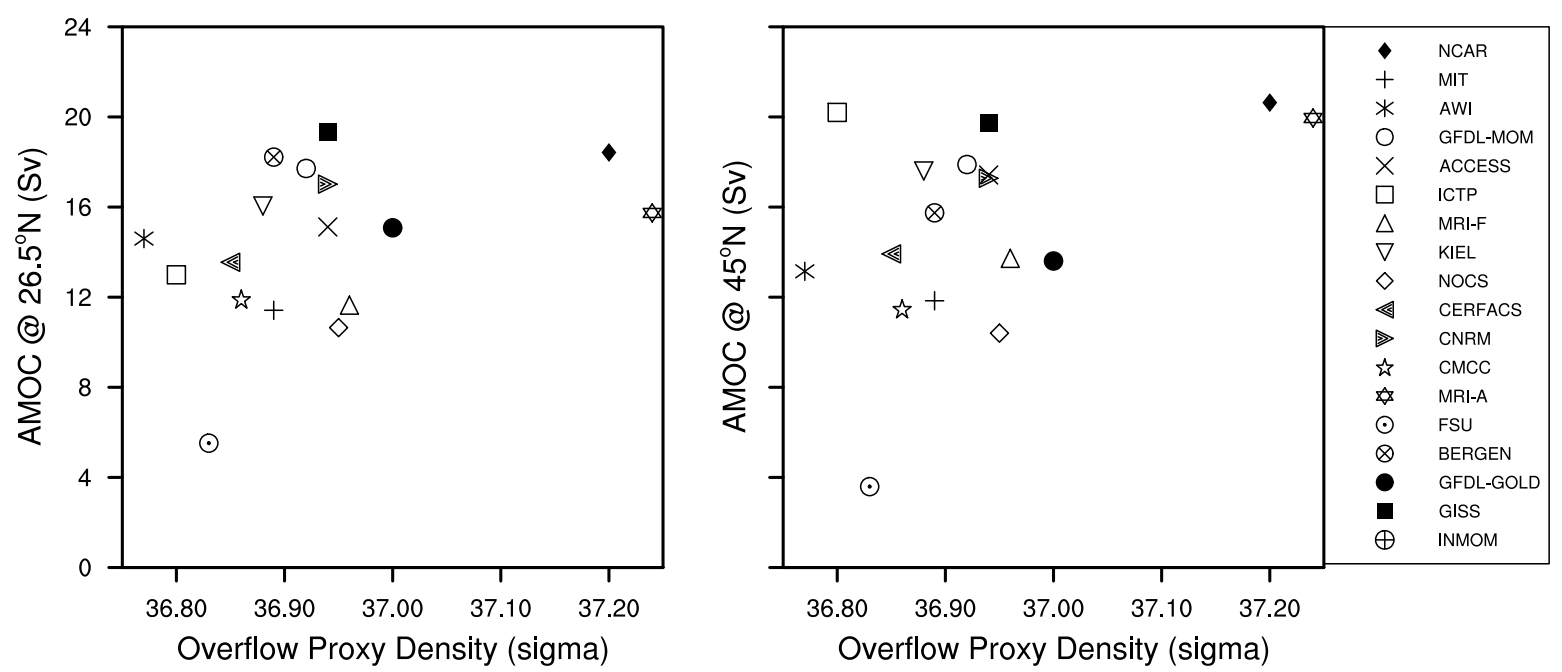

Figure 19: Scatter plots of the AMOC maximum transports at $26.5^{\circ} \mathrm{N}$ (left) and $45^{\circ} \mathrm{N}$ (right) against the overflow proxy density described in Fig. 16. All data are time-mean. Overflow proxy density is not available from INMOM. 

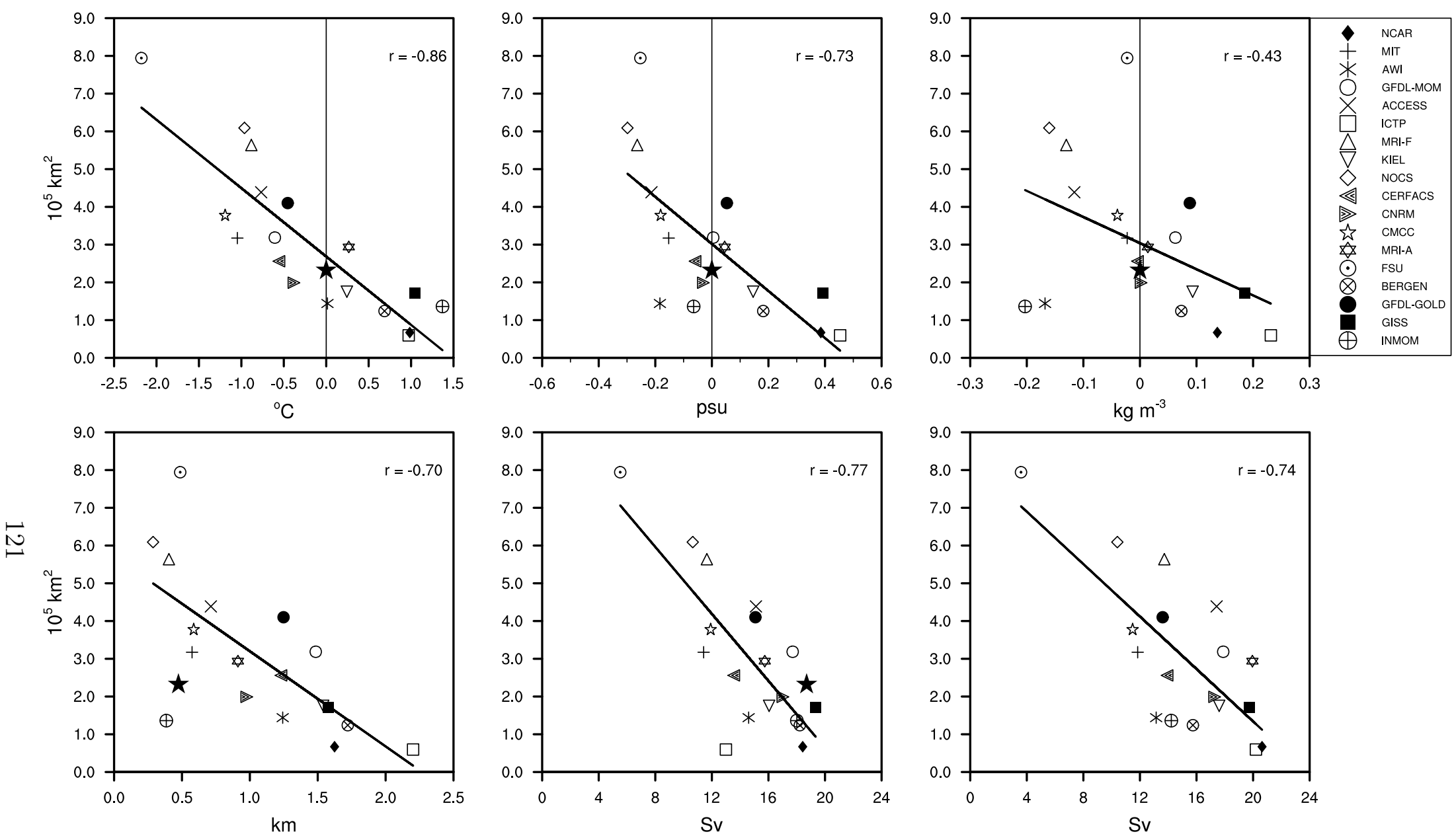

Figure 20: Scatter plots of the LS March-mean sea-ice area against the LS upper-ocean (0-700 $\mathrm{m}$ average) potential temperature (top left), salinity (top middle), and density (top right) biases, and against the LS March-mean MLD (bottom left), AMOC maximum transport at $26.5^{\circ} \mathrm{N}$ (bottom middle), and AMOC maximum transport at $45^{\circ} \mathrm{N}$ (bottom right). Each panel contains the corresponding regression line along with the correlation coefficient. Except MLD and sea-ice area, the model data are for the time-mean. The solid stars in the top panels show observational March-mean sea-ice area plotted against no bias. The solid stars in the lower left and middle panels are for the observational March-mean sea-ice area plotted against the observationally-based March-mean MLD and the 4-year mean RAPID data (April 2004 - March 2008), respectively. 


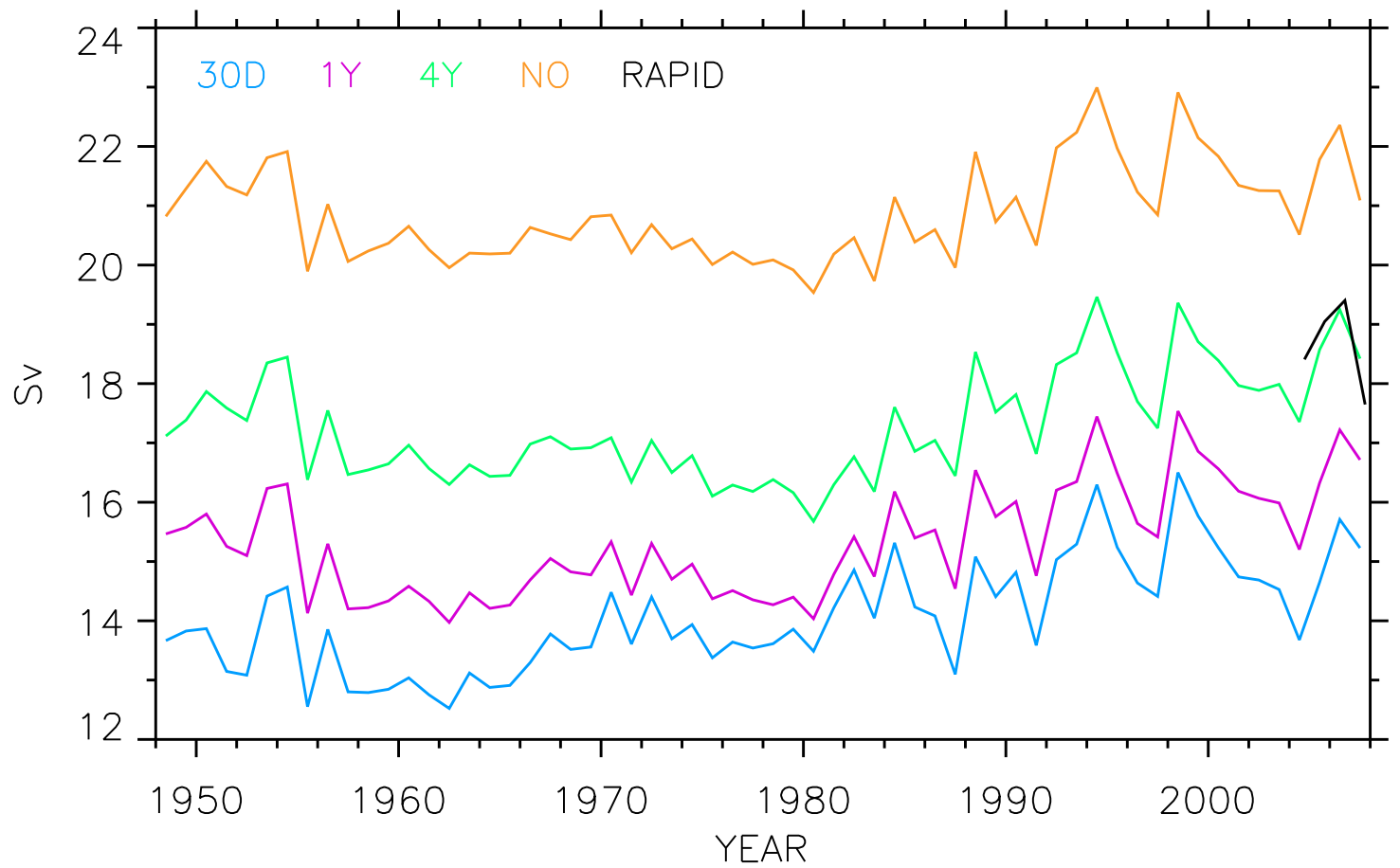

Figure 21: AMOC annual-mean maximum transport time series at $26.5^{\circ} \mathrm{N}$ obtained with a preliminary version of the NCAR model using different SSS restoring time scales: 30 days (30D); 1 year $(1 \mathrm{Y}) ; 4$ years $(4 \mathrm{Y})$; and infinity (NO), i.e., no restoring. The associated length scale is $50 \mathrm{~m}$. RAPID line represents the observational data from Cunningham et al. (2007). The time series are shown for one forcing cycle. 
a

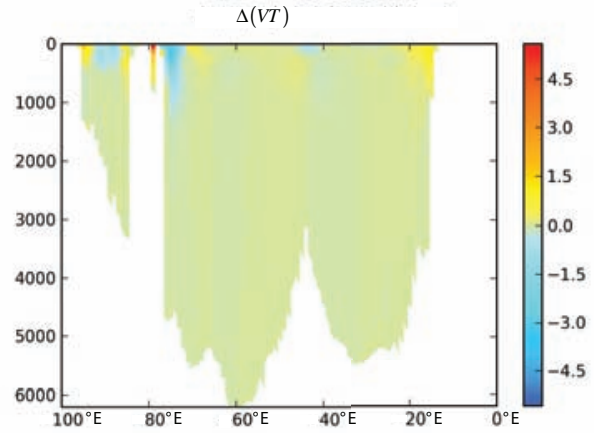

C

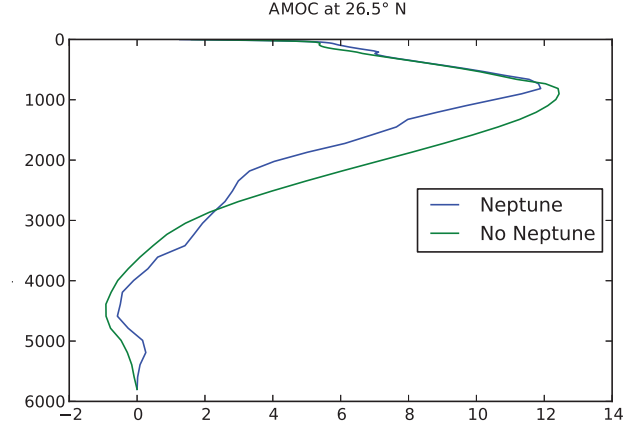

b

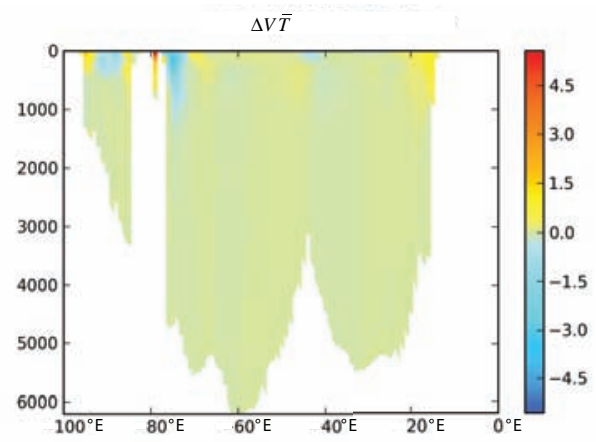

d

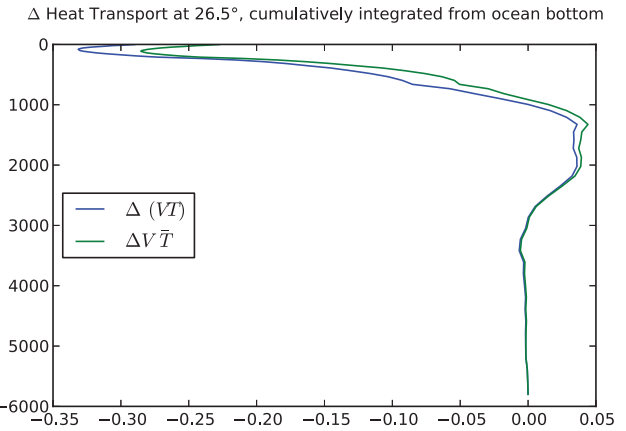

Figure 22: a) Difference (Neptune - standard) in northward annual-mean temperature flux along a quasi-zonal section at $26.5^{\circ} \mathrm{N}$ in ${ }^{\circ} \mathrm{C} \mathrm{m} \mathrm{s}^{-1}$. b) Difference in velocity times mean of the temperatures from the two runs in ${ }^{\circ} \mathrm{C} \mathrm{m} \mathrm{s}^{-1}$. c) Zonally integrated meridional flow cumulatively integrated up from the bottom in Sv for the Neptune run (blue line) and standard run (green line). d) Difference in zonally integrated heat transport cumulatively integrated up from the bottom in PW, calculated using the full temperature flux (blue line) and the approximation, using only the difference in velocities (green line). All plots are for year 2007 of the last forcing cycle. 
Table 1: Summary of the ocean and sea-ice models in alphabetical order according to the participating group name (first column). The table includes the name of the combined ocean - sea-ice configuration (if any); the ocean model name and its version; the sea-ice model name and its version; vertical coordinate and number of layers / levels in parentheses; orientation of the horizontal grid with respect to the North Pole / Arctic; the number of horizontal grid cells (longitude $\times$ latitude); and the horizontal resolution (longitude $\times$ latitude). In MRI-A and MRI-F, the vertical levels shallower than $32 \mathrm{~m}$ follow the surface topography as in sigma-coordinate models. In FESOM, the total number of surface nodes is given under horizontal grid, because it has an unstructured grid. H79 is Hibler (1979) and MK89 is Mellor and Kantha (1989).

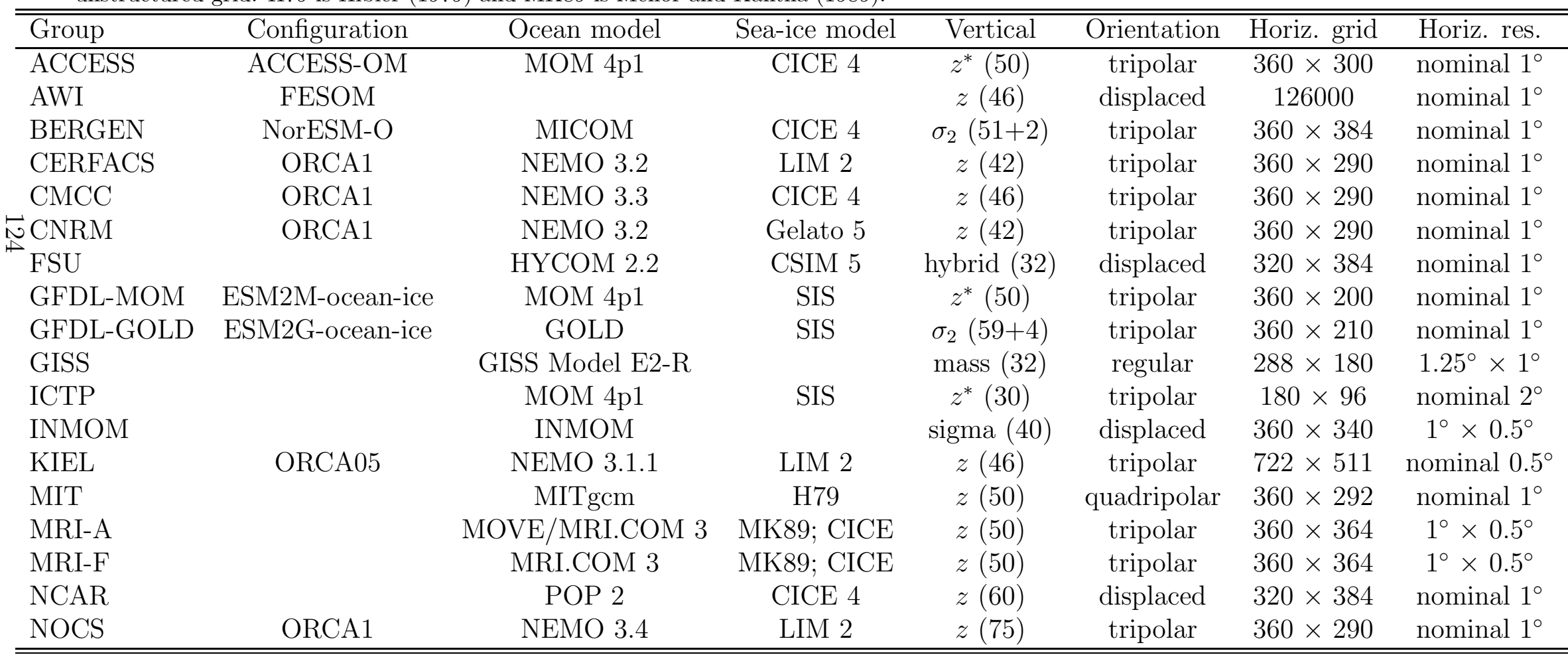


Table 2: Summary of the surface freshwater / salt fluxes and salinity restoring choices in alphabetical order according to the participating group name (first column). Salt vs. water column indicates the type of surface fluxes used for hydrological forcing with water and salt denoting real fresh water and virtual salt fluxes, respectively. The sea surface salinity (SSS) restoring time scales are given in days over a $50 \mathrm{~m}$ length scale. The NEMO-based models convert salinity restoring to a fresh water flux (denoted as fw in the column). The other groups apply salinity restoring as a salt flux. Region column indicates the region over which the salinity restoring is used. As shown by $|\Delta \mathrm{SSS}| \leq 0.5$, the majority of the models limit the magnitude of mismatch between the model and observed SSS to $0.5 \mathrm{psu}$. Under sea-ice column shows whether restoring is applied under sea-ice covered areas. Normalize restoring column indicates whether the model subtracts the global mean of restoring fluxes. Finally, normalize $\mathrm{P}+\mathrm{R}-\mathrm{E}$ refers to whether some sort of normalization to $\mathrm{P}+\mathrm{R}-\mathrm{E}$ is applied to reduce drift.

\begin{tabular}{|c|c|c|c|c|c|c|}
\hline Group & Salt vs. water & Time scale (day) & Region & Under sea-ice & Norm. restoring & Norm. $\mathrm{P}+\mathrm{R}-\mathrm{E}$ \\
\hline ACCESS & water & 150 & global $(|\Delta S S S| \leq 0.5)$ & yes & yes & yes \\
\hline AWI & salt & 300 & global & yes & yes & yes \\
\hline BERGEN & salt & 300 & global $(|\Delta S S S| \leq 0.5)$ & yes & no & yes \\
\hline CERFACS & water & $300(\mathrm{fw})$ & global $(|\Delta \mathrm{SSS}| \leq 0.5)$ & yes & no & yes \\
\hline $\mathrm{CMCC}$ & water & $365(\mathrm{fw})$ & global & yes & yes & yes \\
\hline CNRM & water & $300(\mathrm{fw})$ & global $(|\Delta \mathrm{SSS}| \leq 0.5)$ & yes & no & yes \\
\hline $\mathrm{FSU}$ & salt & 1460 & global $(|\Delta \mathrm{SSS}| \leq 0.5)$ & yes & yes & yes \\
\hline GFDL-GOLD & water & 50 & global $(|\Delta \mathrm{SSS}| \leq 0.5)$ & yes & yes & yes \\
\hline GFDL-MOM & water & 300 & global $(|\Delta S S S| \leq 0.5)$ & yes & yes & yes \\
\hline GISS & water & 1250 & global & yes $^{a}$ & yes & yes \\
\hline ICTP & water & 275 & global $(|\Delta \mathrm{SSS}| \leq 0.5)$ & no & yes & yes \\
\hline INMOM & salt & 365 & global & yes & no & no \\
\hline KIEL & water & $1500(\mathrm{fw})$ & global $(|\Delta \mathrm{SSS}| \leq 0.5)$ & no & no & yes \\
\hline MIT & water & 1500 & global $^{b}$ & yes & yes & yes \\
\hline MRI-A & water & 365 & global $^{c}$ & yes & yes & yes \\
\hline MRI-F & water & 365 & global $^{c}$ & yes & yes & yes \\
\hline NCAR & salt & 1450 & global & yes & yes & yes \\
\hline $\mathrm{NOCS}$ & water & $300(\mathrm{fw})$ & global $(|\Delta \mathrm{SSS}| \leq 0.5)$ & yes & no & yes \\
\hline
\end{tabular}

${ }^{a}$ In GISS, under sea-ice salinity restoring is used only for the grid cells for which the Hadley Center data-set has sea-ice in its 1975-1984 average. The restoring time scale is 42 days.

${ }^{b}$ In MIT, model SSS is relaxed to the WOA05 data (PHC3 in the Arctic). These observational data were modified in the North Atlantic by increasing the salinity values by $0.5 \mathrm{psu}$.

${ }^{c}$ In MRI-A and MRI-F, salinity restoring is not used in coastal grid points with sea-ice cover. 